Linköping University Medical Dissertation

No. 1522

\title{
Environmental and Genetic Influences in Attention Deficit Hyperactivity Disorder (ADHD) and its Comorbidities
}

\author{
Andrea Johansson Capusan
}

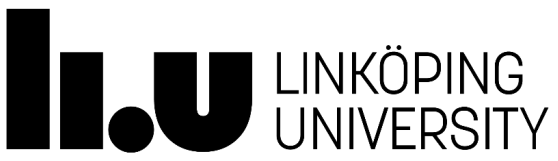

Department of Medical and Health Sciences

Linköping University, SE-581 83 Linköping, Sweden

Linköping 2016 
Front cover illustration: "Vägen till Motala" reproduced with permission of the owner

Figure 1, Heinrich Hoffman, "Merry Tales and Funny Pictures", 1848, English translation, Release Date: April 23, 2004, Project Gutenberg Figures reproduced with permission of Nature Publishing Group (Figures 2-3) and Springer Publishing Ltd. (Figure 4)

Previously published articles reprinted with the permission from the publisher.

Published by Linköping University

Printed in Sweden by LiU-Tryck

(C) Andrea Johansson Capusan, 2016

ISSN 0345-0082

ISBN 978-91-7685-758-8 


\section{Environmental and Genetic Influences in Attention Deficit Hyperactivity Disorder (ADHD) and its comorbidities}

Thesis for doctoral degree

By

\section{Andrea Johansson Capusan}

Principal supervisor

Professor Preben Bendtsen, MD, PhD

Linköping, University

Department of Medical specialist and

Department of Medical and Health Sciences

Co-supervisor

Professor Henrik Larsson, $\mathrm{PhD}$,

Örebro University

Department of Medical Sciences, and

Karolinska Institutet

Department of Medical Epidemiology and Biostatistics (MEB), Stockholm

Co-supervisor

Ina Marteinsdottir, $\mathrm{MD}, \mathrm{PhD}$

Linköping University

Department of Clinical and Experimental

Medicine, Center for Social and Affec-

tive Neuroscience (CSAN)
Opponent

Professor Jaakko Kaprio, MD, PhD

University of Helsinki,

Genetic Epidemiology in the Department of Public Health,

Director of the Institute for Molecular Medicine Finland FIMM, and Research Professor at the National Institute for Health and Welfare

Examination Board

Professor Carina Berterö, $\mathrm{PhD}$

Linköping, University

Department of Medical and Health Sciences

Professor Susanne Bejerot, MD, PhD

Örebro University

Department of Medical Sciences

Professor Bruno Hägglöf, $\mathrm{MD}, \mathrm{PhD}$

Umeå University,

Department of Clinical Sciences, Child and Adolescent Psychiatry 
September 2016

ISBN 978-91-7685-758-8

Linköping University Medical Dissertations

No. 1522

ISSN 0345-0082 
"...the influences of the environment are differential, the product varying not only in accord with the environmental force itself, but also in accord with the original nature upon which it operates"

Edward L. Thorndike, 1905 The Journal of Philosophy, Psychology and Scientific Methods 
Department of Medical and Health Sciences

Linköping University

SE-581 83 Linköping, Sweden 


\section{Abstract}

Research in past decades has demonstrated the persistence of attention deficit hyperactivity disorder (ADHD) into adulthood, but many questions regarding prevalence, causes, and comorbidities of ADHD in adults remain to be investigated. Previous research focusing on childhood ADHD identified high heritability. Genetic and environmental influences on ADHD symptoms in adults and their association with comorbid conditions are not fully understood.

The overall aim of this thesis was to study adult ADHD symptoms in the population and investigate associations with substance use disorders (SUD) and binge eating. In all four papers, we used population-based self-report data from twins aged 20-46 years from the Swedish Twin Registry. We used twin methods to explore the role of genetic and environmental factors underlying ADHD symptoms and their comorbidities.

Study I examined the phenotypic association between ADHD and various forms of SUD. We found that ADHD in adults was strongly associated with alcohol abuse and alcohol dependence, illicit drug use and regular nicotine use, with no differences between ADHD subtypes and no apparent substance preference.

In Studies II and IV, we used bivariate twin models to examine the role of genetic and environmental factors in the association of adult ADHD symptoms with alcohol dependence (II) and with binge eating (IV). For ADHD symptoms and alcohol dependence, $64 \%$ of the overlap was explained by common genetic factors. The remaining variance was accounted for by environmental factors specific for each twin, with no sex differences for the overlap. Similarly, $91 \%$ of the association between ADHD symptoms and binge-eating behaviour was explained by common genetic factors. The inattentive ADHD symptom shared specific genetic factors with binge eating, even after controlling for genetic factors shared between the HI and IN symptom dimensions.

In Study III, using a within-twin pair analysis, we demonstrated that although most of the association between adult ADHD symptoms and selfreported childhood maltreatment (an environmental risk factor for 
ADHD) was explained by familial (genetic and environmental) confounding, our results were also consistent with a causal interpretation.

In conclusion, adult ADHD symptoms show extensive overlap with SUD and binge-eating behaviour. We replicated findings from adolescent studies for alcohol dependence in an adult population. For binge-eating behaviour, we showed for the first time that common genetic factors play an important role in the overlap with ADHD symptoms in adults. Nonshared environmental factors account for the remaining variance. Our results support, in part, a causal hypothesis regarding association between childhood maltreatment and ADHD symptoms in adults. This needs to be further investigated in longitudinal clinical samples that can examine neurobiological underpinnings of environmental effects.

Recently, common pleiotropic risks have been identified for psychiatric conditions; there is, however, research supporting shared genetic factors specific for ADHD and SUD. Alterations in mesolimbic reward processing as well as the frontal, executive and inhibitory systems have been described for ADHD, alcohol dependence and binge-eating behaviour, possibly suggesting common genetic and neurobiological factors for all three conditions. Research on endophenotypes could add to the understanding of these associations between ADHD and alcohol dependence and between ADHD and binge-eating behaviour.

Clinically, the results of this thesis support that ADHD in adults be considered and addressed in the context of the investigated comorbidities. Given the common genetic risk factors and the role of the early childhood environment, family interventions should be considered for these populations.

Keywords: ADHD, Substance use disorder, Binge-eating behaviour, Twins, Genetic and environmental factors, Childhood maltreatment 


\section{List of Scientific Papers}

I. Comorbidity of Adult ADHD and Its Subtypes With Substance Use Disorder in a Large Population-Based Epidemiological Study.

Capusan AJ, Bendtsen P, Marteinsdottir I, Larsson H. Journal of Attention Disorder 2016 Feb 2.

II. Genetic and environmental contributions to the association between attention deficit hyperactivity disorder and alcohol dependence in adulthood: A large populationbased twin study.

Capusan AJ, Bendtsen P, Marteinsdottir I, Kuja-Halkola R, Larsson $\mathrm{H}$.

American Journal of Medical Genetics B Neuropsychiatric Genetics. 2015 Feb 25.

III. Childhood maltreatment and attention deficit hyperactivity disorder symptoms in adults: a large twin study

Capusan AJ, Kuja-Halkola R, Bendtsen P, Viding E, McCrory E, Marteinsdottir I and Larsson $\mathrm{H}$

Psychological Medicine, 2016 Jul 5:1-10.

[Epub ahead of print]

IV. Genetic and Environmental Contributions to the Association between Attention Deficit Hyperactivity Disorder and Binge Eating in adults: A Population-Based Twin Study Andrea J Capusan, Shuyang Yao, Ralf Kuja-Halkola, Cynthia M. Bulik, Laura M. Thornton, Preben Bendtsen, Ina Marteinsdottir, Annika Thorsell, Henrik Larsson Manuscript 


\section{List of Abbreviations}

ACE Additive Genetic (A), Common Environmental (C)

ADE Additive Genetic (A), Dominant Genetic (D) and Non-Shared Environmental (E) twin model

ADHD Attention deficit hyperactivity disorder

$\mathrm{AE}$ Additive Genetic (A), Non-Shared Environmental (E) twin model

ASD Autism spectrum disorder

BED Binge eating disorder

BN Bulimia nervosa

CO subtype Combined ADHD DSM-IV subtype

CNV Copy number variation

DSM-5 Diagnostic and Statistical Manual, Fifth Edition

DSM-IV Diagnostic and Statistical Manual, Fourth Edition

DSM-IV-TR Diagnostic and Statistical Manual, Fourth Edition, Text revision

DZ Dizygotic (fraternal) twins or twin pairs

GxE Gene-environment interaction

GWAS Genome-wide association studies

HI Hyperactive/impulsive symptoms

HI subtype Hyperactive/impulsive ADHD DSM-IV subtype

ICD International Classification of Diseases

IN Inattentive symptoms

IN subtype Inattentive ADHD DSM-IV subtype

LSC-R Life Stressor Checklist - Revised

$\mathrm{MZ}$

OR

Monozygotic (identical) twins or twin pairs

RCT

Odds ratio

rGE

Randomized controlled trial

SCID

SD

Gene-environment correlation

STAGE

Structured Clinical Interview for DSM

Standard deviation

on the Swedish Twin Registry)

STR Swedish Twin Registry

SUD Substance use disorder 


\section{Table of Contents}

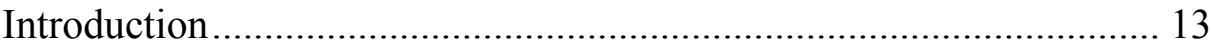

Adult Attention-Deficit Hyperactivity Disorder................................. 15

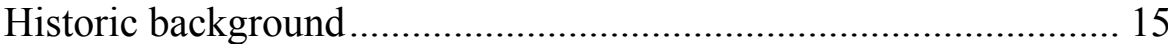

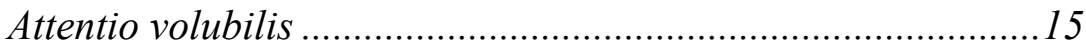

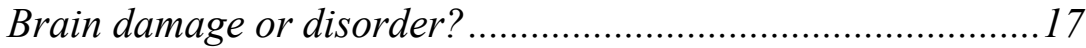

Hyperactivity, inattention, or both? ........................................ 18

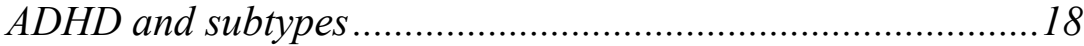

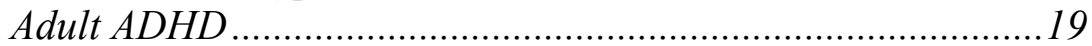

Clinical versus research diagnosis ................................................... 20

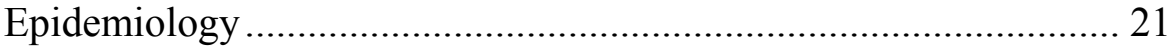

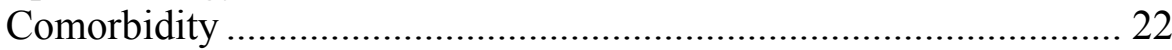

Etiology

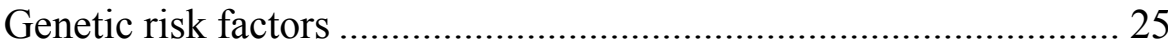

Quantitative genetic studies in ADHD and its comorbidities ...25

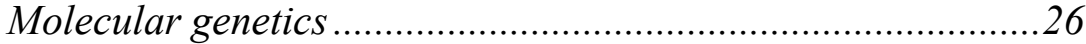

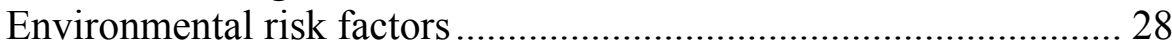

Gene-environment interplay ................................................29

Twin Methods to Study Genetic and Environmental Factors ............... 31

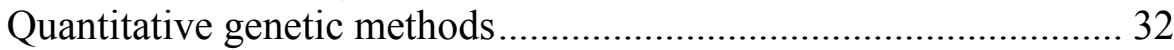

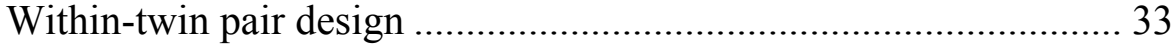

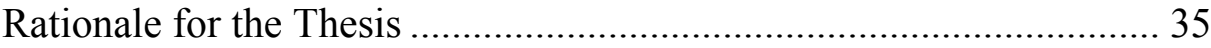

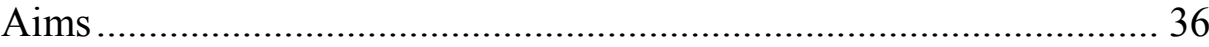

Overall aims of the thesis.............................................................. 36

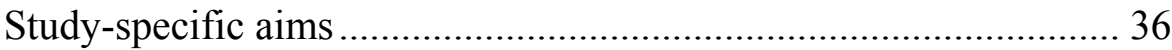

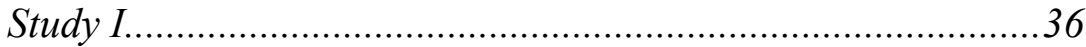

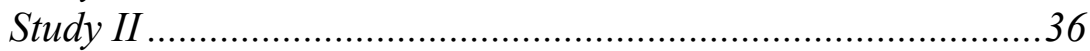

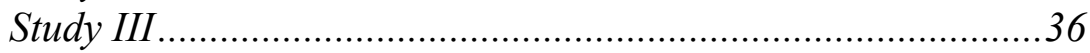

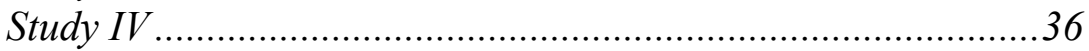

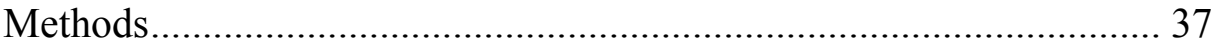

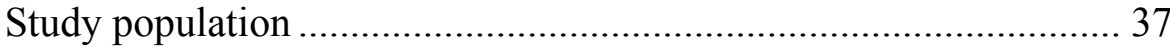

Study designs and measures..................................................... 38

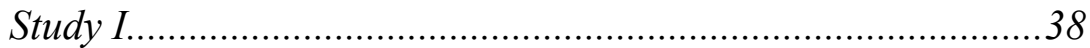

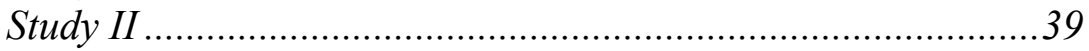

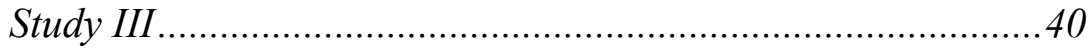

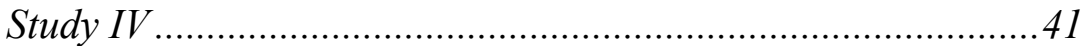

Table 1. Overview of methods by study ......................................... 44

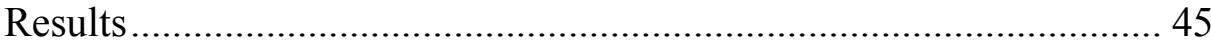

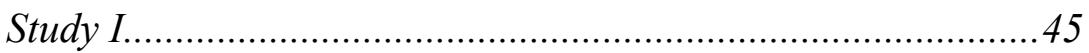




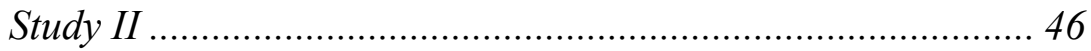

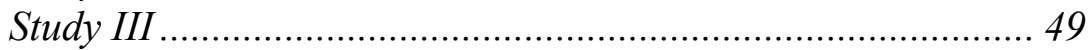

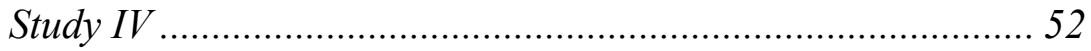

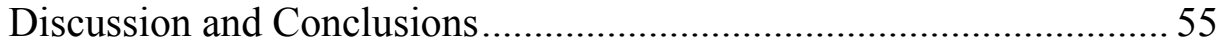

ADHD and substance use disorder.............................................. 55

Common genetic and environmental risks for ADHD and

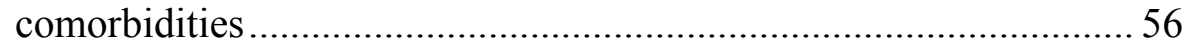

Can environmental risks causally contribute to ADHD? .................. 57

Limitations and methodological considerations...............................5 59

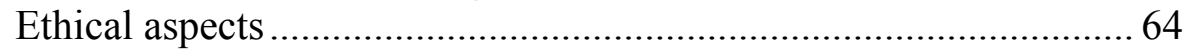

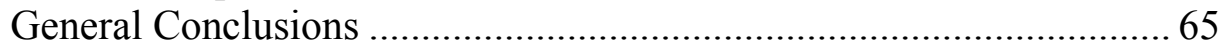

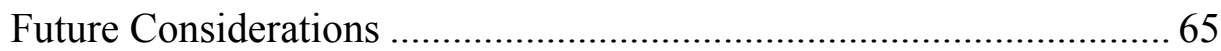

Summary in Swedish - Svensk sammanfattning .................................. 69

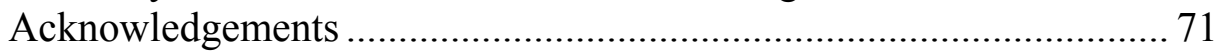

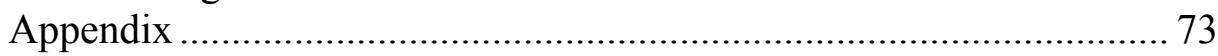

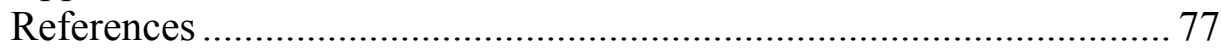




\section{Introduction}

Attention deficit hyperactivity disorder (ADHD) is a persistent disabling condition, manifesting with pathological levels of hyperactivity, impulsivity and inattention $(1,2)$. Although early descriptions from the 18th century recognized a continuity of attention problems over the lifespan $(3,4)$, for the best part of the 20th century, the psychiatric literature considered ADHD as a childhood developmental disorder, which resolved with maturity. I recall the rather vacant expression on the face of my psychiatry teacher during medical school: "ADHD? That's something child psychiatrists do." In recent decades, longitudinal studies have demonstrated the persistence of ADHD over time. Diagnostic criteria, based mainly on childhood referral cases, were revised and adapted to describe symptoms more specific for adults with ADHD (5), and now adult ADHD is a well-established clinical diagnosis $(6,7)$. In adults, ADHD increases the risk for psychological maladjustment, educational and job difficulties, driving problems, disruptive behaviour $(8)$ and multiple psychiatric $(1,9)$ and medical (10) comorbidities. Clinical cases can be regarded as the extreme manifestations of ADHD symptoms that are distributed in the population $(7,11)$.

ADHD is, similar to other psychiatric conditions, a complex disorder, caused by interplay between genetic and environmental risk factors (7). Initially twin and family studies concentrated on childhood manifestation of the disorder (12) and identified a high heritability for childhood ADHD. ADHD has been less studied in adults, and the respective roles of genetic and environmental risk factors in adult ADHD and its comorbidities are not yet fully understood. Several environmental risk factors have been proposed for ADHD in children and adults (13). However, recent genetically informative studies demonstrated that associations, such as between ADHD and smoking during pregnancy, are mainly due to familial (genetic and family environmental) confounding $(14,15)$. This underscores the importance of using genetically informative designs when studying influences of the environment on ADHD.

The cover illustration is a scenery on "The Road to Motala", a small town where I did my residency in psychiatry. It is where I met my first ADHD patient: Sara, a thirtysomething mother of three. She had never completed her education; was hopping between temporary jobs, unable to manage the mess at home, the half abandoned re-decorating projects; forgetting 
stuff she had written on one of her endless to-do lists. Always late, always on the run, castigating herself for yelling at her children, yet unable to stop herself when she got disturbed by some noise the very next day. She was desperate. I thought she was depressed, but both she and I knew it was not only that. I wrote a prescription on antidepressants that didn't help. Only a year later I learned about ADHD in adults, which put Sara's problems in an entirely new perspective. By that time, she had moved. So had I. I had started my training at a small unit for treatment of substance use disorders (SUD), where I ended up assessing and treating adults with ADHD. Mostly young men, a few women as well. Mostly tough guys with behavioral problems. In parallel I continued work in general psychiatric services, also assessing ADHD. Often women in their early thirties. Stressed, anxious, many of them struggling with chronic pain, weight issues, desperate to cope. Same assessment, same diagnosis, yet different! Driving on the road to Motala, during those long hours commuting, I started to wonder: Why were my ADHD patients with concomitant SUD different from the ones I met in general psychiatric outpatient care? Why does ADHD and substance use overlap? Why only in some patients? Are there sex differences in the overlap? Are these two groups of patients different to begin with, or is it the substance use that makes them different?

The main purpose of this thesis was to further elucidate the role of environmental and genetic risk factors for adult ADHD symptoms in the population and some of its more common comorbidities, such as SUD (16) and binge-eating behaviour, utilizing the unique possibilities of the Swedish Twin Registry and twin research. 


\section{Adult Attention-Deficit Hyperactivity Disorder}

ADHD is a childhood-onset, neurodevelopmental disorder characterized by impairing inattention, motor hyperactivity and impulsivity (7). ADHD often continues into adulthood (17) and co-exists with other psychiatric and medical conditions (1).

\section{Historic background}

This short historic background focuses on the development of the modern concept of ADHD, influenced by theories on genetic and environmental risks, and on how knowledge about the persistence of ADHD into adulthood evolved late in the 20th century.

\section{Attentio volubilis}

Although ADHD is a relatively new concept, its two main symptom dimensions, inattention and hyperactivity/impulsivity, were described much earlier. According to Barkley and Peters (18), the first descriptions date back to the 18th century, when German physician and philosopher Melchior Adam Weikard defined, in his medical textbook The Philosophical Physician, 1779 (3), fleeting, fickle attention (Attentio Volubilis) as the incapacity to maintain attention over time. Individuals with this problem were described as "unwary, careless, flighty and bacchanal", who were distracted by "a hundred minor matters", will "only hear half of everything; ... memorize or inform only half of it or do it in a messy manner" (18). The problems were thought to diminish with age but were also identified in adults. A more comprehensive description from 1798, by Sir Alexander Crichton, in "On Attention and its Diseases" (4), depicts the "the incapacity of attending with a necessary degree of constancy to any one object." On the course and prognosis, he wrote:

"It may be either born with a person, or it may be the effect of accidental diseases. When born with a person it becomes evident at a very early period of life, and has a very bad effect, inasmuch as it renders him incapable of attending with constancy to any one object of education. But it seldom is in so great a degree as totally to impede all instruction; and what is very fortunate, it is generally diminished with age."

During the 19th century, German physician Heinrich Hoffmann created children's stories and book illustrations (19) on characters such as Zap- 
pelphilipp (Eng. Fidgety Philip) and Struwwelpeter describing hyperactivity, untidiness, and opposition; and Hans Guck-in-die-Luft (Eng. Johnny Look-in-the-Air), depicting inattention.

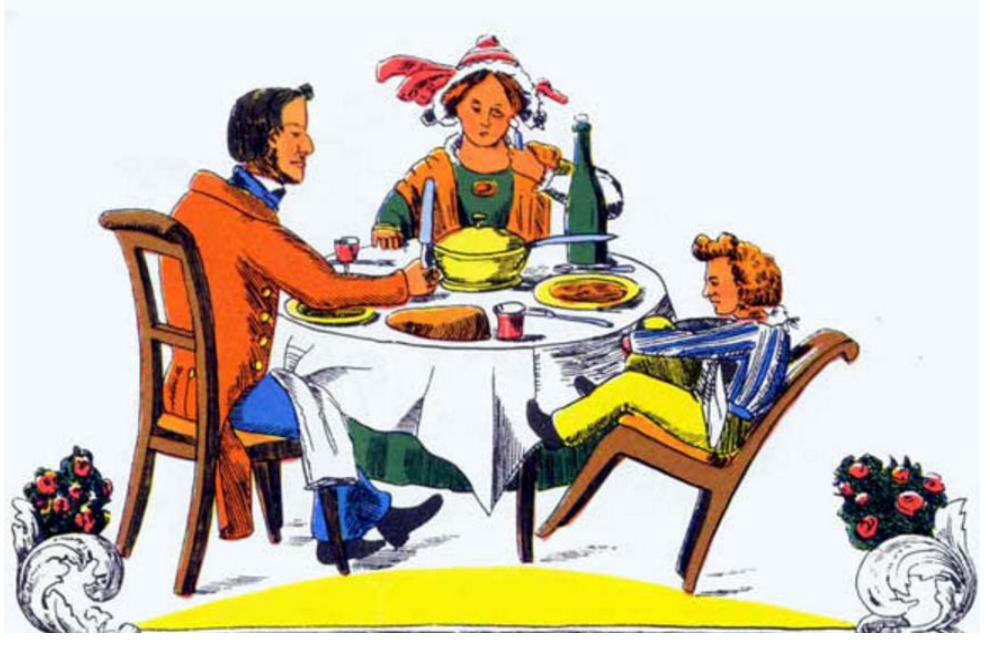

Fig. 1 Zappelphillip, Heinrich Hoffmann 1848 (19)

According to Lange, et al. (20), it is unclear if any of these characters actually described a specific psychopathology, or were simply "humorous depictions of naughty children". Nonetheless, they have become iconic images for ADHD in children, especially in the German literature (20).

Several case descriptions from the late 19th, early 20th century refer to problems with hyperactivity or inattention similar to ADHD in children, but the first scientific description is attributed to Sir George Fredric Still, Professor of Paediatrics at King's College Hospital, London. In a series of lectures (known as the Goulstonian lectures) published in 1902 (21), he conceptualized the "defect of moral control, as a morbid manifestation, without general impairment of intellect and without physical disease." These lectures presented 20 cases with symptoms of hyperactivity, impulsivity, inattention and conduct problems in children. Still identified some of the key symptoms in ADHD, such as an "abnormal incapacity for sustained attention". However, these cases, describing a wide range of externalizing (e.g., hyperactive/impulsive, destructive, oppositional, aggressive) problems in children, are not equivalent to current ADHD 
(20). Remarkably, Still recognized persistence of symptoms into adulthood and seemed to be aware of the role of environmental factors in the outcome:

"although some of them persist into adult life, at no other period are the opportunities for investigating them so favourable as in childhood; for in early years the influence of environment has not yet become so varied and complicated as to be altogether beyond our gauge".

\section{Brain damage or disorder?}

A contemporary of Still, Tredgold (22) identified in 1908 an association between behavioural problems and early brain damage, such as perinatal anoxia. Possible genetic factors were also described for conditions such as "feeble mindedness" (23), but these early genetic considerations in the context of contemporary Europe were soon connected to eugenics, and a dark period in human genetics (24), possibly in part explaining postWorld War II weariness to address genetic factors in mental health. Meanwhile, environmental causes found further confirmation in "postencephalitic behaviour disorder", a consequence of encephalitis lethargica, of which there was an epidemic between 1917 and the late 1920s. The cause is still unknown, but influenza (Spanish Flu) may be a factor. The epidemic affected both adults, with mainly neurological symptoms, and children, who showed markedly changed personality with symptoms of hyperactivity, distractibility, and antisocial, destructive behaviours (25). In the 1930s, the German psychiatrists Kramer and Pollnow (26) described the "hyperkinetic disease of infancy", which Lange et al. (20) found to be very similar to the modern definition of ADHD. It includes both hyperactivity/impulsivity and inattention, alongside other key symptoms of ADHD such as executive function problems and emotional dysregulation. Although influential for a while (6), the two authors had to flee Nazi Germany, and their work on the definition of hyperkinetic problems was soon forgotten.

In 1937, largely unnoticed by the scientific community of the time (27), Bradley (28) published his chance discovery that stimulants (amphetamine) dramatically improved inattention and hyperactivity in about 50\% of children with apparent brain damage. These results were later confirmed in several clinical trials (27). Taylor (6) emphasizes that the efficacy of stimulant medication was established by the medical and scientific community. Early descriptions fuelled the hypothesis of "minimal brain damage" in the 1940s, implicating the brain as the source of ADHD 
(2). Due to the failure to demonstrate an actual brain injury in most cases, the concept of brain damage was redefined as "minimal brain dysfunction" (MBD) (29) or "minimal cerebral dysfunction" (22). However, these concepts were problematic. They assumed brain damage or dysfunction from a description of behavioural symptoms without actually being able to demonstrate either in most cases (20). There were also concerns that an increase in diagnosis and medication came with the commercialization of Ritalin for the treatment of MBD during the 1970s (6).

\section{Hyperactivity, inattention, or both?}

In the early 1960s, a condition similar to ADHD, the "hyperkinetic reaction" was included in the second edition of the Diagnostic and Statistical Manual of Mental Disorders, the DSM-II (30). Authors such as Chess (31) considered hyperactivity, with motoric disinhibition as the main symptom (32). In this period, several authors emphasized that symptoms resolved in adulthood $(31,33)$. A decade later, following recognition of attention problems related to MBD, authors such as Douglas and Peters $(6,34)$, described inattention as the primary manifestation of the disorder. Consequently, the DSM-III introduced the term Attention Deficit Disorder with or without hyperactivity (35). Meanwhile the International Classification of Diseases (ICD) included, in its 8th and 9th editions, "hyperkinetic disorder", with hyperactivity as the key symptom (36). Hyperkinetic disorder does not entirely overlap with ADHD. It covers the more severe spectrum of the disorder, somewhat limiting comparability of research using ICD (mainly in Europe) and DSM.

\section{ADHD and subtypes}

Later research indicated that neither hyperactive/impulsive nor inattentive symptoms seem to be the primary problem. The two symptom dimensions co-vary with moderate to high correlation $(r=0.63,0.75)(37)$. They share in part genetic risk factors $(38,39)$, but genetic influences specific for each symptom dimension have also been identified (38).

Consequently, the contemporary term "ADHD" introduced in DSM-IV (40) is characterized by impairing symptoms of both hyperactivity/impulsivity and inattention. A large validation study based on children and adolescents in the United States (41) identified three clinical subtypes, which were included in DSM-IV: predominantly inattentive (IN), predominantly hyperactive/impulsive (HI) and combined (CO). 


\section{Adult ADHD}

Although we do not know if the conditions described more than two centuries ago $(3,42)$ were indeed ADHD, these early accounts seemed to recognize persistence of symptoms into adulthood. Weikard (3), for instance described, a young chaplain distracted from his duties by "every humming fly, every shadow, every sound... even his imagination, if and when it is copious". Persistence into adulthood is also mentioned by Still (21). Why then, for the best part of the 20th century, were hyperactivity/impulsivity and inattention problems seen as childhood disorders that resolve with maturity? Authors such as Barkley (33) describe several possible contributing factors. For example, focus on early family environmental causes of behavioural problems in psychoanalytic approaches could be one. The belief that symptoms resolved by adolescence (31) may also have contributed to delaying recognition of ADHD as a persisting condition. Another explanation could be that similar symptoms in adults were seen as secondary to other disorders. For instance, in the second edition of the Oxford Textbook of Psychiatry in 1988, when looking up attention problems (p. 33), we find:

"Attention is the ability to focus on the matter in hand. Concentration is the ability to maintain that focus. These abilities may be impaired in a wide variety of psychiatric disorders including depressive disorders, mania, anxiety disorders, schizophrenia, and organic disorders. Therefore the finding of abnormalities of the attention and concentration does not assist in diagnosis." (43)

Given the large number of comorbidities in adults, identifying underlying ADHD may have been difficult.

From the late 1960s, an increasing number of publications described persisting ADHD symptoms $(44,45)$ into adulthood. Studies revealed that the role of the early environment may have been overemphasized in behaviours such as hyperactivity/impulsivity (45). Later research demonstrated that about $65 \%$ of all childhood cases have continued functional impairment and about 15\% have the full syndrome (Fig. 2) (2).

Clinically, adult ADHD was still diagnosed using childhood criteria in DSM-IV-TR (TR, text revision) (46). The 5th edition DSM-5 (5) finally included adult ADHD as a distinct diagnosis. The threshold for diagnosis in adults was lowered, based on the recognition that symptoms, especially HI symptoms (47), diminish with age. Age of onset was increased from 
before age 7 years to before age 12 years, based on research findings supporting similarities in the course of disease, severity, and comorbidities $(48,49)$.

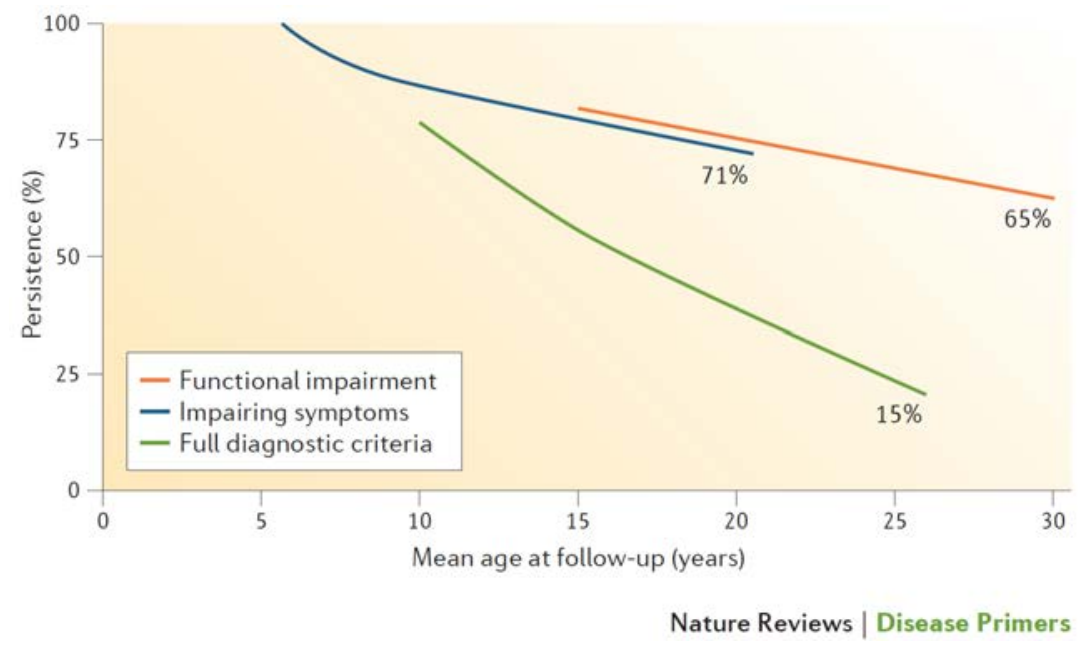

Fig. 2. The age-dependent decline and persistence of ADHD throughout the lifetime. Faraone et al. (2015) (2), Nat. Rev. Dis. Primers.

\section{Clinical versus research diagnosis}

Similar to most behavioural disorders, ADHD is a syndrome diagnosis based on reported symptoms, with no specific tests or laboratory findings to ascertain the diagnosis. In clinical settings, a dichotomous diagnosis is necessary to inform decisions on referral, medication, and management. However, the symptoms of ADHD in the population seem to vary across a continuum within the symptom dimensions (hyperactive/impulsive and inattentive). Subthreshold cases, i.e. individuals who have ADHD symptoms without meeting the criteria for a full diagnosis, may be less severe manifestations of the syndrome (48). Twin research has demonstrated similar heritability estimates for dichotomously assessed ADHD and for ADHD symptoms as a continuous variable in the population $(11,50)$. Furthermore, the same genes seem to be associated in ADHD, as in ADHD symptoms in the general population (51). Therefore, from a research perspective, there is evidence supporting a continuous, dimensional approach to $\operatorname{ADHD}(7,11)$.

In some settings, a dichotomous research diagnosis, or cut-off, is necessary for population studies. One method, suggested by Barkley and Fisher 
(52) is a norm-based approach, which sets a cut-off at 1.5 or 2.0 standard deviations (SD) above the mean on the symptom count scales of hyperactivity/impulsivity and inattention. In American college students, a 2 SD cut-off resulted in prevalence similar to DSM-IV diagnosis (53), however, in other population studies, it rendered higher estimates, probably including subthreshold cases (54).

\section{Epidemiology}

ADHD is the most common developmental disorder. Recent meta-analyses (55) including 86 child and adolescent studies $(N=163,688)$ and 11 adult studies $(N=14,112)$ based on DSM-IV criteria, estimated the prevalence of ADHD at 5.9-7.1\% in children and adolescents. In adults, the prevalence is between $2.5 \%$ and $5 \%$ (55-57). Similar to other neurodevelopmental disorders, ADHD is more common in males than in females. Child and adolescent studies reported male/female ratios of 1.9:1 based on self-rating and 3.2:1 for combined parent and teacher rating (55). Adult samples are generally more balanced for sex (58).

Variability in prevalence is thought to be due to methodological differences such as the source of information or diagnostic tools used $(55,56$, 59). The most recent meta-analytical review of the literature (60) did not confirm geographic variability in prevalence. Nonetheless, there are cultural differences in the recognition, diagnosis and treatment of ADHD, affecting prevalence estimates in different countries, mainly due to differences in attitudes towards stimulant medication (6).

In Sweden, the prevalence of adult ADHD in the population is still unclear. Earlier studies reported a prevalence around 2.1 and $8.8 \%$ based on self-reports in the general population $(54,61)$, and between $6.6 \%$ and $21.9 \%(61,62)$ in adult psychiatric outpatients. National diagnose register studies show an increase in clinically diagnosed cases between 2006 and 2011 from $0.11 \%$ to $0.48 \%$ (63). Prescription data from the Swedish National Board of Health and Welfare indicates a nationwide prevalence of ADHD in adults 20 years and older of around 1\% (64), which is still much lower compared with the self-reported data.

Is the prevalence of ADHD increasing, or is the increase still an effect of the growing recognition of the disorder during the past decades? Recent population surveys in the United States indicated increasing prevalence 
of ADHD (65), but a meta-analytical review conducted in 2014 found no evidence for this over the past three decades, when DSM-II to IV were used (59). The lower threshold for diagnosis in DSM-5 raised concerns about increased prevalence. Initial research indicates a certain increase in ADHD diagnosed with DSM-5 compared with DSM-IV $(66,67)$. There is some evidence that the additional cases, were more likely from a lower income and ethnic minority background, which suggests that "late-onset" cases may actually be "late-recognized cases" (60) in individuals with less access to health care.

Another group potentially contributing to an apparent increase in prevalence are adults seeking help with lifetime problems not previously recognized as ADHD. There is a concern that cases seeking help in adulthood differ from those recognized as childhood ADHD (58). This poses questions regarding the concept of ADHD as a lifetime developmental disorder. It also raises the issue of comorbidities and differential diagnosis, especially difficult in adults. In addition to possible unrecognized ADHD, adults may have developed cognitive and behavioural consequences of other psychiatric and substance-related problems, presenting with ADHD-like symptoms. Therefore, a better understanding of ADHD and its comorbidities in adults is crucial.

\section{Comorbidity}

ADHD in adults shows considerable comorbidities with other psychiatric disorders, mainly affective, anxiety, substance use, eating and personality disorders $(1,8)$, as well as with medical disorders $(8,10)$ including obesity and cardiovascular disease.

Substance use disorder (SUD) is one of the most common and harmful comorbidities in adults with $\operatorname{ADHD}(1,63)$, resulting in poorer outcome, lower quality of life (16), higher rates of other psychiatric comorbidities (68), and poorer intellectual performance (69), in individuals with both conditions compared with those with only ADHD or SUD. Higher prevalence of ADHD in adults with SUD $(68,70-72)$ and vice versa more SUD in individuals with $\operatorname{ADHD}(73,74)$ compared with the general population have been reported repeatedly. This comorbidity was also identified in selected populations such as prison inmates $(61,75)$, or inpatients in SUD clinics (71). Several longitudinal studies suggest that childhood 
ADHD is an important risk factor for SUD later in life $(76,77)$. Clinically, the comorbidity is especially important as SUD may delay an ADHD diagnosis (73). Also, individuals with both conditions may have different therapeutic needs (78) compared with individuals with only ADHD or only SUD.

Several aspects of the association with SUD are poorly understood. First, only a few studies describe the association between adult ADHD symptoms in the general population and SUD. Clinical studies have the problem of selection bias, because treatment-seeking individuals are probably at the more severe end of the spectrum.

Second, the role of ADHD DSM-IV subtypes in the association between adult ADHD symptoms with SUD in the general population is not clear. There is some evidence that HI ADHD symptoms were more often associated with externalizing disorders including conduct, and antisocial personality disorder, and SUD, whereas the IN symptoms were associated with internalizing problems such as depression and anxiety (37). Prior research regarding the role of the ADHD subtypes in comorbidities with SUD is conflicting. Some authors find an association mainly between the HI subtype with SUD $(76,79,80)$; others identified more SUD in the combined (CO) subtype (81). The IN subtype has mainly been associated with increased nicotine dependence (82-85). However, more recently, a large epidemiological study of retrospectively recorded childhood/adolescent ADHD symptoms found no significant differences between the three ADHD subtypes and risk for SUD in adults (86). Also, it is still unclear if ADHD leads to specific substance preferences and whether this differs across subtypes. Preference for stimulants $(69,87)$ and cannabis (87) in individuals with ADHD have been proposed; whereas a preference for nicotine use was suggested for the IN subtype (82), consistent with a self-medication hypothesis. Clearly, it is relevant to examine the specific roles of the ADHD subtypes in the risk for different types of SUD.

Binge-eating behaviour and related eating disorders, such as binge-eating disorder (BED) and bulimia nervosa $(\mathrm{BN})$, have recently been recognized as comorbid conditions to ADHD (88-90). Prior research indicate the role of impulsivity in the association between ADHD and binge-eating behaviors $(88,91)$. Other studies suggest that impulsivity is not the only factor leading to the co-morbidity between ADHD and binge eating (92). 
ADHD and binge-eating behaviour show overlapping problems in neurobehavioral mechanisms that involve response inhibition, emotional regulation, and reward processing (93). To date, the association between ADHD and binge-eating behaviour and disorders in the Swedish population and to which extent genetic and environmental risk factors contribute to this association are not known.

\section{Etiology}

ADHD is a complex disorder; its pathophysiology and cause are not fully understood. Similar to other psychiatric disorders, genetic and environmental risk factors interact, contributing to ADHD (7).

At a population level, individuals with ADHD display deficits in several neurocognitive domains such as working memory, inhibitory control, vigilance, and planning $(94,95)$. This leads to suboptimal decision making and preference for immediate as opposed to delayed rewards $(96,97)$. Large inter-subject variability suggest a heterogeneity of cognitive deficits in ADHD (94). This explains why no specific neurocognitive test can identify the disorder.

Neuroimaging studies have identified some of the anatomical and functional structures underlying cognitive deficits in ADHD. For instance, functional magnetic resonance imaging (fMRI) studies identified lower frontostriatal activation, and hyper-activation in the visual, somatomotor and default mode networks (98) in individuals with ADHD compared with controls. Findings also include lower ventral striatum activity in reward anticipation (99) and lower connectivity in the default mode and the frontostriatal cognitive and motivational networks (100). Structural MRI studies found reduced total brain size (101) and reduced grey matter volume (102) compared with controls, and an inverse association between brain size and ADHD symptoms in the population (103). Longitudinal MRI studies in children with ADHD show delayed cortical development and maturation $(104,105)$, and contraction over time of ventral striatal areas (106), potentially explaining altered reward processing in ADHD. Remission of ADHD in adulthood is associated with a decrease of the observed abnormalities, but most patients with ADHD do not show complete recovery (2). 


\section{Genetic risk factors}

Multiple twin, family and adoption studies have demonstrated a strong heritability for ADHD (13). First-degree relatives of individuals with ADHD run a 5- to 10 -fold increased risk for the disorder $(87,107)$. Twin studies played an important role in demonstrating the genetic nature of ADHD (108). The first indication came from a univariate twin study identifying genetic factors for hyperactivity (109), later confirmed in several studies $(12,110)$.

\section{Quantitative genetic studies in ADHD and its comorbidities}

In the beginning, ADHD was mainly regarded as a childhood disorder, therefore the initial twin and family studies concentrated on ADHD in children and identified $70-80 \%$ heritability (107). In adolescent and adult samples based on self-report, heritability was estimated to be around 40$50 \%(39,111)$. More recently, heritability similar to that in childhood samples was found in adult clinical samples $(12,107,112)$. Lower reliability of measurements in self-rating, with higher risks for measurement errors (12), as well as rater effects (113) explain the variability in heritability estimates. Twin research also indicated a continuous distribution of ADHD-related problems in the population $(11,50)$, a finding supported by molecular genetic (51) and structural imaging (103) studies.

Given the sex difference for ADHD in children, several studies have explored possible sex differences for genetic factors. Twin studies using opposite sex DZ twin pairs indicate that girls may require a higher genetic liability in order to manifest ADHD symptoms (114-116). We do not know, however, if there are sex differences in the overlap between ADHD and comorbidities (e.g. with alcohol dependence).

Research regarding the overlap between ADHD and comorbid conditions initially also focused on children, identifying common genetic factors for externalizing disorders $(79,117-119)$, with autism spectrum disorder (ASD) (120), cognitive performance such as reading problems (121), as well as with psychiatric disorders such as mood disorder (122). More recently, common genetic factors have been identified in adults for a wide range of psychiatric disorders, indicating involvement of a set of pleiotropic genes (123). Common genetic risk factors for adolescent ADHD and SUD (124), family aggregation of ADHD and SUD in adults (125), as well as common genetic risk factors for adult ADHD and problem drinking (126) in the general population, have been described. 
Previous studies have generated conflicting results regarding the role of genetic and environmental risk factors in the association between alcohol dependence and ADHD. A family study (127) suggested independent familial transmission of ADHD and alcohol dependence, whereas a twin study (79) found shared genetic risks for adolescent ADHD in males and alcohol dependence. The role of genetic and environmental risk factors in the overlap between adult ADHD symptoms and alcohol dependence needs to be clarified.

Even less is known about the role of genetic and environmental risk factors in the association between ADHD and binge-eating behaviour. Research (88-90) indicates an association between these phenotypes. Although genetic factors play a substantive role in both $\operatorname{ADHD}(12,39,113)$ and binge-eating behaviours and disorders (128-133), to our knowledge no previous twin study has examined the extent to which genetic and environmental factors are shared between ADHD symptoms and binge eating.

\section{Molecular genetics}

ADHD is a complex polygenic disorder. Common genetic factors with small effects sizes, rare variations with larger effect sizes (such as copy number variations $[\mathrm{CNVs}]$ ) and very rare chromosomal anomalies, with even bigger effect sizes, contribute to the disorder in the population (2, 134) (Fig. 3).

Genome-wide association studies (GWAS) suggest that $40 \%$ of the heritability of ADHD is explained by a large number of common genetic variants (Fig. 3). Combined GWAS for ADHD, ASD, bipolar disorder, and schizophrenia identified four genome-wide significant loci (135). Polygenic risk scores for ADHD showed a positive association with ADHD symptoms in the general population (51), supporting earlier twin and family findings. More recently pathway analysis of GWAS studies suggests the possible role of the regulation of neurotransmitter release, neurite outgrowth and axon guidance in contributing to ADHD (136).

Genome-wide linkage studies found rare (prevalence $<1 \%$ ) genetic variants, such as CNVs in 15.6-42.4\% of cases of ADHD, with or without concomitant intellectual disability. CNVs involve genes implicated in other disorders such as ASD and schizophrenia $(2,137)$. This supports twin and family research mentioned earlier (120), as well as the suggested pleiotropic genetic risks for psychiatric disorders (123). 
Fig. 3 Genetics of attentions deficit/hyperactivity disorder. Faraone et al. (2015) (2), Nat. Rev. Dis. Primers.

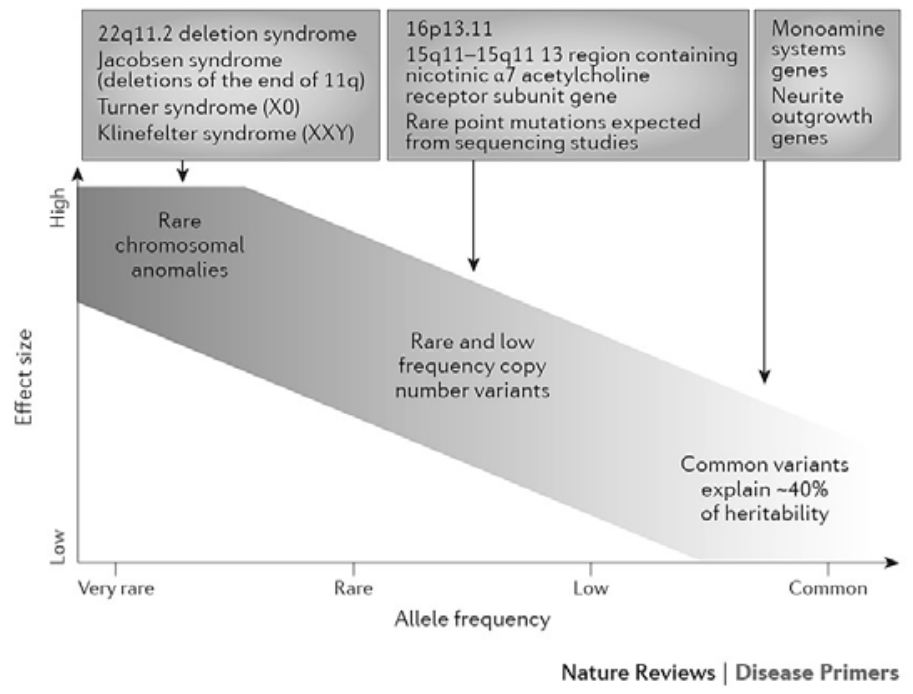

Candidate gene studies were the earliest attempts to identify genetic causes of ADHD. Studies on childhood ADHD on the role of dopaminergic and serotonergic genes as well as genes involved in synaptic plasticity $(107,138)$, have repeatedly been replicated, although effect sizes are small. Other studies, such as recent meta-analysis, involve SNAP-25 (a cellular calcium modulator) polymorphism (139). Candidate gene studies identified both similarities and differences between genetics of childhood and adult ADHD (12). This emphasizes the importance of specifically studying genetic risk factors for adult ADHD.

To address the genetic complexity of psychiatric disorders and heterogeneity of diagnostic constructs, Gottesman and Gould (140) suggested the use of endophenotypes or intermediate phenotypes. These are heritable, measurable phenotypic markers associated with the disorder, more often present in healthy family members of cases than in the general population, and more closely linked to genes. Several endophenotypes involving neuropsychological and neuroimaging findings $(141,142)$ have been described for ADHD. Research suggests that this approach increases power and could be more successful at identifying relevant genes for ADHD $(141,143)$ (Fig. 4). 
Fig. 4. Simplified schematic representation of the endophenotype concept in psychiatric genetics. Franke et al, 2009 (141), Human Genet.

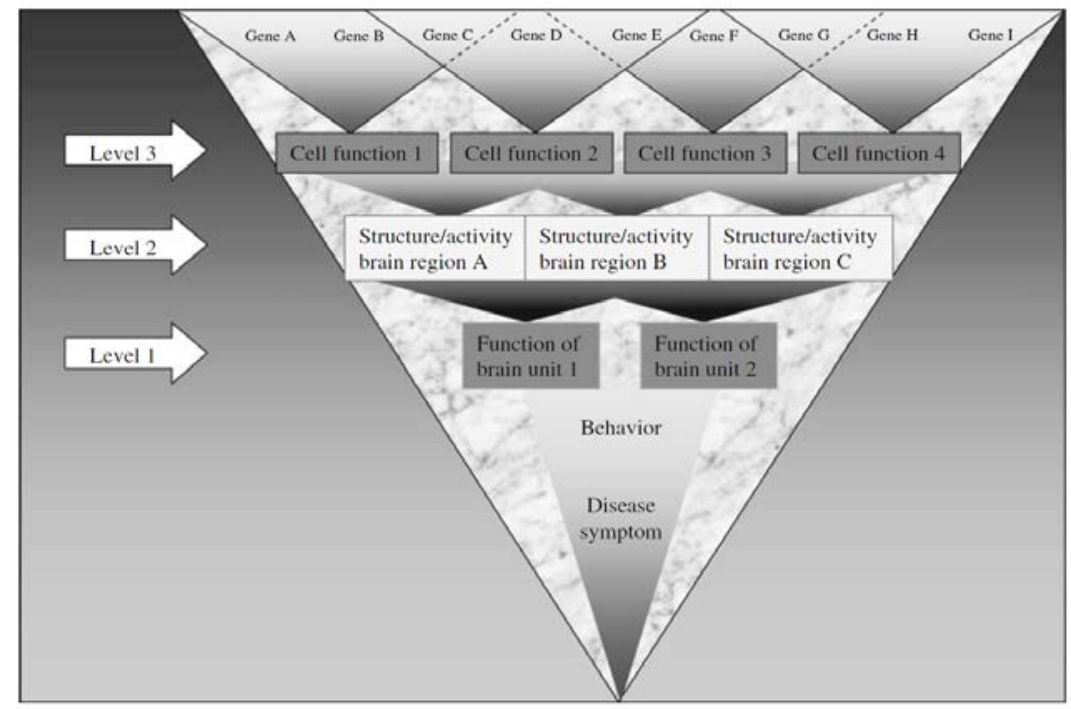

Many genes (genes A-I) are involved a categorical disease phenotype or symptoms and behaviours. A decreasing number of genes are involved in disease-related endophenotypes at functional, structural and cellular levels (Levels 1 to 3).

\section{Environmental risk factors}

ADHD is associated with a wide range of pre-, peri- and postnatal environmental risk factors (7). Twin studies in both children and adults suggest a significant role for (non-shared) environmental risk factors. However, much remains to be investigated on their role in causing ADHD and comorbidities (6). Many associations have proved not to be causal when tested with genetically informative, quasi-experimental studies (144). For instance, one of the most robust associations, smoking during pregnancy (145), initially thought to cause ADHD in the offspring, proved to be mainly due to unmeasured familial confounding $(14,15)$.

Psychosocial risks factors have also been described in ADHD, but their role as causal environmental risk factors is still unclear $(6,13)$. Low income, family adversity, and hostile parenting proved to be correlated with ADHD rather than causal (7). Childhood maltreatment has been associated with ADHD in children (146-149) and adults (150, 151), but these studies have not been able to rule out the role of familial confounding. 
One prior genetically informative study demonstrated that severe institutional deprivation leads to ADHD-like inattention/overactivity (148). Childhood maltreatment may affect working memory, executive and emotional control (152), inhibitory network connectivity, and response inhibition (153). These are neurocognitive processes potentially involved in ADHD. It is therefore important to study the association between childhood maltreatment and adult ADHD and the potential role of familial confounding with genetically informative studies.

\section{Gene-environment interplay}

Nature and nurture operate together, the respective effects of genes and environment are strongly intertwined $(13,154)$. Genetic influences may confound assumed environmental effects and vice versa, environmental influences may lead to expression of genetic risks.

According to the classification proposed by Kraemer et al. (155), risk is the probability of developing an outcome. A widely held view is that, in the case of complex disorders, no single risk factor is either necessary or sufficient to cause the disorder. Rather, their influence has to be understood in the context of other factors (155). Risks operating in the whole population, over the normal distribution, exert a "probabilistic rather than deterministic" effect (156). Thus causal risk factors (X) can be defined as factors that alter the risk of an outcome (Y) when manipulated. For one factor $X$ to cause an outcome $Y, 1) X$ has to precede $Y, 2) X$ has to be related to $\mathrm{Y}$ and 3) no plausible alternative explanation can better explain Y. There are many reasons why an observed association might not be causal. Rutter (157) describes several alternative explanations, such as genetic mediation of environmental risk factors, other factors offering a plausible alternative explanation (confounding), and selection bias, to mention only a few. In epidemiological studies, identifying and ruling out alternative explanations is essential.

One mechanism for genetic mediation is gene-environment correlation (rGE) $(154,158)$, divided into: 1) passive $r G E$, which occurs because parents provide both their genes and the home environment, and 2) nonpassive $r G E$, which is subdivided into 2 a) evocative $r G E$, where a certain genetically influenced trait in the child will evoke a response from the rearing environment (e.g. disruptive behaviour evoking harsh parenting) and $2 \mathrm{~b}$ ) active $r G E$, where children will seek certain environments due to their genetic make-up (e.g. children with high verbal cognitive abilities will go to the library more often, or children with high novelty-seeking 
traits will more often expose themselves to potentially dangerous situations, increasing risk for injury). Passive rGE has been identified as a mechanism in the intergenerational transmission of externalizing behaviours (including ADHD and SUD) (159), whereas evocative rGE may play a role in corporal punishment in conduct disorder (160), as well as in the association between hostile parenting style and ADHD symptoms (161). Rutter (154) also described several other forms of gene-environment interplay, such as gene-environment interactions, epigenetic effects of environmental risks, as well as variations in heritability according to environmental circumstances.

Clever designs, such as sibling comparison designs and discordant twin designs can rule out passive rGE (144), but not reverse causation, i.e. evocative and active rGE. Other designs can address these mechanisms, where exposure precedes the studied outcome and cannot be influenced by behaviour in the offspring (e.g. intrauterine exposure), and thus strengthen causal inference $(144,157)$. Other possible designs to study the effect of non-passive rGE are adoption studies and children of twins studies (157).

To strengthen causal inference, gene-environment interplay needs to be addressed when examining possible environmental risk factors in observational studies. This can be done with the use of different quasi-experimental designs in various settings and populations $(144,162)$. 


\section{Twin Methods to Study Genetic and Environmental Risk Factors}

Before the era of molecular genetics, twin, family and adoption studies were the only way to estimate the role of genetic risk factors in the occurrence of a disorder. In essence, twin studies rely on the difference between monozygotic (MZ) (identical) twins who share $100 \%$ of their genes and fraternal, dizygotic (DZ) twins sharing an average of $50 \%$ of their segregating genes. First discovered by Galton in 1875 (163), twin research developed with the recognition of the difference between $\mathrm{MZ}$ and DZ twins in the early 20th century $(164,165)$. Its importance in behavioural sciences and in studying the interplay between genetic (the original nature) and environmental factors was already recognized in 1905 by Thorndike (166): “...the influences of the environment are differential, the product varying not only in accord with the environmental force itself, but also in accord with the original nature upon which it operates".

Progress in mathematical knowledge, such as the introduction of Pearson's correlation coefficient, which allowed computing twin correlations; and Fisher's analysis of variance and the possibility of obtaining intraclass correlations, partitioning variance between and within twin pairs, contributed to the development of twin research (165). These advances led to the establishment of national twin registries, the first in Denmark in 1954 (167), followed a few years later by the Swedish National Twin Registry (STR) (168). Including around 200,000 individuals, 150,000 with known zygosity, the STR is the largest in the world. Zygosity is assigned based on intra-pair similarities in childhood, validated with DNA analysis, a method with 98\% accuracy (169). Data have been repeatedly collected from the registry in various studies since the 1960s.

Traditionally, twin research used twin correlations and analysis of variance to calculate heritability (167). Twin correlations, i.e. the correlation between the same phenotype (trait) measured in both twins in pairs, give an indication of the role of genetic and environmental factors. Correlations in MZ twins $>\mathrm{DZ}$ twins for a phenotype indicate genetic effects. $\mathrm{MZ}$ correlations $<2$ times the DZ correlations suggest the role of common environmental factors, and $\mathrm{MZ}$ correlations $<1$ indicate the role of environmental effects that make twins different (non-shared environment). Thus, $\mathrm{MZ}$ correlations $=1$ and $\mathrm{DZ}$ correlations $=0.5$, indicates $100 \%$ heritability; if however MZ $=\mathrm{DZ}$ correlations, heritability is 0 
(158). Twin correlations can also show genetic factors in the overlap between two traits, utilizing cross-twin cross-trait (CTCT) correlations. If correlations for a trait in one twin and the other trait in the other twin in $\mathrm{MZ}$ pairs exceed respective CTCT correlations in DZ twins, we can assume a genetic overlap between traits.

\section{Quantitative genetic methods}

Using MZ and DZ twins, quantitative genetic methods evaluate the percentage of total variance of a trait attributed to genetic factors (i.e. heritability, traditionally labelled $h^{2}$ ). Heritability in a narrow sense refers to additive genetic effects (A), i.e. the extent to which genotypes "breed true" in the offspring. If a parent has a certain allele, the offspring has $50 \%$ chance of getting the same allele. The total $(100 \%)$ variance of a trait can be defined in a simple model as a sum of additive genetic factors (A), common environmental factors (C) and non-shared environmental factors (E). This can also be represented as a path diagram, where the variance is decomposed into A, C and E. (Fig. 5).

Fig. 5. Path diagram for classical twin analysis.

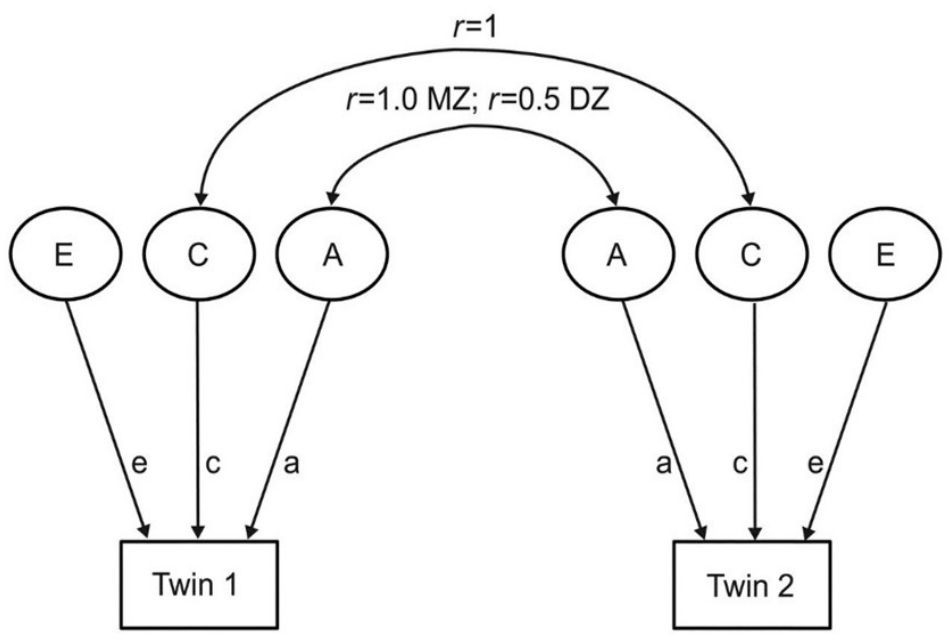

$\mathrm{A}=$ additive genetic $\mathrm{C}=$ shared environmental; and $\mathrm{E}=$ non-shared environmental influences. $\mathrm{A}+\mathrm{C}+\mathrm{E}=$ Total variance; $\mathrm{MZ}=$ monozygotic twins; $\mathrm{DZ}=$ dizygotic twins.

In Figure 5, A, C and $\mathrm{E}$ have an associated path a, c and e, respectively. In this model, we assume no difference in the genetic and environmental 
influences for twin 1 and twin 2, therefore paths are written with the same letter. The assumption is valid if twins are assigned randomly as twin 1 and twin 2. The paths can be estimated using observed correlations for a trait $(r)$ for $\mathrm{MZ}$ and $\mathrm{DZ}$ twins. Correlations, written as the sum of shared genetic and environmental effects, are: $r \mathrm{MZ}=a^{2}+c^{2}$ for $\mathrm{MZ}$ twins and $r \mathrm{DZ}=a^{2} / 2+c^{2}$ for DZ twins. It is now possible to calculate: $a^{2}=2(r \mathrm{MZ}-$ $r \mathrm{DZ}), c^{2}=r \mathrm{MZ}-a^{2}$ and $e^{2}=1-r \mathrm{MZ}$.

This is of course a simplified model. Genetic factors may include other genetic effects, such as dominance (D). MZ correlations $>2$ times DZ correlations indicate dominant genetic effects. This necessitates another model: $\mathrm{A}+\mathrm{D}+\mathrm{C}+\mathrm{E}=$ total variance. However, as we can only observe two distinct correlations ( $r_{\mathrm{MZ}}$ and $r_{\mathrm{DZ}}$ ), this equation cannot be solved, and another simplified model $\mathrm{A}+\mathrm{D}+\mathrm{E}=$ total variance can be used (158). C and D cannot be estimated simultaneously with twin methods.

Modern computational methods permit modelling of genetic, shared environmental and non-shared environmental (unique for each twin) influences. The most widely used model is structural equation modelling (covariance modelling), where contributions of genetic and environmental factors are modelled as unmeasured (latent) variables for the potential differences between individuals by using likelihood-based methods. The variance of a phenotype, as well as the covariance between phenotypes, are decomposed into additive genetic (A), shared environmental (C) or dominant genetic factors (D), and non-shared environmental (E) factors (ACE or ADE analysis) (170). Model fitting has several advantages: it permits testing and comparison of different models, estimation of confidence intervals, and can accommodate covariates (158). Modelling allows for testing the influence of sex on heritability estimates. Models can also give an indication of possible GxE effects by including environmental measures, by which the sample can be stratified (167). Twin modelling can be done for one trait (univariate models), estimating the role of genetic and environmental factors for that trait, and for the overlap between traits, i.e. bivariate twin models or multivariate models, estimating the respective role of genetic and environmental factors in the overlap.

\section{Within-twin pair design}

Twin studies can also be used to strengthen causal inferences in observational studies by examining the role of possible underlying genetic and 
family environmental confounders in an environmental risk factor. Randomized controlled trials (RCT) are the most accurate method for studying causal relationships between an exposure and an outcome. The role of potentially harmful exposures or exposures that are not randomly assigned in the population (e.g. childhood maltreatment or smoking during pregnancy) obviously cannot be studied using RCTs. In these situations, observational studies offer an alternative. They also have an advantage in the possibility of studying large samples from the general population. But, observational studies are subject to confounding and bias. Quasiexperimental designs can address underlying genetic and family environmental confounding in observational studies (144). MZ and DZ twins have differential genetic relatedness, and are matched on a large number of known (e.g. age, sex) and unknown familial (genetic and shared environmental) confounders. With a co-twin control design, it is possible to study the relationship between an environmental risk factor and an outcome, controlling for these unmeasured familial factors.

Lichtenstein et al. (169) described co-twin control as an analysis in three steps. The first step is to analyse the association in the populations (unrelated individuals). In the next step, disease discordant or exposure discordant twin pairs are analysed. An association within twin pairs similar to the one in the population supports a causal inference not confounded by familial factors. Lower associations within-DZ and -MZ twin pairs, indicate familial (environmental and/or genetic) confounding. In the third step, MZ twin pairs are used to control for the role of shared genetic factors. If the studied association within genetically identical MZ twin pairs, discordant for an exposure or outcome, is zero, we can conclude that it is due to shared genetic factors (genetic confounding). If, on the other hand, the association within exposure discordant $\mathrm{MZ}$ twin pairs is less than in the population, but more than zero, this will be indicative of both familial confounding and also consistent with a causal interpretation for the environmental risk factor studied.

We can only study environments where siblings are differentially exposed. If, the differential exposure is confounded by an underlying environmental factor that causes dissimilarity in exposure, and is associated with both the exposure and the outcome, then an observed association may be spurious (144). 


\section{Rationale for the Thesis}

ADHD in adults has been recognized as a clinical entity only in recent decades. Earlier genetically informative studies have mainly focused on childhood manifestations, and ADHD in adults is less studied. ADHD symptoms are continuously distributed in the population, and clinical cases are the extreme manifestations of these traits $(7,11,48)$, with similar heritability estimates and genetic influences $(11,50,51)$ warranting study of genetic and environmental aspects of ADHD in populationbased samples on ADHD symptoms. Treatment-seeking cases may be a selected group different from ADHD in the population, therefore findings regarding comorbidities have to be replicated in population-based samples. According to several studies, adults are a reliable source of information regarding ADHD symptoms, and self-reported measures of ADHD symptoms display acceptable psychometric properties $(171,172)$ and stability over time (39).

ADHD in adults shows multiple comorbidities. Some of these, such as with SUD, have been extensively described, but the role of subtypes and possible substance preference have not been studied sufficiently in population-based samples in adults. Other comorbidities in adult ADHD, such as with binge-eating behaviour, are emerging and have yet to be characterized.

In addition, it is still unclear to what extent the association between ADHD symptoms in adults and comorbidities with alcohol dependence and with binge-eating behaviour can be explained by common genetic or environmental risk factors.

There are surprisingly few studies regarding the role of environmental risk factors in adult ADHD in the population. Childhood maltreatment is one of the known risk factors for childhood and adult ADHD. Environmental risks can be confounded by genetic aspects, therefore genetically informative designs are necessary to rule out the role of possible unmeasured familial (genetic and environmental) confounding. 


\section{Aims}

\section{Overall aims of the thesis}

The aim of the thesis was to analyse the association between ADHD symptoms in adults with SUD and with binge-eating behaviour in the general population, and the role of genetic and environmental risk factors in these associations. We also analysed the importance of a specific environmental risk factor, namely self-reported childhood maltreatment, and to what extent this association was confounded by unmeasured familial (genetic and environmental) factors or could be causal.

\section{Study-specific aims}

\section{Study I}

In the first study, we aimed to analyse the association between self-reported ADHD symptoms and alcohol use disorder, use of common illicit drugs and regular nicotine use in a large adult sample from the general population. Also, the role of ADHD DSM-IV subtypes in these associations and possible substance preferences were analysed.

\section{Study II}

In this paper, we focused specifically on the association between ADHD symptoms and alcohol dependence. We used twin methods to elucidate if the association was best explained by common genetic or environmental factors. We also examined potential sex differences for the overlap between ADHD symptoms and alcohol dependence.

\section{Study III}

This study analysed a specific environmental risk factor, namely childhood maltreatment, and its associations with ADHD symptoms in adults. The main focus of the study was to explore, using a within-twin pair design, whether the association between ADHD and self-reported childhood maltreatment was mainly due to familial confounding or if it could be regarded as causal.

\section{Study IV}

In this paper, the aim was to analyse the association between ADHD and binge-eating behaviour and related disorders (BED and BN). Using a bivariate twin method, we examined if this association was mainly due to common genetic or environmental factors. 


\section{Methods}

\section{Study population}

This thesis is based on data from the national Swedish Twin Registry, the Study of Twin Adults: Genes and Environment (STAGE) (173). The project was reviewed and approved by the regional ethics committee of the Karolinska Institutet Stockholm, Sweden (reference number 03-224). All participants provided informed consent. Participants, who were adult Swedish twins born between 1959 and 1985, where both individuals had survived their first birthday, received a personal login to the study's web page. The questionnaire contained around 1300 questions on lifestyle, physical and mental health $(54,169,174)$. Questions were set in a "branching" format, which meant that subsequent questions were only asked if participants answered yes to the first "gate"-question/s in a section. Non-responders were reminded up to three times and offered the alternative of a telephone interview with a trained interviewer using a computer-based data collection method and an additional self-administered paper questionnaire instead of the web page. Test-retest reliability and comparison of methods of data collection (i.e. web versus telephone interview) were assessed in 100 twins after 2-5 months (175). From the initial target population of 42,582 twins, 25,484 (60\%) responded in STAGE. Zygosity was determined with a standard similarity questionnaire, described in more detail elsewhere $(169,176)$, which had previously been validated through genotyping. A subsample of 200 twin pairs also provided DNA to determine zygosity (175).

ADHD symptoms: 18,167 twins, provided data on current ADHD symptom in adulthood; assessed with the 18 self-report items based on and DSM-IV-TR criteria ( $9 \mathrm{IN}$ and $9 \mathrm{HI}$ items), with three possible answers: $0=$ "no", 1 = "yes, to some extent" and 2 = "yes". Two years later, 54 twins were re-assessed with Adult ADHD Self-Report Scales (ASRS) $(177,178)$. The correlation coefficient between ADHD symptom counts and ASRS measures estimated at $0.63(\mathrm{p}<0.001)$ suggested stability over time for ADHD symptoms (39), in accordance with previous findings on self-reported adult ADHD symptoms (111). Data on childhood symptoms and functional impairment were not available. 
Substance use disorders were assessed with questions set in a branching format. Alcohol abuse and addiction were assessed according to DSMIV criteria with questions based on the Structured Clinical Interview for DSM-IV-TR (SCID) (173). Of all STAGE participants, 17,734 individuals provided data on both ADHD symptoms and alcohol dependence, 17,940 for alcohol abuse and 17,779 for drug use and ADHD symptoms. Drug use was assessed in a branching format, regarding ever use. Current use and repeated use were also assessed for classes of substances. However, these classes of substances also included prescription drugs. Nicotine use was assessed with questions set in a branching format, i.e. frequency of use was assessed in those who reported use (see Appendix). All 18,167 provided data on nicotine use and ADHD symptoms.

Binge eating was assessed with questions based on SCID for DSM-IVTR questions on eating disorders. 23,767 provided data on binge eating. Only 18,029 provided information on both binge eating and ADHD symptoms. Questions were set in a branching format. Subsequent questions were only asked if gate questions were answered with yes. For instance, compensatory behaviour in association with binge-eating behaviour was only assessed if eating binges were endorsed (see Appendix for SCID symptoms and questions). The total sample included 13,773 females with known zygosity.

\section{Study designs and measures}

\section{Study I}

Study population: 18,167 adult twins, aged $20-46$ years; $7281(40 \%)$ males, mean age 34.0 years and 10,886 (60\%) females, mean age 33.6 years.

\section{Measures:}

$A D H D$, and ADHD DSM-IV HI, IN and CO subtypes - Self-reported symptoms based on DSM-IV-TR. To create cut-offs, we used a normbased approach, based on 2 standard deviation (2 SD) above the mean on a symptoms scale $(52,54)$. With this method, the DSM-IV HI subtype was defined as $2 \mathrm{SD}$ above the mean on the hyperactive/impulsive scale but not on the inattentive scale. Correspondingly, the IN subtype was defined if an individual was 2 SD above the mean on the inattention scale but below $2 \mathrm{SD}$ on the hyperactive/impulsive scale. The $\mathrm{CO}$ subtype was classified if a participant scored 2 SD above the mean on 
both scales. ADHD was set as yes if any of the subtypes was set as yes.

Alcohol abuse - Based on self-reported symptoms assessed with questions from SCID for DSM-IV-TR (173). Set as yes, according to DSM-IV criteria, if $\geq 1$ criteria was yes and no alcohol dependence was set (see Appendix for criteria and STAGE questions).

Alcohol dependence - Based on self-reported symptoms assessed with questions from SCID for DSM-IV-TR (173). According to DSM-IV, set as yes if $\geq 3$ DSM-IV criteria were set as yes during 1 year (see Appendix for criteria and questions).

Illicit drug use - Yes, if tried at least one illicit drug.

Polysubstance use - Yes, if tried $\geq 2$ illicit drugs.

Polysubstance use and alcohol - Yes, if tried $\geq 2$ illicit drugs and/or alcohol use disorder (abuse or addiction).

Cannabis use, stimulant use, opioid use - Use any drug in the respective class at least once. Included prescription drugs. Frequency of cannabis use was assessed as times/month.

Regular nicotine use - Daily use of cigarettes or Swedish-type smokeless tobacco (snus) for a period of time during the life span.

Study design: Cross-sectional epidemiological study in a large twin sample from the general population.

Statistical analysis: Random effect logistic regression for binary outcome, logit-link and adjusting for sex and age on completing the questionnaire and education to obtain prevalence odds ratios (OR) and 95\% confidence intervals (CI) as measures of association between ADHD symptoms and substance use-related outcomes. To assess sex differences for the overlap between ADHD and any SUD, we repeated the analysis stratified for sex. Data were analysed using STATA 11.2 (StataCorp LP).

\section{Study II}

Study population: 18,167 adult twins, same as Study I. 17,711 twins (total 12,291 pairs, 5420 complete) were included in the twin analyses.

\section{Measures:}

ADHD symptoms - Symptom count of self-reported DSM-IV symptoms, used as a continuous variable in the twin analysis $A D H D$ and ADHD DSM-IV subtypes - Same as Study I 
Alcohol dependence - Based on DSM-IV criteria assessed by self-reported questions from SCID (173), same as above.

Study design: Bivariate twin study (bivariate correlated factors model).

Statistical analysis: Random effect logistic regression as in Study I for descriptive purposes. We used the "lincom" command in Stata to analyse differences between HI, IN and CO subtypes and alcohol dependence (STATA 11.1; StataCorp LP).

Intra-class correlations, assessing twin similarity for a trait, and crosstwin cross-trait correlations (CTCT), i.e. correlation between twin 1's status on trait 1 and the co-twin's status on trait 2, were used for an initial examination of the relative contributions of additive genetic (A) (bivariate heritability), common environmental (C) and non-shared environmental (E) factors to the overlap between ADHD and alcohol dependence.

We used structural equation modelling to perform maximum-likelihood model-fitting analyses with OpenMx (179). In a bivariate model, we estimated the additive genetic ( $\mathrm{rA}$ ), shared (rC), non-shared environmental (rE) correlations between ADHD and alcohol dependence. These correlations vary from -1.0 to +1.0 and indicate the extent to which genetic and environmental influences on one measure overlap with those on the other. We then calculated the proportion of the overlap between ADHD and alcohol dependence explained by A (bivariate heritability), $\mathrm{C}$ and $\mathrm{E}$. We fitted models separately for males and females as well as for the whole population; considering both quantitative (we allowed males and females to have different magnitude of A, C, and E) and qualitative (opposite sexed twin pairs were allowed to have lower correlation in A parameters than same sexed twin pairs) sex differences.

We assessed goodness of fit for the different twin models by a likelihood ratio $\chi^{2}$ test. Akaikes Information Criterion (AIC) was computed and used to assess the overall best-fitting model (in ACE and AE separately, as well as across all models). Lower AIC values indicate better fit of the model to the observed data. AIC rewards parsimony.

\section{Study III}

Study population: same as Studies I and II

\section{Measures:}

ADHD symptoms - Same as Study II, ADHD symptoms used as a standardized continuous variable. 
Childhood maltreatment - Based on retrospective self-reports of five Life Stressor Checklist - Revised (LSC-R) (180) items: 1) emotional neglect, 2) physical neglect, 3) physical abuse, 4) sexual abuse, and 5) witnessing family violence. If the response to any of these was yes before age 18 years, childhood maltreatment was set as yes; if yes before age 7 years, then childhood maltreatment before age 7 years was set as yes (see Appendix for measures and STAGE questions).

Childhood neglect - Yes, if emotional and/ or physical neglect were set as yes before age 18 years, and before age 7 years for childhood neglect before age 7 years.

Childhood abuse - Yes, if physical and/or sexual abuse was set as yes, before age 18 years, and before age 7 years for childhood abuse before age 7 years.

Study design: Within-twin pair design.

Statistical analysis: We used linear regression models to evaluate the association between childhood maltreatment and adult ADHD symptoms (as a standardized continuous variable), comparing individuals exposed and unexposed to maltreatment, controlling for sex, age when completing the questionnaire, and lack of independence of twin data using a clusterrobust sandwich estimator.

Conditional linear regression (within-twin pair analysis) was performed for the associations between childhood maltreatment and adult ADHD symptoms within-DZ and -MZ twin pairs discordant for childhood maltreatment.

Sensitivity analyses:

1) Association between childhood maltreatment and HI and IN ADHD symptom scores separately analysed using the same methods as above; 2) association between maltreatment before age 7 years and ADHD symptoms, controlling for subsequent maltreatment between age 7 and 18 years; and 3) analyses separately for neglect and abuse before age 7 years with adult ADHD symptoms.

\section{Study IV}

Study population: From the STAGE population, 23,767 provided data on binge-eating behaviour and nutrition and 18,167 on ADHD. For the twin analysis, the total population included 13,773 female twins (3664 complete pairs, 6445 incomplete pairs): $\mathrm{MZ}=5262$ (2156 complete) 
pairs; same sex DZ $=4089$ (1508 complete) pairs; and 4422 opposite sex DZ twins.

\section{Measures:}

$A D H D$ - same as Studies II and III

Binge eating - Set as yes if binge-eating behaviour ever and loss of control were both yes. Binge eating DSM-5, set if binge-eating behaviour at least 3 months, at least 4 times/ month

Binge eating disorder (BED) - Based on DSM-5 criteria, yes = bingeeating behaviour for at least 3 months, at least 4 times/month, no compensatory behaviour, and at least three additional DSM-5 symptoms for BED.

Bulimia nervosa (BN) based on DSM-5 - Set as yes when binge eating for at least 3 months, at least 4 times/month, at least one type of compensatory behaviour, and self-evaluation unduly influenced by body shape and weight (see Appendix for measures and questions).

Study design: Bivariate twin study in female adult twins.

Statistical analysis: Mixed effect logistic regression, with random effects shared between twins in the same pair, controlling for sex and age at assessment, for descriptive purposes (STATA 11.1; StataCorp LP). Structural equation modelling similar to Study II, with OpenMx (179). We used maximum-likelihood model-fitting analyses and fitted first a fully saturated model and then compared this with more parsimonious models (ACE, AE, ADE etc.). We used AIC to assess the overall bestfitting model. Binge-eating behaviour was defined as a binary trait. We used a liability-threshold approach (observed binge eating is 1 if the liability is above a threshold and 0 if below). Underlying normally distributed liability to binge eating is assumed. The phenotypic correlation, refers to the correlation between the ADHD symptoms and underlying liability to binge-eating behaviour. We estimated heritability for ADHD and binge-eating behaviour with univariate analysis. We estimated bivariate correlations with a bivariate correlated factors model and also calculated the proportion of the total phenotypic covariance between ADHD and binge-eating behaviour explained by genetic and environmental factors. $\mathrm{BED}$ and $\mathrm{BN}$ could not be analysed due to low power.

Sensitivity analysis: We analysed separately the overlap between bingeeating behaviour and HI and IN ADHD symptom dimensions. Phenotypic 
correlations, intra-class correlations and CTCT were estimated. To determine if the genetic or environmental effects shared with binge-eating behaviour were specific to HI or IN symptom dimensions, we fitted two separate tri-variate models. First we fitted a model that allowed us to estimate the partial correlation, as well as the genetic and non-shared environmental correlation between $\mathrm{HI}$ and binge-eating behaviour when controlling for the IN symptom dimension. The second tri-variate model estimated the partial correlation between IN and binge-eating behaviour, as well as the genetic and non-shared environmental correlation between IN and binge-eating behaviour when controlling for HI. 


\section{Table 1. Overview of methods by study}

\begin{tabular}{|c|c|c|c|c|}
\hline Study & $\begin{array}{l}\text { Study } \\
\text { population }\end{array}$ & Measures & $\begin{array}{l}\text { Research } \\
\text { questions }\end{array}$ & Statistical analysis \\
\hline $\mathrm{I}$ & $\begin{array}{l}18,167 \text { twins aged } \\
20-46 \text { years from } \\
\text { the Study of Adult } \\
\text { Twins - Genes and } \\
\text { Environment } \\
\text { (STAGE), from } \\
\text { the Swedish Twin } \\
\text { Registry }\end{array}$ & $\begin{array}{l}\text { ADHD and HI, IN, CO subtypes: } \\
\text { self-reported current symptoms, } \\
\text { norm-based approach, with } 2 \mathrm{SD} \\
\text { cut-off. } \\
\text { Alcohol abuse: self-reported DSM- } \\
\text { IV criteria } \\
\text { Alcohol dependence: self-reported } \\
\text { DSM-IV criteria (se below) } \\
\text { Illegal drug use: tried at least one } \\
\text { illicit drug } \\
\text { Polysubstance use: tried } \geq 2 \text { illicit } \\
\text { drugs } \\
\text { Polysubstance use and alcohol: tried } \\
\geq 2 \text { illicit drugs and/or alcohol use } \\
\text { disorder } \\
\text { Regular nicotine use: daily use of } \\
\text { cigarettes or Swedish smokeless } \\
\text { tobacco }\end{array}$ & $\begin{array}{l}\text { Association in the } \\
\text { population between } \\
\text { ADHD symptoms and } \\
\text { substance use disorder? } \\
\text { Is there a difference } \\
\text { between subtypes? } \\
\text { Does ADHD or subtypes } \\
\text { lead to preference of any } \\
\text { class of substances? }\end{array}$ & $\begin{array}{l}\text { Mixed effect logistic } \\
\text { regression for binary } \\
\text { predictor, binary } \\
\text { outcome, controlled for } \\
\text { sex and age and a } \\
\text { random effect shared } \\
\text { between twins }\end{array}$ \\
\hline II & $\begin{array}{l}18,167 \text { twins, as } \\
\text { above. } \\
17,711 \text { twins } \\
\text { (12,291 pairs, } \\
5420 \text { complete) } \\
\text { included in the } \\
\text { twin analyses }\end{array}$ & $\begin{array}{l}\text { ADHD norm-based, } 2 \text { SD approach, } \\
\text { for descriptive purposes } \\
\text { ADHD symptoms score used as a } \\
\text { continuous variable in the twin } \\
\text { analysis } \\
\text { HI and IN symptoms: scores on the } \\
\text { respective ADHD symptom scales. } \\
\text { Alcohol dependence: based on } \\
\text { DSM-IV, yes if } \geq 3 \text { DSM-IV } \\
\text { criteria }\end{array}$ & $\begin{array}{l}\text { Is the association between } \\
\text { ADHD symptoms and } \\
\text { alcohol dependence best } \\
\text { explained by common } \\
\text { genetic or environmental } \\
\text { risks? } \\
\text { Are there sex differences } \\
\text { in this association? }\end{array}$ & $\begin{array}{l}\text { Bivariate structural } \\
\text { equation modelling for } \\
\text { maximum-likelihood } \\
\text { model-fitting analyses to } \\
\text { estimate the additive } \\
\text { genetic shared } \\
\text { environmental and non- } \\
\text { shared environmental } \\
\text { risk factors }\end{array}$ \\
\hline III & $\begin{array}{l}18,167 \text { twins, as } \\
\text { above }\end{array}$ & $\begin{array}{l}\text { ADHD symptoms score used as a } \\
\text { standardized continuous variable } \\
\text { Childhood maltreatment = based } \\
\text { Life Stressor Checklist Revised: } 1 \text { ) } \\
\text { emotional neglect; } 2 \text { ) physical } \\
\text { neglect; } 3 \text { ) physical abuse; } 4 \text { ) } \\
\text { sexual abuse; } 5 \text { ) witnessing family } \\
\text { violence + specify when } \\
\text { maltreatment first occurred by } \\
\text { intervals } 0-6 \text { years, } 7-12,13-15 \text {, } \\
16-18 \text { or }>18 \text { years }\end{array}$ & $\begin{array}{l}\text { Is there an association } \\
\text { between self-reported } \\
\text { childhood maltreatment } \\
\text { and ADHD symptoms in } \\
\text { adults? } \\
\text { Is the association due to } \\
\text { familial confounding or } \\
\text { could it be consistent with } \\
\text { a causal hypothesis? }\end{array}$ & $\begin{array}{l}\text { Linear regression, } \\
\text { adjusted for sex, } \\
\text { controlled for lack of } \\
\text { independence of twin } \\
\text { data. } \\
\text { Conditional linear } \\
\text { regression, within-DZ } \\
\text { and -MZ twin pairs } \\
\text { discordant for } \\
\text { childhood maltreatment }\end{array}$ \\
\hline IV & $\begin{array}{l}23,767 \text { provided } \\
\text { data on binge- } \\
\text { eating behaviour } \\
18,167 \text { on ADHD. } \\
13,773 \text { female } \\
\text { twins ( } 3664 \\
\text { complete, } 6445 \\
\text { incomplete pairs) } \\
\text { in the twin } \\
\text { analysis }\end{array}$ & $\begin{array}{l}\text { ADHD symptoms score, used as a } \\
\text { continuous variable. } \\
\text { HI and IN = symptom scores on the } \\
\text { respective ADHD symptom scales. } \\
\text { Binge eating = lifetime eating binges } \\
\text { with loss of control; BED = based } \\
\text { on DSM- } 5 \text { criteria } \\
\text { BN = based on DSM- } 5 \text { criteria }\end{array}$ & $\begin{array}{l}\text { Is there an association } \\
\text { between adult ADHD } \\
\text { symptoms and binge- } \\
\text { eating behaviour, BED } \\
\text { and BN in the general } \\
\text { population? } \\
\text { Is the association best } \\
\text { explained by common } \\
\text { genetic or environmental } \\
\text { risk factors? }\end{array}$ & $\begin{array}{l}\text { Structural equation } \\
\text { modelling for } \\
\text { maximum-likelihood } \\
\text { model fitting. } \\
\text { Univariate modelling } \\
\text { for ADHD and binge- } \\
\text { eating behaviour and } \\
\text { bivariate modelling for } \\
\text { the association between } \\
\text { ADHD and binge- } \\
\text { eating behaviour }\end{array}$ \\
\hline
\end{tabular}




\section{Results}

\section{Study I}

\section{Comorbidity of adult ADHD and its Subtypes with SUD}

ADHD with a norm-based, 2 SD approach was observed in 1598 participants $(8.8 \%)$, with similar distribution in males and females. We identified alcohol dependence in 1070 individuals $(6.0 \%)$, alcohol abuse in $3.0 \% ; 16.5 \%$ had ever tried illicit drugs, $15.5 \%$ had tried cannabis, $2.5 \%$ reported ongoing use, and $3.9 \%$ had tried stimulants (181).

Table 2. Associations of ADHD symptoms with SUD (adjusted for sex, age, education and controlled for the random effect of twins) compared with controls/ twins with no ADHD symptoms

\begin{tabular}{|c|c|c|c|c|c|c|c|c|c|}
\hline \multirow[t]{2}{*}{$\begin{array}{l}\text { Substance } \\
\text { abuse }\end{array}$} & \multirow[t]{2}{*}{ All twins, $n(\%)$} & \multicolumn{2}{|c|}{ ADHD, total } & \multicolumn{2}{|c|}{$\begin{array}{l}\text { ADHD, hyperactive/im- } \\
\text { pulsive }\end{array}$} & \multicolumn{2}{|c|}{ ADHD, inattentive } & \multicolumn{2}{|c|}{ ADHD, combined } \\
\hline & & OR & $95 \% \mathrm{CI}$ & OR & $95 \% \mathrm{CI}$ & OR & $95 \% \mathrm{CI}$ & OR & $95 \% \mathrm{CI}$ \\
\hline $\begin{array}{l}\text { Alcohol } \\
\text { Alcohol abuse }\end{array}$ & $\begin{array}{l}543 / 17,940 \\
(3.06)\end{array}$ & $1.88 * * *$ & $1.44-2.46$ & $1.61 *$ & $1.03-2.51$ & $1.68 * *$ & $1.15-2.46$ & $3.17 * *$ & $1.89-5.29$ \\
\hline $\begin{array}{l}\text { Alcohol de- } \\
\text { pendence }\end{array}$ & $\begin{array}{l}1070 / 17,734 \\
(6.03)\end{array}$ & $3.58^{* * *}$ & $2.86-4.49$ & $2.52 * * *$ & $1.75-3.63$ & $3.63 * * *$ & $2.69-4.91$ & $6.29 * * *$ & $4.01-9.87$ \\
\hline $\begin{array}{l}\text { Drugs } \\
\text { Stimulants }\end{array}$ & $\begin{array}{l}688 / 17,779 \\
(3.87)\end{array}$ & $2.45^{* * *}$ & $1.79-3.35$ & 1.69 & $0.99-2.89$ & $2.32 * * *$ & $1.51-3.57$ & $5.17 * * *$ & $2.72-9.81$ \\
\hline Opiates & $\begin{array}{l}1912 / 17,779 \\
(10.75)\end{array}$ & $1.97 * * *$ & $1.65-2.36$ & $1.77 * * *$ & $1.32-2.37$ & $2.17 * * *$ & $1.69-2.78$ & $1.88^{* *}$ & $1.24-2.87$ \\
\hline Cannabis & $\begin{array}{l}2751 / 17,779 \\
(15.47)\end{array}$ & $2.19 * * *$ & $1.80-2.68$ & $1.83 * * *$ & $1.33-2.52$ & $2.15 * * *$ & $1.63-2.83$ & $3.45^{* * *}$ & $2.21-5.41$ \\
\hline Illicit drug use & $\begin{array}{l}2940 / 17,779 \\
(16.54)\end{array}$ & $2.27 * * *$ & $1.86-2.76$ & $1.83 * * *$ & $1.33-2.51$ & $2.27 * * *$ & $1.73-2.98$ & $3.58 * * *$ & $2.30-5.57$ \\
\hline $\begin{array}{l}\text { Polysubstance } \\
\text { use }\end{array}$ & $\begin{array}{l}1425 / 17,779 \\
(8.02)\end{array}$ & $2.54 * * *$ & $2.00-3.23$ & $1.84 * *$ & $1.23-2.74$ & $2.71 * * *$ & $1.95-3.76$ & $3.95^{* * *}$ & $2.34-6.68$ \\
\hline $\begin{array}{l}\text { Polysubstance } \\
\text { use including } \\
\text { alcohol }\end{array}$ & $\begin{array}{l}1704 / 18,027 \\
(9.42)\end{array}$ & $2.78 * * *$ & $2.21-3.50$ & $2.03 * * *$ & $1.39-2.96$ & $2.81 * * *$ & $2.06-3.84$ & $4.98^{* * *}$ & $3.04-8.18$ \\
\hline \multicolumn{10}{|c|}{ Nicotine (smoke and/or snus) } \\
\hline $\begin{array}{l}\text { Regular nico- } \\
\text { tine use }\end{array}$ & $\begin{array}{l}3115 / 18,167 \\
(17.15)\end{array}$ & $1.33 * *$ & $1.12-1.59$ & 1.23 & $0.92-1.63$ & $1.39 * *$ & $1.09-1.77$ & 1.41 & $0.94-2.12$ \\
\hline
\end{tabular}

OR, odds ratio, calculated from multilevel logistic regression adjusted for sex, age, education and controlled for the random effect of twins; $95 \% \mathrm{CI}, 95 \%$ confidence interval, ${ }^{*} p<0.05 ;{ }^{*} p<0.01$; $* * * p<0.001$. 
All substance use was significantly more common in men compared with women. ADHD and ADHD subtypes were associated with all the SUDrelated outcomes (Table 2). Overall, we found no statistically significant differences between subtypes, as indicated by overlapping confidence intervals. But estimates for the CO subtype were higher for alcohol use disorder, illicit drug use and polysubstance use. No evidence for substance preferences emerged for participants with ADHD or within any of the ADHD subtypes. Participants with ADHD symptoms used cannabis significantly more often every month: 7.49 (95\% CI: 6.23, 8.75) individuals compared with $5(95 \%$ CI: 4.54, 5.40) individuals without ADHD, $p<0.001$, with similar results for all subtypes.

Given significant sex differences regarding SUD variables in the population, we also analysed data stratified for sex. We found no sex differences in the association between ADHD and various types of SUD-related outcomes.

\section{Study II}

Genetic and environmental factors in the association between adult ADHD and alcohol dependence

We identified a strong phenotypic association between ADHD and alcohol dependence. Individuals with ADHD had a 3.58-fold (95\% CI: 2.85, 4.49) increased risk for alcohol dependence $(p<0.001)$ compared with those without ADHD. All ADHD subtypes, HI, IN and CO, were associated with an increased risk for alcohol dependence. Odds ratios (OR) were 2.52 (95\% CI: $1.75,3.63)$ for the HI subtype; 3.63 (95\% CI: 2.69, 4.91) for the IN subtype; and 6.29 (95\% CI: 4.01, 9.87) for the CO subtype. ORs for the CO subtype were higher than for the IN subtype $(p<0.035)$, and compared with the HI subtype $(p<0.001)$. HI and IN did not significantly differ $(p<0.108)$.

Twin correlations indicated genetic factors for the overlap between ADHD and alcohol dependence. Model fitting suggested that shared environmental influences $(\mathrm{C})$ were negligible and that there were no sex differences present for the overlap between ADHD and alcohol dependence. The full sex difference AE model, where A stands for additive genetic and $E$ for non-shared environmental factors, did not fit the data less well than the full sex difference ACE model $\left(\chi^{2}=0.82, \mathrm{df}=6, p<0.992\right)$, also including shared environmental (C) factors. We tested for qualitative and quantitative sex differences. Our final best-fitting model (AE model including qualitative sex difference in ADHD) did not fit the data any worse than the full AE model $\left(\chi^{2}=4.85, \mathrm{df}=\right.$ 
$7, p<0.678$ ). Estimates from the best-fitting univariate models (Table 3) showed moderate heritability, 41\% (95\% CI: 38, 44) for ADHD and 57\% (95\% CI: 27, 66) for alcohol dependence. E factors explained the remaining variance for $\mathrm{ADHD}$ of $59 \%(95 \% \mathrm{CI}: 56,62)$ and $43 \%(95 \% \mathrm{CI}: 34,53)$ for alcohol dependence. Parameter estimates from the full ACE model and sexstratified results are also shown for descriptive purposes (Table 3).

We observed a statistically significant genetic correlation between ADHD and alcohol dependence $\left(r_{\mathrm{A}}=0.33\right.$; 95\% CI: $\left.0.24,0.42\right)$ as well as a significant non-shared environmental correlation $\left(r_{\mathrm{E}}=0.18 ; 95 \% \mathrm{CI}: 0.10,0.26\right)$ (Table 3). Common genetic factors (A) explained 64\% (95\% CI: 47, 80) of the covariance between ADHD and alcohol dependence. Non-shared environmental factors were also significant, whereas the role of $\mathrm{C}$ was small and not significant. Parameter estimates from the ACE model for females, males and collapsed over gender (whole population) generated a similar pattern of results. (Table 3 ) 


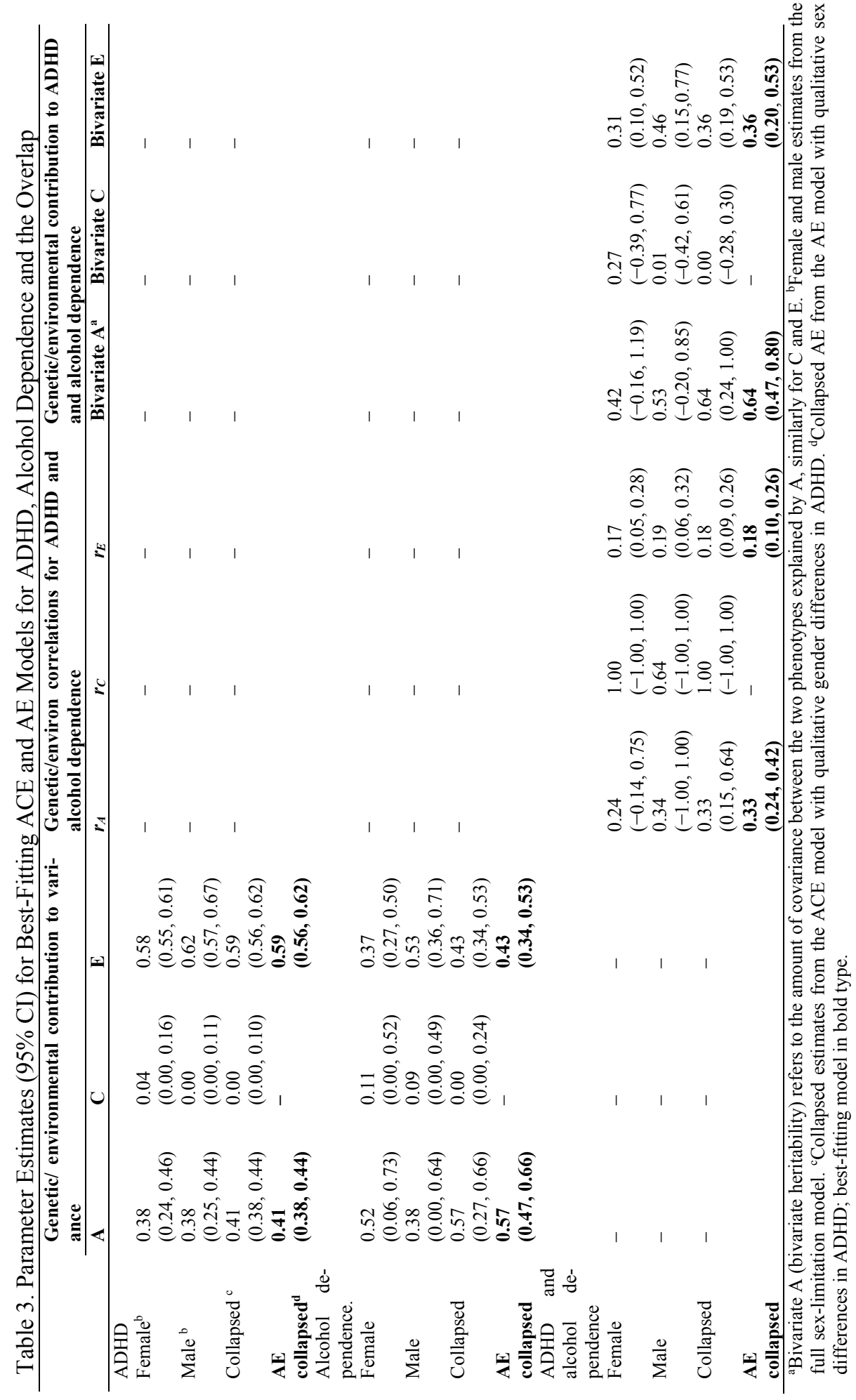




\section{Study III}

\section{Childhood Maltreatment and ADHD Symptoms in Adults}

All self-reported childhood maltreatment was more common in the ADHD symptom group compared with the non-ADHD group (Table 4). Women reported sexual abuse more often than men, both in the whole population $(7.9 \%$ in women compared with $1.0 \%$ in men) and in the ADHD symptom group ( $16.7 \%$ in women compared with $1.9 \%$ in men) (Table 4). Most childhood maltreatment first occurred before puberty. Participants born before 1980 (age at data collection $>25$ years) reported slightly less childhood maltreatment compared with younger twins (OR, 0.85, 95\% CI: $0.75,0.97)$. The distribution of self-reported childhood maltreatment in the population by ADHD symptom status and sex is presented in Table 4.

Table 4. Distribution of retrospectively recalled childhood maltreatment before age 18 years in the population by ADHD symptoms ( 2 SD on the symptoms scale cut-off) and gender

\begin{tabular}{llllllll}
\hline & $\begin{array}{l}\text { Total } \\
n(\%)\end{array}$ & $\begin{array}{l}\text { No ADHD } \\
n(\%)\end{array}$ & & & $\begin{array}{l}\text { ADHD } \\
n(\%)\end{array}$ & \\
\cline { 3 - 7 } & & Total & Male & Female & Total & Male & Female \\
\hline Total & 18,168 & 16,570 & 6644 & 9926 & 1598 & 637 & 961 \\
No trauma & 11,508 & 10,784 & 4511 & 6273 & 724 & 298 & 426 \\
& $(63.3)$ & $(65.1)$ & $(67.9)$ & $(63.9)$ & $(45.3)$ & $(47.8)$ & $(44.3)$ \\
CM & $\mathbf{6 6 6 0}$ & $\mathbf{5 7 8 6}$ & $\mathbf{2 1 3 3}$ & $\mathbf{3 6 5 3}$ & $\mathbf{8 7 4}$ & $\mathbf{3 3 9}$ & $\mathbf{5 3 5}$ \\
& $\mathbf{( 3 6 . 7 )}$ & $\mathbf{( 3 4 . 9 )}$ & $\mathbf{( 3 2 . 1 )}$ & $\mathbf{( 3 6 . 8 )}$ & $\mathbf{( 5 4 . 7 )}$ & $\mathbf{( 5 3 . 2 )}$ & $\mathbf{( 5 5 . 7 )}$ \\
Neglect & 4940 & 4251 & 1516 & 2733 & 689 & 262 & 427 \\
& $(27.2)$ & $(25.6)$ & $(22.8)$ & $(27.6)$ & $(43.1)$ & $(41.1)$ & $(44.4)$ \\
Emotional & 4834 & 4164 & 1494 & 2670 & 670 & 255 & 415 \\
neglect & $(26.6)$ & $(25.1)$ & $(22.5)$ & $(26.9)$ & $(41.9)$ & $(40.0)$ & $(43.2)$ \\
Physical & 647 & 504 & 159 & 345 & 143 & 55 & 88 \\
neglect & $(3.6)$ & $(3.0)$ & $(2.4)$ & $(3.5)$ & $(9.0)$ & $(8.6)$ & $(9.2)$ \\
Abuse & 2479 & 2083 & 612 & 1471 & 396 & 117 & 279 \\
& $(13.6)$ & $(12.6)$ & $(9.2)$ & $(14.8)$ & $(24.8)$ & $(18.4)$ & $(29.0)$ \\
Physical & 1779 & 1486 & 567 & 919 & 293 & 110 & 183 \\
abuse & $(9.8)$ & $(9.0)$ & $(8.5)$ & $(9.3)$ & $(18.3)$ & $(17.3)$ & $(19.0)$ \\
Sexual & 1016 & 844 & 65 & 779 & 172 & 12 & 160 \\
abuse & $(5.6)$ & $(5.1)$ & $(1.0)$ & $(7.9)$ & $(10.8)$ & $(1.9)$ & $(16.7)$ \\
Witnessed & 3043 & 2596 & 1081 & 1515 & 447 & 182 & 265 \\
family vio- & $(16.8)$ & $(15.7)$ & $(16.3)$ & $(15.3)$ & $(28.0)$ & $(28.6)$ & $(27.6)$ \\
lence & & & & & & & \\
\hline CM
\end{tabular}

CM, childhood maltreatment. 
Linear regression revealed an association between childhood maltreatment and ADHD symptoms in adults (Table 5), with regression coefficient estimated to $0.4(95 \% \mathrm{CI}: 0.37,0.43)$, which means that each reported childhood maltreatment increased ADHD symptoms with 0.4 standard deviations (SD).

Table 5. Association between adult ADHD symptoms and childhood maltreatment before age 18 years: results from linear regression analysis, crude and adjusted for sex, age and substance misuse, as well as within-DZ ${ }^{1}$ and $-\mathrm{MZ}^{2}$ twin pairs and for $\mathrm{HI}^{3}$ and $\mathrm{IN}^{4} \mathrm{ADHD}$ symptom dimensions

\begin{tabular}{|c|c|c|c|c|}
\hline & $\begin{array}{l}\text { Crude } \\
\left(95 \% \mathrm{CI}^{5}\right)\end{array}$ & $\begin{array}{l}\text { Adjusted }^{6} \\
(95 \% \mathrm{CI})\end{array}$ & $\begin{array}{l}\text { Within-DZ pairs } \\
(95 \% \mathrm{CI}) \text { [no. of } \\
\text { exposure discord- } \\
\left.\text { ant twins }{ }^{7}\right]\end{array}$ & $\begin{array}{l}\text { Within-MZ pairs } \\
(95 \% \text { CI) [no. of ex- } \\
\text { posure discordant } \\
\text { twins }^{7} \text { ] }\end{array}$ \\
\hline $\begin{array}{l}\text { ADHD } \\
\text { Childhood mal- } \\
\text { treatment }\end{array}$ & $\begin{array}{l}0.40 \\
(0.37,0.43)^{* *}\end{array}$ & $\begin{array}{l}0.40 \\
(0.37,0.43) * *\end{array}$ & $\begin{array}{l}0.29 \\
(0.21,0.36)^{* *} \\
{[2,072]}\end{array}$ & $\begin{array}{l}0.18 \\
(0.10,0.25)^{* *} \\
{[1452]}\end{array}$ \\
\hline $\begin{array}{l}\text { Neglect } \\
\text { Emotional neglect }\end{array}$ & $\begin{array}{l}0.41 \\
(0.37,0.44)^{* *}\end{array}$ & $\begin{array}{l}0.40 \\
(0.37,0.44)^{* *}\end{array}$ & $\begin{array}{l}0.31 \\
(0.22,0.39)^{* *} \\
{[1836]}\end{array}$ & $\begin{array}{l}0.19 \\
(0.12,0.27)^{* *} \\
{[1360]}\end{array}$ \\
\hline Physical neglect & $\begin{array}{l}0.66 \\
(0.55,0.77)^{* *}\end{array}$ & $\begin{array}{l}0.67 \\
(0.56,0.78)^{* *}\end{array}$ & $\begin{array}{l}0.47 \\
(0.21,0.74)^{* *} \\
{[238]}\end{array}$ & $\begin{array}{l}0.25 \\
(-0.04,0.54)^{\mathrm{NS}} \\
{[170]}\end{array}$ \\
\hline \multicolumn{5}{|l|}{ Abuse } \\
\hline Physical abuse & $\begin{array}{l}0.47 \\
(0.40,0.53)^{* *}\end{array}$ & $\begin{array}{l}0.46 \\
(0.40,0.53)^{* *}\end{array}$ & $\begin{array}{l}0.31 \\
(0.18,0.45)^{* *} \\
{[814]}\end{array}$ & $\begin{array}{l}0.08 \\
(-0.06,0.23)^{\mathrm{NS}} \\
{[586]}\end{array}$ \\
\hline Sexual abuse & $\begin{array}{l}0.43 \\
(0.36,0.51)^{* *}\end{array}$ & $\begin{array}{l}0.45 \\
(0.37,0.53)^{* *}\end{array}$ & $\begin{array}{l}0.21(0.04,0.38)^{*} \\
{[556]}\end{array}$ & $\begin{array}{l}0.20 \\
(0.02,0.38)^{*} \\
{[380]}\end{array}$ \\
\hline $\begin{array}{l}\text { Witnessing family } \\
\text { violence }\end{array}$ & $\begin{array}{l}0.41 \\
(0.36,0.45)^{* *}\end{array}$ & $\begin{array}{l}0.41 \\
(0.37,0.46)^{* *}\end{array}$ & $\begin{array}{l}0.27 \\
(0.16,0.39)^{* *} \\
{[1066]}\end{array}$ & $\begin{array}{l}0.16 \\
(0.05,0.28)^{* *} \\
{[756]}\end{array}$ \\
\hline $\begin{array}{l}\text { ADHD: HI } \\
\text { Childhood maltreat- } \\
\text { ment }\end{array}$ & $\begin{array}{l}0.29 \\
(0.26,0.32)^{* *}\end{array}$ & $\begin{array}{l}0.29 \\
(0.26,0.32)^{* *}\end{array}$ & $\begin{array}{l}0.21 \\
(0.13,0.29)^{* *} \\
{[2072]}\end{array}$ & $\begin{array}{l}0.14 \\
(0.06,0.22)^{* *} \\
{[1452]}\end{array}$ \\
\hline $\begin{array}{l}\text { ADHD: IN } \\
\text { Childhood maltreat- } \\
\text { ment }\end{array}$ & $\begin{array}{l}0.39 \\
(0.36,0.42)^{* *}\end{array}$ & $\begin{array}{l}0.39 \\
(0.36,0.43)^{* *}\end{array}$ & $\begin{array}{l}.28 \\
(.20, .36)^{* *} \\
{[2072]}\end{array}$ & $\begin{array}{l}0.17 \\
(0.08,0.25)^{* *} \\
{[1452]}\end{array}$ \\
\hline
\end{tabular}

${ }^{\mathrm{NS}} p>0.05 ;{ }^{*} p<0.05 ;{ }^{* *} p<0.01 .{ }^{1} \mathrm{DZ}$ dizygotic (fraternal) twins. ${ }^{2} \mathrm{MZ}$ monozygotic (genetically identical) twins. ${ }^{3} \mathrm{HI}$, hyperactive/impulsive symptom dimension. ${ }^{4} \mathrm{IN}$, inattentive symptom dimension. ${ }^{5} \mathrm{CI}$, confidence interval. ${ }^{6}$ Adjusted for sex and age when answering the questionnaire. ${ }^{7}$ Exposure discordant twins, number of individual twins (participants) from exposure discordant twin pairs in analysis.

Adjustments for sex and age did not influence the observed association. Separate analysis by sex did not reveal any differences as indicated by 
overlapping confidence intervals. Within-twin pair analyses suggested familial confounding (unmeasured genetic and environmental factors), as seen by the decreasing estimates for within-DZ and -MZ twin pairs. Results, significantly $>0$ within-MZ twin pairs, were also consistent with a causal interpretation of the association for different types of maltreatment with ADHD symptoms, as well as for HI and IN ADHD symptoms.

\section{Sensitivity analyses}

We examined the association between childhood maltreatment before age 7 years and ADHD symptoms in adults, controlling for later re-traumatization. Results reveal the role of familial confounding and are also consistent with a causal hypothesis, regarding the role of early childhood maltreatment, before age 7 years (Fig. 6) and adult ADHD symptoms.

In a second sensitivity analysis we analysed the associations for ADHD symptoms with neglect and abuse before age 7 years separately. Both associations decreased in within-twin pair analyses for DZ and MZ twins for abuse to a point estimate of 0.08 (95\% CI: $0.06,0.23)$; for physical neglect, the estimate was 0.25 , with a similar though wider CI $(0.04$, 0.54 ), due to lower power, both suggesting familial confounding.

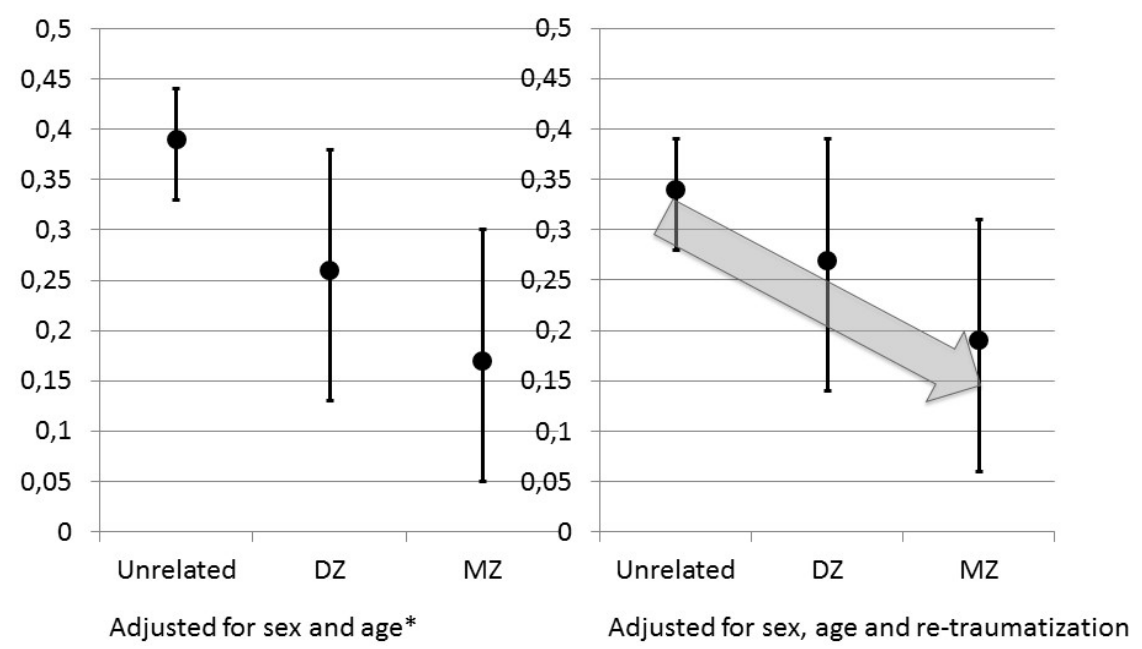

Fig 6. Estimates for the association between childhood maltreatment before age 7 years and adult ADHD symptoms, unadjusted and adjusted for re-traumatization. *Age when completing questionnaire. MZ, monozygotic twins; DZ, dizygotic twins. 
Within-pair estimates for MZ twins were more than zero for both estimates and were statistically significant for abuse (physical and sexual), which is consistent with a causal interpretation. Although estimates were similar for neglect, estimates within $\mathrm{MZ}$ were not significant. It is unclear if this is due to the limited sample size or, if in the case of neglect at such a young age, associations are entirely due to familial confounding.

\section{Study IV}

\section{Genetic and environmental factors in the association between adult ADHD and binge-eating behaviour}

Binge-eating behaviour and related outcomes were rare in the population: $639(2.69 \%)$ had life-time binge-eating behaviour with loss of control, $355(1.50 \%)$ reported binge-eating behaviour DSM-5 (3 months, at least 4 times/ month); 43 (0.18\%) DSM-5 BED, 277 (1.18\%) BN. All binge eating outcomes were particularly rare in males. Adult ADHD symptoms (2 SD above the mean cut-off) were significantly associated with increased risk for binge-eating behaviour (odd ratio $(\mathrm{OR})=3.65[95 \% \mathrm{CI}$ : $2.72,4.91], \mathrm{p}<.001)$ as well as binge eating DSM-5 (OR $=3.01[95 \% \mathrm{CI}$ : $2.09,4.35], \mathrm{p}<.001)$ compared to those without ADHD symptoms. Also, both $\mathrm{BED}(\mathrm{OR}=2.55,[95 \% \mathrm{CI}: 1.11,5.86], \mathrm{p}<.05)$ and $\mathrm{BN}(\mathrm{OR}=3.09$, [95\%CI: $2.09,4.56], \mathrm{p}<.001)$ were significantly more common in adults with ADHD symptoms.

Model fitting showed that a parsimonious AE model, including additive genetic (A) and non-shared environmental (E) effects, was the best-fitting model for both ADHD, binge-eating behaviour and the association between ADHD and binge-eating behaviour. The AE model did not fit the data significantly worse than the fully saturated model. The heritability estimate in female twins for current ADHD symptoms was $0.42(95 \% \mathrm{CI}$, $0.41-0.44)$, and 0.65 (95\% CI, 0.54-0.74) for lifetime binge-eating behaviour (Fig. 7). Bivariate twin analysis revealed moderate genetic correlation of 0.35 (95\% CI, 0.25-0.46) between these phenotypes.

The bivariate heritability estimate, i.e. the proportion of the total covariance between ADHD and binge-eating behaviour explained by genetic factors, was 91\% (Fig. 7); non-shared environmental factors explained the remaining covariance. 


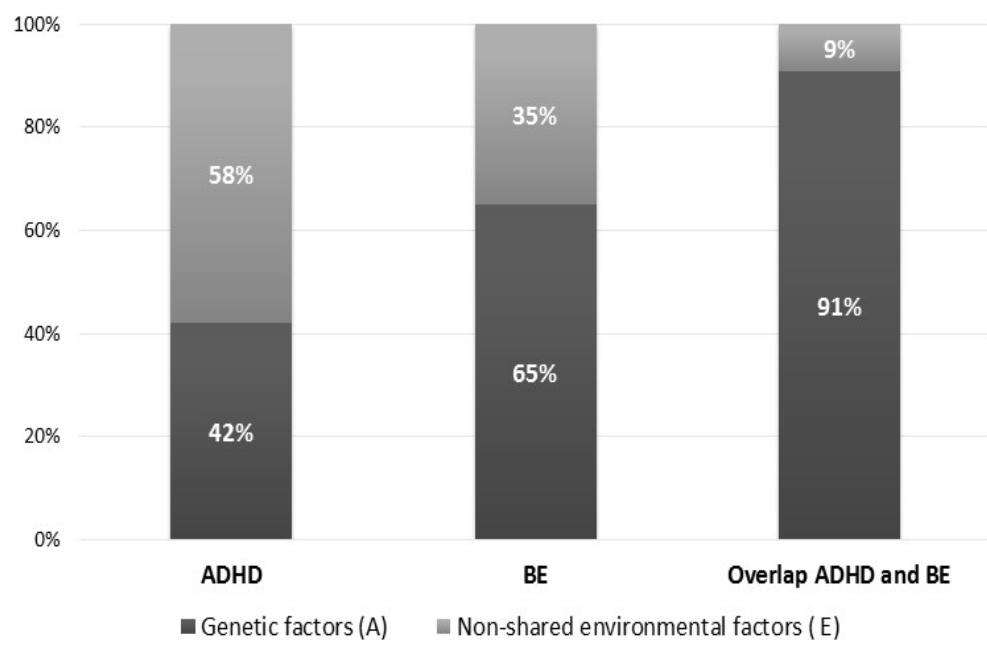

Fig. 7. Proportion of the variance for $A D H D$, binge-eating behaviour (BE) from univariate (AE) models, and of the covariance between ADHD and BE explained by genetic and non-shared environmental factors from the bivariate (AE) twin model, in female adult twins.

\section{Sensitivity analysis}

Analysis of the association between hyperactive/impulsive (HI) and inattentive (IN) ADHD symptom dimensions and binge-eating behaviour showed similar phenotypic correlation between the HI symptom dimension and binge-eating behaviour of 0.18 (95\%CI: $0.12,0.24)$, and between the IN symptom dimension and binge-eating behaviour 0.18 (95\% CI: 0.13, 0.24). CTCT indicated shared genetic factors for both the $\mathrm{HI}$ and the IN dimension with binge-eating behaviour (Table 6).

The partial correlation between binge-eating behaviour and the IN symptom dimension when controlling for the HI symptom dimension $(0.10$ 95\% CI: $0.06,0.13$ ) was somewhat stronger and compared with the partial correlation between binge-eating behaviour and the $\mathrm{HI}(0.03,95 \% \mathrm{CI}$ : $-0.01,0.07)$ when controlling for IN. The genetic correlation for the IN symptom dimension and binge-eating behaviour remained statistically significant when controlling for the factors shared between the HI and IN dimension $(0.28,95 \% \mathrm{CI} 0.13,0.42)$. In contrast, the genetic $(0.03,95 \%$ CI $-0.14,0.18)$ and environmental correlations $(0.05,95 \% \mathrm{CI}-0.06,0.16)$ 
between the HI symptom dimension and binge-eating behaviour attenuated substantially and became non-significant, when controlling for factors common for the HI and IN symptom dimensions.

Table 6. Phenotypic correlations, intra-class correlations, and cross-twin cross-trait correlations for hyperactive/impulsive (HI) and inattentive (IN) ADHD symptoms with binge-eating behaviour in 13,773 female twins (3664 complete twin pairs), adjusted for age (linear), and males set as missing

\begin{tabular}{llll}
\hline Type of correlation & & $\begin{array}{l}\text { Correlation } \\
\text { timate }\end{array}$ & \\
HI and binge-eating & behaviour & & \\
\hline Phenotypic correlation $^{1}$ & MZ female & 0.18 & $(0.12,0.24)$ \\
& DZ female & 0,14 & $(0.10,0.18)$ \\
\hline Intra-class correlation, HI & MZ female & 0.40 & $(0.35,0-44)$ \\
& DZ female & 0.18 & $(0.12,0.24)$ \\
\hline Intra-class correlation, & MZ female & 0.66 & $(0.55,0.76)$ \\
binge-eating behaviour & DZ female & 0.30 & $(0.09,0.49)$ \\
\hline CTCT $^{2}$ & MZ female & 0.16 & $(0.10,0.23)$ \\
& DZ female & 0.05 & $(-0.04,0.12)$ \\
\hline IN and binge-eating behaviour & & \\
\hline Phenotypic correlation & MZ female & 0.18 & $(0.13,0.24)$ \\
& DZ female & 0.19 & $(0.14,0.23)$ \\
\hline Intra-class correlation IN & MZ female & 0.38 & $(0.34,0.43)$ \\
& DZ female & 0.16 & $(0.10,0.22)$ \\
\hline Intra-class correlation & MZ female & 0.65 & $(0.54,0.75)$ \\
binge-eating behaviour & DZ female & 0.30 & $(0.09,0.49)$ \\
\hline CTCT & MZ female & 0.17 & $(0.11,0.23)$ \\
& DZ female & 0.07 & $(-0.01,0.15)$ \\
\hline
\end{tabular}

$95 \% \mathrm{CI}=95 \%$ confidence interval. Means and prevalence assumed symmetric between twin 1 and twin 2; Variance of each phenotype allowed to differ between different twin types; ${ }^{1}$ Phenotypic correlation assumed the same in twin 1 and twin $2 ;{ }^{2}$ Cross-twincross-trait correlation assumed to be the same between twin 1 and twin 2 as between twin 2 and twin 1. 


\section{Discussion and Conclusions}

\section{ADHD and substance use disorder}

We examined the association between ADHD symptoms and subtypes on the one hand with SUD and related outcomes on the other, in a population representative sample of over 18,000 adult Swedish twins aged 20-46 years. All SUD-related outcomes (alcohol dependence and abuse, illicit drug use and regular nicotine use), as well as multiple substance use, were more common in adults reporting ADHD symptoms compared with controls. Our findings are in line with the literature regarding increased risks for SUD in adults with ADHD (16, 70, 79, 82, 85, 182-185).

We found that all adult ADHD subtypes were associated with substance use-related problems, similar to a recent epidemiological study in adolescent ADHD (86). Prior research, mainly studying childhood and adolescent ADHD symptoms, has mainly linked HI $(76,79,85,124)$ or IN (82) ADHD symptoms with SUD. Apart from methodological differences, one possible explanation for the difference in results for adult and adolescent studies could be that ADHD subtypes are not stable over time. HI symptoms tend to diminish with age (47), and we can therefore not exclude that adults reporting mainly IN symptoms in our sample possibly had more HI symptoms earlier in life. Adults tend to be more bothered by IN symptoms; HI symptoms are more subtle and may be under-reported (171). We can therefore not exclude misclassification of $\mathrm{HI}$ or $\mathrm{CO}$ as IN. It is also possible that adults with more severe HI symptoms were less likely to have responded to a lengthy questionnaire. In general, no statistically significant differences were detected between subtypes, as indicated by overlapping confidence intervals. During the years since DSM$\mathrm{IV}$, the role and validity of the subtypes is increasingly being questioned, but $\mathrm{HI}$ and IN symptom dimensions do seem to play a role in comorbidities (37).

Self-medication has been proposed as a theory to explain the association between ADHD symptoms and possible preference for various substances of abuse $(69,82,84,85,186,187)$. The present results did not support a preference for any type of substance studied. Individuals with ADHD probably try to alleviate symptoms using various substances, possibly depending on availability rather than preference for a specific sub- 
stance type. For example, a study in Iceland (182) found that a large proportion of adolescents with ADHD reported abuse of sedatives, which were more readily available locally. Another possible explanation could be that preference for stimulants, for example, is present in severe cases of ADHD involving antisocial behaviours (69), a group unlikely to have answered the lengthy questionnaire in the present study.

\section{Common genetic and environmental risks for ADHD and comorbidities}

We examined the overlap between self-reported ADHD symptoms with alcohol dependence (Study II), and with binge-eating behaviour (Study IV). We were able to establish that a substantial part of the association between ADHD and both comorbidities were explained by common genetic factors. The remaining variability was accounted for by non-shared environmental risks.

Our findings on alcohol dependence and ADHD symptoms in adults replicate for the first time findings similar to those described for adult ADHD in association with less severe forms of alcohol use disorder (problem drinking) (126) as well as the results for adolescent ADHD in men and alcohol dependence in adulthood (79). We found no sex differences in the genetic and environmental overlap. These results show a robust genetic overlap across different developmental periods, similar in males and females, and present in those with milder and more severe alcohol use problems.

Common pleiotropic genetic risks have been described for psychiatric disorders, and externalizing disorders also share genetic risks $(79,117-$ 119). There is some evidence for a specific genetic overlap between ADHD and alcohol dependence (79), not entirely explained by genetic risks common for externalizing problems, as well as between ADHD and SUD (125) even after controlling for other psychiatric disorders. These findings suggest that the genetic overlap between ADHD symptoms and alcohol dependence could be at least in part specific for these two conditions and not entirely be due to common pleiotropic risks for psychiatric disorders.

Non-shared environmental factors explained the remaining part of the overlap between ADHD and alcohol dependence. Shared environmental 
factors, although important in alcohol dependence (188), were of minimal importance. This was similar to a previous twin study on ADHD and problem drinking (126). It was also in line with a large meta-analysis of heritability in humans (189), which indicates a parsimonious model with shared genetic and non-shared environmental factors for the majority of complex traits, without considerable influence of shared environmental effects.

The association between adult ADHD symptoms and lifetime binge-eating behaviour, was largely explained by common genetic factors (91\%), with non-shared environment accounting for the remaining variance. Both the HI and the IN symptom dimensions were associated with bingeeating behaviour. Based on previous literature $(88,91,92)$, we expected that HI symptoms would be more strongly associated with binge-eating behavior. However, we found somewhat stronger partial correlation for the IN symptom dimension with binge-eating behaviour as well as significant genetic correlations between IN and binge-eating behaviour, even after controlling for the genetic effects shared with HI. This supports a dimension specific genetic effect on binge-eating behaviour for IN symptoms. In contrast, the genetic correlation between HI and binge-eating behaviour was primarily explained by genetic factors shared between the two ADHD symptoms dimensions.

Our results indicate that non-shared environmental risk factors play a significant role in the association between ADHD symptoms and alcohol dependence and may play a role in the association between ADHD and binge-eating behaviour. Research has not previously focused on these factors, and how they possibly contribute to the manifestation of genetic predispositions.

\section{Can environmental risks causally contribute to ADHD?}

Study III examined childhood maltreatment as a specific environmental risk factor for adult ADHD symptoms, and found that, similar to earlier research $(146,147,149,150)$, self-reported maltreatment during childhood was associated with increased levels of ADHD symptoms in adults. Using a genetically informative design, we extend previous studies by showing that the observed association could partly be causal in nature and partly due to familial confounding. 
Within-MZ twin pair estimates $>0$ provide a basis to infer a causal effect of childhood maltreatment on ADHD symptoms in adults. This is consistent with an earlier adoption study reporting that severe institutional deprivation can cause inattention/overactivity symptoms (148) and with similar findings for other psychiatric conditions $(190,191)$. Vulnerability for ADHD symptoms could result from alterations in neural pathways involved in working memory, executive and emotional control $(152,153$, 192) following maltreatment. Maltreatment is also associated with epigenetic changes influencing the expression of genes potentially implicated in neurocognitive processes underlying $\operatorname{ADHD}(193,194)$.

Results also revealed that the association between childhood maltreatment and ADHD symptoms in adults is partly due to familial confounding, as indicated by attenuation of estimates in within-DZ and -MZ twin pairs compared with population estimates. Similar findings have been reported regarding the association between physical punishment and ADHD (195), as well as intergenerational transmission of externalizing behaviours (159). Familial confounding could be explained by passive, evocative and active gene-environment correlations (rGE) $(158,196)$. Evocative rGE is of little importance in the case of severe maltreatment (physical or sexual abuse) according to Jaffe et al. $(160,197)$, but may be relevant in corporal punishment (160) and hostile parenting style (161). Based on previous findings we assumed that abuse would be less influenced by genetic factors and more likely be due to idiosyncratic events in children' lives. We found however similar patterns of association for both abuse and neglect, but we cannot draw any more specific inferences, given lower power, when maltreatment variables were examined separately. A recent international study (198) suggested that interaction between evocative rGE mechanisms (externalizing behaviour in children) and societal norms (parents' perception of normativeness of corporal punishment in their community), predicted maltreatment. This suggests that both evocative rGE and social factors may contribute to our results. Somewhat fewer twins born before 1979 reported childhood maltreatment compared with twins born after this year, when corporal punishment was made illegal in Sweden (199). Societal norms changed gradually, from the 1960s to the 1990s (199), when study participants were growing up. We cannot exclude that changes in attitudes may have influenced recall and thus our estimates. Younger participants may have reported physical punishment as maltreatment. However, differences in recall 
could also explain the differences in reported maltreatment. Participants in their early 20 s may more easily remember and report events occurring before age 18 years compared with older participants.

Active rGE, where a child selects certain environments as a result of genetically influenced characteristics, is probably less relevant for maltreatment of children before age 7 years, who are less likely to actively choose harmful environments unless parenting is insufficient $(160,200)$. However, this mechanism may be relevant in adolescents with ADHD. Due to impulsivity, low tolerance to boredom or substance use, adolescent with ADHD may be more prone to select potentially dangerous environments, thereby increasing the risk of physical or sexual violence. We analysed the effect of childhood maltreatment before the age of 7 years and controlled for later re-traumatization to isolate the effect of early childhood maltreatment. The pattern of results was similar to that in the main analysis, indicating that this form of reversed causation (i.e. adolescent with ADHD actively seeking more harmful environments) did not fully explain the observed associations.

Our results support, for the first time, that childhood maltreatment could, at least in part, be a causal psychosocial risk factor for ADHD symptoms in adulthood. This is similar to effects in other psychiatric conditions, such as depression, eating disorders and alcohol dependence (190), as well as in the overlap between alcohol dependence, anxiety and depression (201). Possibly, several of these outcomes are due to common neurobiological changes affecting regulation of negative affects (202), working memory, executive and emotional control (152), as well as inhibitory network connectivity and response inhibition (153). The mechanisms explaining structural and functional alterations of the brain are not entirely clear but could possibly occur due to gene-environment interaction in susceptible individuals, altering gene expression.

\section{Limitations and methodological considerations}

Response rates

Response rates around $60 \%$ for STAGE were in line with similar epidemiological research. Drop-out was chiefly attributed to unwillingness to respond to a lengthy questionnaire (39). Drop-out analysis showed that participants did not differ from non-participants regarding birthweight and age, but non-participants were significantly more often male, had at 
least one parent born outside Sweden, had more often been diagnosed with a psychiatric disorder, and been convicted of any type of crime (39, $54,174)$. ADHD in adults is associated with psychiatric comorbidities (1) and is more common in prison populations $(61,75)$. Individuals with more severe ADHD are less likely to have answered a questionnaire comprising 1300 questions, therefore we have to assume that non-responders were more often individuals with severe ADHD problems. This limits generalizability to the more severe cases of the ADHD spectrum.

Self-reported measures for ADHD symptoms

Studies I to IV used self-reported measures of ADHD symptoms, which in adults are considered to have adequate psychometric properties (171, 172), and are stable over time (39). However, information on childhood onset of ADHD symptoms or degree of functional impairment were not available. This and the norm-based $2 \mathrm{SD}$ approach account for a higher prevalence of ADHD symptoms (8.8\%) in our material compared with the international prevalence of ADHD of between 5.9 and $7.1 \%$ in children and adolescent (55) and between 2.5 and $5 \%$ in adults $(55-57,203)$. The 2 SD cut-off level has been described as optimal for a DSM-IV cutoff in American college population $(52,53)$, but is higher according to other studies (54). Higher prevalence suggests that the ADHD symptoms group in our studies partly covers subthreshold cases, where ADHD symptoms are present without reaching a clinical diagnosis. These may be the less severe expression of the syndrome (48), which nonetheless have similar heritability estimates $(11,50)$ and polygenic risks in molecular genetic studies (51) as for the dichotomously assessed ADHD. Therefore, we can assume that the genetic overlap between the self-reported ADHD symptoms will also apply for the clinical cases of ADHD. However, this will need to be confirmed in future behavioural and molecular genetic studies focusing on clinical ADHD and comorbidities. As ADHD diagnoses were not clinically confirmed, we cannot exclude that the sample also contains phenocopies, where symptoms of inattention and hyperactivity are related to other disorders, such as for instance post-traumatic stress disorder or personality disorders.

Self-reported measures for comorbidities

The SUD data in Studies I and II are also self-reported. Over-reporting of substance-related problems in epidemiological surveys is unlikely, and 
drop-out cases more often had psychiatric and conduct problems, consequently our data may underestimate the prevalence of substance use overall. Another limitation is that measures for SUD are heterogeneous. For alcohol, as DSM-5 was not available, cut-offs are based on DSM-IV diagnostic criteria separately for dependence and abuse, instead of alcohol use disorder. Illicit drugs were assessed regarding use, which may overestimate prevalence by possibly including individuals only experimenting with these substances. However, the results are in line with previous Swedish data regarding serious problem drinking affecting around 10$15 \%$ of men and $3-5 \%$ of women (204) and illicit drug use affecting around $16 \%$ of high school youths (age 17-18 years) in Sweden (205), and somewhat lower compared with earlier international studies (85). It is therefore unlikely that our data overestimate the prevalence of substance use-related outcomes.

Even data regarding binge eating in Study IV was self-reported. Prevalence for binge-eating behaviour was extremely low, which suggests that our results are conservative. It is possibly that asking about loss of control over food intake contributes to underreporting, especially among men (206), because these symptoms are generally considered shameful. Another limitation is that, while we assess lifetime occurrence of binge-eating behaviour, ADHD is assessed as current symptoms. Data are crosssectional; we are not able to draw any inference on whether ADHD leads to binge eating but, in children and adolescents, earlier longitudinal follow-up indicated ADHD as a risk factor for binge eating $(90,207,208)$.

\section{Retrospectively reported childhood maltreatment data}

Another limitation is that childhood maltreatment in Study III is retrospectively reported. Several studies support the use of retrospectively recorded childhood maltreatment data, which display acceptable psychometric properties (209), predict emotional problems later in life (210), and was equally associated with increased risk for psychopathology as prospective data (211). Some aspects of maltreatment, such as emotional neglect (212), may be more influenced by recall bias (213) as well as by raters' perception, probably explaining the large number of twins discordant for emotional neglect in our results. In clinical populations, it has been suggested that individuals with ADHD have difficulties recalling their childhood. However problems recalling childhood experiences have been broadly described in epidemiological studies (214) and are not specific 
for the ADHD population. Therefore, although maltreatment data could be influenced by recall bias, it is unlikely that this differentially affects reporting in ADHD and non-ADHD individuals.

Probably due to the methodology used to define our variables, prevalence of maltreatment in our population was relatively high (36\%). This was mainly accounted for by a high proportion of emotional neglect (27\%), a variable not included in other studies (215). Reported physical abuse $(9.8 \%)$ was lower compared with a Swedish study on adolescents $(15.2 \%)$ (216) but comparable with British data (7\%) (215). Reported sexual abuse $(5.6 \%)$ was similar to other Nordic countries for both men and women (217) but lower than $11 \%$ in British youth, supporting the validity of our data regarding these variables. Associations with ADHD symptoms for childhood maltreatment in general (including emotional neglect), and specifically for different types of maltreatment (physical and sexual abuse, etc.) were similar, which indicates that this limitation is probably of lesser importance. Also, our present results could be conflated by unknown environmental risk factors, potentially influencing both ADHD and maltreatment, affecting the causal interpretation.

\section{Limitations inherent to twin methods}

Twin methods rely on a number of basic assumptions such as: 1) the equal environment assumptions, 2) the assumption on random mating in the population, 3) the assumption that genes and environment exert their influences separately, without gene-environment interaction, and 4) usually they consider only one (or maximum two) types of genetic mechanisms. Violation of these assumptions could influence how results of twin studies can be interpreted.

For instance, the equal environment assumption has long been questioned. One argument is that $\mathrm{MZ}$ twins tend to be treated more alike compared with DZ twins where parents are more likely to emphasize differences. This type of rater effect possibly inflates heritability estimates (108). However, when studying cases where perceived zygosity was not the actual zygosity of the twins, parental perception did not seem to influence resemblance regarding common psychiatric disorders (major depression, generalized anxiety disorder, phobia, and alcoholism) (218), 
which shows that significant violations of the equal environmental assumption are unlikely, and supports the use of twin studies in psychiatric research.

Assortative mating, violating the second assumption, would increase the variability of a trait in the population and affect heritability estimates in first-degree relatives. In twin studies, assortative mating may increase DZ correlations (DZ twins as first-degree relatives), while leaving MZ (identical) twin correlations unaffected. The net effect would be to spuriously decrease heritability estimates for the traits (158). Indeed, recent evidence has emerged for non-random mating in populations with a wide range of psychiatric conditions such as ADHD, SUD and affective and anxiety disorders (219). Thus, if anything, true heritability may in fact exceed the estimates obtained in twin studies.

We were unable to explore the role of gene-environment interactions (GxE). It has previously been suggested that GxE underlies the association between conduct disorder and childhood maltreatment (160), but this was not replicated by later studies $(220,221)$. The role of GxE is still unclear for ADHD and comorbidities.

Within-twin design does not rule out reverse causation. In this regard, both evocative and active rGE constitute possible contributing mechanisms. Also, within-twin pair design cannot identify the relative importance of different types of rGE. Maltreatment in older children and adolescents could at least in part be a consequence of ADHD-related behaviours, increasing the risk for potentially harmful and traumatic situations. In addition, data were not available on whether trauma occurred before or after the onset of ADHD-related problems.

Although large twin registries are representative of the population (175) and twins are in many ways similar to the general population, they also differ for instance regarding the intrauterine environment and birth weight (175). Furthermore, given that shared genetic risks play an important role in the comorbidity between ADHD and the conditions studied $(125,222)$, associations may be spuriously increased in a twin population. These issues raise concerns regarding external validity and generalizability of findings from twin research to the general population. 


\section{Ethical aspects}

Research regarding the genetic nature of psychiatric disorders raises several ethical concerns. Current research was approved by the ethics committee of the Karolinska Institute, and all participant provided informed consent. Register data are anonymized before being used for research, so that sensitive information on individual participants is not be divulged to the researchers. Accumulating health care and research data in registries to further explore the genetic nature of diseases is a priority for epidemiological and behavioural genetic research, but the risks for data leakage are obvious and therefore this has to be done with adequate measures for robust data security (223).

The genetic nature of disease poses significant ethical, public health and professional concerns (224). For complex disorders, genetic risk factors are probabilistic rather than deterministic $(155,156)$. Patients and sometimes professionals tend to regard genetic risks as static, and this may lead to misinterpretation of research findings. It is therefore very important how the research community and health care professionals communicate these genetic risks, both to the public and the individual patients. Patients are in general concerned with straightforward questions such as: "Do I have a disorder or not?", "If my parents have a disorder, does this mean that there is nothing I can do about becoming ill myself?", or "Are my children at risk?" The knowledge we now have about the genetic contributions to the risk for several psychiatric conditions will obviously not enable us to give confident yes or no answers to these questions. It becomes increasingly important to include knowledge on interpreting and communicating data on complex genetic and environmental risks in the training of professionals working in psychiatric and addiction services. 


\section{General Conclusions}

Symptoms of adult ADHD in the population are strongly associated with substance use disorder (SUD) in both men and women, with no evidence for specific substance preference associated with ADHD or any ADHD subtypes. Clinicians need to consider evaluation and treatment for ADHD as part of the management of SUD in adults.

The overlap between ADHD symptoms and alcohol dependence in adults was largely explained by shared genetic risk factors, similar for men and women. Non-shared environment also played a significant role in the overlap. This suggests that individuals with ADHD and their family members are important targets for alcohol use disorder prevention and treatment.

The association between adult ADHD symptoms and lifetime binge eating was mainly explained by common genetic risk factors. The remaining overlap was due to non-shared environmental risk factors. We found a somewhat stronger specific genetic association between IN symptoms and binge-eating behaviour, when controlling for genetic factors shared with HI symptoms, but not for the HI symptoms when controlling for IN.

Retrospectively recorded childhood maltreatment is strongly associated with ADHD symptoms in adults. Our findings suggest, for the first time in an adult population, that while part of the association is attributable to familial confounding, this may at least in part reflect a casual association.

\section{Future Considerations}

Genetic overlap between ADHD symptoms in adults and alcohol dependence and binge eating are important steps towards understanding the underlying nature of the risk of these comorbidities in patients with ADHD. Emerging evidence suggests a common pleiotropic genetic risk for psychiatric conditions, which could in part explain the genetic overlap that we identified $(2,123,137)$. However, for SUD, there is also evidence for specific genetic risk factors in the association with ADHD (125).

Previous research has failed to identify the genetic risk variants underlying psychiatric disorders, possibly because the current definitions of these conditions include complex heterogeneous behaviours (6). Hyperactivity, 
impulsivity and inattention are complex behavioural constructs, the components of which will need to be studied in individuals with ADHD and their healthy relatives, to better understand the mechanisms underlying the heritability of traits. Future research could focus on endophenotypes (140), which are intermediate, measurable components between a disorder and the genotype. Studies have focused on identifying endophenotypes specific for ADHD, alcohol dependence (225), or eating disorders (226). Future research informed by the genetic overlap between these conditions could explore possible endophenotypes common for ADHD, alcohol dependence and/or binge eating.

As an alternative approach to studying psychiatric disorders, the National Institute of Mental Health proposed the Research Domain Criteria (RDoC) (227), which instead of the clinical diagnoses, focuses on functional constructs (representing specified functional dimensions of behaviour) characterized in aggregate by the genes, molecules and circuits. An RDoC approach could probably identify several domains shared by ADHD, SUD and possibly at least some forms of binge eating. Earlier studies have identified several different mechanisms involving reward deficiency, difficulties in emotional regulation, lack of inhibitory control, and preference for immediate versus later rewards present in ADHD (9497). These could potentially contribute to the overlap with SUDs (73) and also with binge eating (93).

Non-shared environmental risk factors and how they possibly contribute to the manifestation of genetic predispositions have previously been underemphasized. Future directions for research could be to investigate the role of various common environmental factors, as well as possible mechanisms for gene-environment interaction. These might, for instance, include the role of prevalent alcohol- or food-related cues in the modern environment in individuals with low executive control, as well as psychosocial risk factors in the expression of inherited vulnerabilities.

Our finding regarding a causal hypothesis for childhood maltreatment for ADHD symptoms will need to be replicated in longitudinal, clinical studies with prospectively recorded childhood maltreatment. The neurocognitive and neurobiological underpinnings to the observed associations will have to be investigated. Recognizing and studying different causes of ADHD symptoms could improve interventions for adults who have experienced childhood maltreatment and present with ADHD symptoms. 
In Studies II and IV, we have shown that non-shared environmental factors explain part of the variance in the association between ADHD symptoms with alcohol dependence and binge eating. Future studies should consider investigating childhood maltreatment as one of these possible common environmental risk factors.

We found a strong association between binge eating in the population and ADHD symptoms. However, binge eating was rare, especially in men. Men may under-report their eating-related problems, possibly due to fear for stigmatization (206). More knowledge and possibly other methods, such as structured interviews in clinical populations regarding impulsive/ compulsive behaviours, including loss of control over food intake, are necessary to investigate binge eating problems and their association with ADHD in adults.

Given increasing evidence that ADHD and its comorbidities with other conditions have a significant degree of shared heritability, it is important that health providers are educated in interpreting and communicating genetic and environmental risks to their patients. 



\section{Summary in Swedish - Svensk sammanfattning}

Attention deficit hyperactivity disorder (ADHD) är en funktionsnedsättning som drabbar 2,5 - $5 \%$ av vuxna. ADHD-symptom återfinns i varierande grad i hela befolkningen och är förknippade med liknande genetiska faktorer som hos de som uppfyller kriterier för diagnos, varför populationsstudier är viktiga för att kunna undersöka ADHD och överlappande tillstånd. Orsaken till ADHD är okänd. Både ärftlighet och miljöfaktorer har betydelse. Hur dessa inverkar på samsjukligheter är oklart.

Avhandlingens huvudsyfte var att studera genetiska och miljöfaktorers betydelse i överlappningen mellan ADHD-symptom i befolkningen med två av dess vanligaste samsjukligheter: beroende/missbruksproblem och hetsätning. Den undersökte också eventuellt orsakssamband mellan misshandel i barndomen (en miljöfaktor) och ADHD-symptom i vuxen ålder. I samtliga studier användes självrapporterade data från över 18000, 2046 år gamla tvillingar, från det Svenska Nationella Tvillingregistret.

Första delarbetet undersökte sambandet mellan självrapporterade ADHD-symptom, indelade i 1.) hyperaktivitet/ impulsivitet, 2.) ouppmärksamhet, och 3.) kombination av de båda symtomgrupperna, med beroende/missbruk. Samtliga substansrelaterade besvär (alkoholberoende/ missbruk, användning av illegala droger och regelbunden rökning/snusning) var vanligare vid samtliga typer av ADHD-symptom. Ingen preferens för viss typ av substans framkom. De olika ADHD typerna medförde lika stor riskökning för beroende/ missbruk.

Tvillingmetoder användes för att undersöka om samsjuklighet mellan ADHD-symptom och alkoholberoende (delarbete II) respektive hetsätning (delarbete IV) bäst förklaras av gemensamma genetiska faktorer eller miljö. Generellt talar ett starkare samband hos enäggstvillingar (med $100 \%$ lika genuppsättning) jämfört med tvåäggstvillingar (som i genomsnitt delar 50\% av sina segregerande gener) för ärftlighet. Delarbete II visade att samsjukligheten mellan ADHD-symptom hos vuxna och alkoholberoende i befolkningen i hög grad (64\%) förklaras av gemensamma genetiska faktorer, medan resterande $36 \%$ förklarades av egna miljöfaktorer för varje individ i tvillingparet. Gemensamma miljöfaktorer (uppväxt och familjemiljö) hade ingen betydelse för sambandet. Det fanns ingen skillnad mellan könen vad gäller genetiska risker. 
Delarbete IV påvisade för första gången att sambandet mellan ADHDsymptom och hetsätning hos kvinnor till största delen (91\%) beror på gemensam ärftlighet för de två tillstånden, men egna miljöfaktorer är också av betydelse. Män rapporterade i mycket liten omfattning symptom på hetsätning. Forskning har visat förändringar i hjärnans belöningssystem, nedsatt förmåga till känsloreglering, exekutiv- och impulskontroll vid både $\mathrm{ADHD}$, alkoholberoende och hetsätning. Det skulle kunna finnas gemensamma genetiska faktorer mellan samtliga tre tillstånd.

I delarbete III framkom ett starkt samband mellan självrapporterad misshandel (vanvård, psykisk, fysisk och sexuell misshandel) i barndomen och ADHD-symptom hos vuxna. Med tvillingmetod undersökte vi om sambandet främst beror på familjefaktorer (genetiska och gemensamma miljöfaktorer) eller kan vara kausalt. Resultaten visar för första gången att det kan finnas ett orsakssamband mellan misshandel i barndomen och ADHD-symptom hos vuxna, men att en del av sambandet beror på gemensam ärftlighet och miljö under uppväxten. Fynden är preliminära och behöver undersökas vidare i kliniska populationer med objektivt registrerat trauma. Funktionella hjärnavbildningsstudier kan ge information om hur trauma kan påverka hjärnan och ge ADHD symptom.

Kliniker behöver vara medvetna om samsjuklighet mellan ADHD, beroende/ missbruk och hetsätning. Verksamheter behöver undersöka och behandla dessa problem parallellt. Med tanke på stark samsjuklighet, bör diagnostik och behandling av ADHD ingå vid behandling av beroende/ missbruksbesvär hos vuxna. Den gemensamma ärftligheten gör tidigare familjeinterventioner viktiga för individer med ADHD, beroende/missbruk, och ätstörningar. 


\section{Acknowledgements}

I would like to express my most sincere gratitude to all those who helped me during my work with this thesis.

Thank you to my supervisor professor Preben Bendtsen, my co-supervisors professor Henrik Larsson and Ina Marteinsdottir; to my co-authors, in particular Ralf Kuja-Halkola, Shuyang Yao, Cynthia M. Bulik and Laura M. Thornton; to my fellow researchers at MEB, Linköping University, CSAN; to professor Markus Heilig, professor Per Gustafsson and Elisabeth Skogh; to Kajsa Bendtsen in Linköping and Barbro Sandin at MEB; to my colleagues, my coworkers, my friends, and my family, who all of you stood by me, supported and helped me during my journey towards this dissertation. Thank you Björn for your love and support and patience, and for your skills as a researcher.

Thank you also to my patients, who showed me how it is to live, cope and not always cope with ADHD and its comorbidities.

The cover illustration: "The Road to Motala” is about a journey. What should have been a few months, to learn Swedish and get to know the medical system, became eleven years of commuting. Eleven years of passing sceneries, shifting lights, colors, and seasons.

Working on my thesis was another journey. I did not find the answers to all of my questions. I came up with a few more instead and learned a lot about doing research, about focus, frustration and occasional fun.

"I may not have gone where I intended to go, but I think I have ended up where I needed to be." Douglas Adams, The Long Dark Tea-Time of the Soul 



\section{Appendix}

\section{Study I Substance use disorder variables used in Study I}

\section{Measures}

Alcohol abuse: Alco-

hol abuse $=$ yes if $\geq 1$

DSM-IV criteria $=$ yes

and alcohol depend-

ence $=0$

1) Failure to fulfil major role obligations at work, school or home

\section{Self-report questions}

Based on SCID for DSM-IV (Structured Clinical Interview for DSM-IV) with 3 response alternatives, "yes", "no", "don't know/don't wish to answer"

Did you ever miss, during this period work or school because you were intoxicated, high, or very hung over? What about doing a bad job at work or failing courses at school because of your drinking?

What about not keeping your house clean, or not taking proper care of your children because of your drinking?

2) Recurrent use in situations where the use is physically hazardous (driving, operating machinery while intoxicated)

3) Recurrent alcoholrelated legal problems

4) Continued use despite alcohol-related social or interpersonal problems

Alcohol dependence Illicit drug use $=$ yes, if tried at least one illicit drug

Polysubstance use $=$ yes, if tried $\geq 2$ illicit drugs

\section{Polysubstance use} and alcohol $=$ yes, if tried $\geq 2$ illicit drugs
Did you ever drink/Have you ever drank in a situation in which it might have been dangerous to drink at all? Did you ever drive/Have you ever driven while you were really too drunk to drive?

How many times?

Did your drinking get//Has your drinking gotten you into trouble with the law?

Did it happen more than once?

Did your drinking cause/Has your drinking caused problems with other people, such as with family members, friends, or people at work? Did you get/Have you ever gotten into physical fights when you were drinking? What about having bad arguments about what happens when you drink too much?

See below

Questions set in branching format

Have you ever used any of the following drugs? Marijuana, hashish, opium, morphine, heroin, codeine (Codeine, Treo-Comp ${ }^{\circledR}$, Citodon $\left.\AA\right)$, cocaine, amphetamine, methylphenidate (Ritalina ${ }^{\circledR}$, Ritalin $\left.\AA\right)$, LSD, hallucinogenic mushrooms (psilocybin, psilocin), Rohypnol ${ }^{\circledR}$ (Roppar), other sedatives or sleeping medication (e.g. So- 


\begin{tabular}{|c|c|}
\hline $\begin{array}{l}\text { and/or alcohol use dis- } \\
\text { order }\end{array}$ & 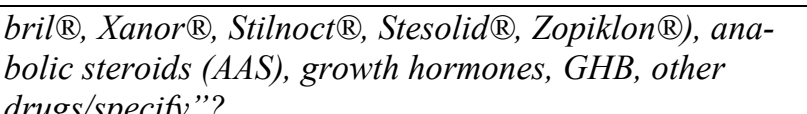 \\
\hline Cannabis use & Use at least once of either marijuana or hashish or both. \\
\hline Stimulant use & Use at least once of any of the following stimulants: co- \\
\hline Opioid use & caine, amphetamine and methylphenidate. \\
\hline & Use at least once of any opiates (heroin, opium, mor- \\
\hline & \\
\hline Regular nicotine & Questions set in branching format \\
\hline$\geq 1 \mathrm{x} /$ day for a period of & Have you ever tried smoking or snus? with alternatives \\
\hline $\begin{array}{l}\text { time during the life } \\
\text { span }\end{array}$ & $\begin{array}{l}\text { "no", "yes but only tried smoking/snus", "yes, occasion- } \\
\text { ally smoking/ snus", "yes regularly smoking/snus". Sub- }\end{array}$ \\
\hline & $\begin{array}{l}\text { sequent questions in a branching format, about quantity } \\
\text { and duration }\end{array}$ \\
\hline
\end{tabular}

\section{Study II Criteria for alcohol dependence and self-report questions used} in Studies I and II

\begin{tabular}{ll}
\hline Measures & Self-report questions \\
\hline 1) Development of tol- & $\begin{array}{l}\text { Did you during this period notice you needed to drink } \\
\text { erance }\end{array}$ \\
& $\begin{array}{l}\text { more to get the same effect? } \\
\text { alcohou notice being less affected by the same amount of }\end{array}$ \\
&
\end{tabular}

2) Symptoms of withdrawal or avoidance of withdrawal symptoms by means of continued alcohol use
3) Alcohol consumption for a longer time or higher amounts than intended

4) Persistent desire to control alcohol use
Have you felt you needed a drink first thing in the morning (eye opener), to steady your nerves or to get rid of a hangover?

During this period notice did you any signs of withdrawal when you cut down or stopped drinking entirely? (Mark in the list below if relevant)

Sweating

Tremor of the limbs

Difficulties sleeping

Nausea, vomiting

Restlessness

Anxiety

Epileptic fits or seeing, feeling, hearing things that were not real

Did you often find/Have you often found that when you started drinking you ended up drinking much more than you were planning to?

What about drinking for a much longer period of time than you were planning to?

Have you ever felt you needed to cut down on your drinking?

Have people annoyed you by criticizing you drinking? 


\begin{tabular}{|c|c|}
\hline & $\begin{array}{l}\text { Have you ever felt guilty about drinking? } \\
\text { Did you try/Have you tried to cut down or stop drinking } \\
\text { alcohol? } \\
\text { Did you ever actually stop drinking altogether? } \\
\text { (How many times did you try to cut down or stop alto- } \\
\text { gether?) } \\
\text { Times } \\
\text { Did you want to stop or cut down? }\end{array}$ \\
\hline $\begin{array}{l}\text { 5) Great amount of } \\
\text { time spent on obtaining } \\
\text { alcohol }\end{array}$ & $\begin{array}{l}\text { Did you spend/Have you spent a lot of time drinking, be- } \\
\text { ing high, or hung over? }\end{array}$ \\
\hline $\begin{array}{l}\text { 6) Decrease in social } \\
\text { activity due to the sub- } \\
\text { stance use }\end{array}$ & $\begin{array}{l}\text { Did you have times/Have you had times when you would } \\
\text { drink so often that you started to drink instead of working } \\
\text { or spending time at hobbies or with your family or } \\
\text { friends, or engaging in other important activities, such as } \\
\text { sports, gardening, or playing music? }\end{array}$ \\
\hline $\begin{array}{l}\text { 7) Continued use of al- } \\
\text { cohol despite proven } \\
\text { negative effects }\end{array}$ & $\begin{array}{l}\text { Did your drinking during this period lead to psychiatric } \\
\text { problems such as anxiety, depression, sleeping problems } \\
\text { or memory loss? } \\
\text { Did your drinking during this period lead to any disease } \\
\text { or worsen a disease you already had? } \\
\text { Did you continue drinking nontheless? }\end{array}$ \\
\hline
\end{tabular}

Study III Childhood maltreatment measures based on Life Stressor
\begin{tabular}{ll} 
Checklist - Revised (LSC-R) $(180)$ \\
\hline Measures & Self-report items from LSC-R \\
\hline Emotional neglect & $\begin{array}{l}\text { Have you ever been emotionally abused or ne- } \\
\text { glected? For example, being frequently shamed, em- } \\
\text { barrassed, ignored, or repeatedly told that you were } \\
\text { "no good" }\end{array}$
\end{tabular}

Physical neglect Have you ever been physically neglected? For example, not fed, not properly clothed, or left to take care of yourself when you felt you were too young or ill

Physical abuse Have you ever been physically abused - hit, choked, burned, or beaten or severely punished (e.g. locked up in a closet, tied up, or chained) by someone you knew well such as a parent, sibling, boyfriend or girlfriend?

Sexual abuse

Were you ever touched or made to touch someone else in a sexual way, because you felt forced in some way or threatened by harm to yourself or someone else? 


\begin{tabular}{|c|c|}
\hline & $\begin{array}{l}\text { Did you ever have sex because you felt forced in } \\
\text { some way or threatened by harm to yourself or some- } \\
\text { one else? With sex, we mean orally, anally, and/or } \\
\text { genitally' If any of these two questions were an- } \\
\text { swered with "yes", sexual abuse was set as "yes" }\end{array}$ \\
\hline Witnessing family violence & $\begin{array}{l}\text { When you were young, before age } 18 \text { years, did you } \\
\text { ever observe physical violence between family mem- } \\
\text { bers? For example, hitting, kicking or punching }\end{array}$ \\
\hline
\end{tabular}

\section{Study IV Measures for binge eating, BED and BN based on Structured Clinical Interview (SCID) (173)}

Measures
Binge eating
Frequency
Loss of control over
food intake $=$ yes if $\geq 2$
on the Likert scale

Influence of body shape and weight on self-evaluation Self-reported items based on SCID

Have you ever had eating binges when you ate what most people would regard as an unusually large amount of food in a short period of time?

Compensatory behaviours to avoid weight gain $=$ at least one set as yes

Feeling distressed over binge eating $=\geq 2$ defined as yes

Specific binge eating disorder symptoms, DSM assessed by yes or no questions
For how long did you have binge eating episodes?

When you were binging the most, how many binges would you have in a month?

When you were having eating binges, did you feel your eating was out of control? With responses on a fivepoint Likert scale: 1, not at all; 2, slightly; 3, somewhat; 4, very much; 5, extremely

Weight and body shape do not at all influence how I feel about myself" to "weight and body shape is most important for how I feel about myself"

Which of these did you use during the same time that you were binge eating? Making yourself vomit? Laxatives? Diuretics? Diet pills? Exercise more than 2 hours per day? Fast or not eat? Other methods?

How distressed or unhappy were you when binge eating? With responses on a five-point Likert scale: 1 , not at all; 2, a little; 3, somewhat; 4, much; 5, extremely

1) Eating much more rapidly than normal; 2) eating until feeling uncomfortably full; 3) eating large amounts of food when not feeling physically hungry; 4) eating alone because of being embarrassed by how much one is eating; 5) feeling disgusted with oneself, depressed, or very guilty after overeating, all assessed by yes or no answers 


\section{References}

1. Kessler RC, Adler L, Barkley R, Biederman J, Conners CK, Demler O, et al. The prevalence and correlates of adult ADHD in the United States: results from the National Comorbidity Survey Replication. American Journal of Psychiatry. 2006;163(4):716-23.

2. Faraone SV, Asherson P, Banaschewski T, Biederman J, Buitelaar JK, Ramos-Quiroga JA, et al. Attention-deficit/hyperactivity disorder. Nat Rev Dis Primers. 2015;1:15020.

3. Weikard MA. Der philosophische Arzt, Dritter Band Frankfurt am Main1799 [cited 2015 2015-01-27].

4. Crichton A. An inquiry into the nature and origin of mental derangement: on attention and its diseases. Journal of Attention Disorder. 2008;12(3):200-4; discussion 5-6.

5. American Psychiatric Association. Diagnostic and statistical manual of mental disorders : DSM-5. 5th ed. Washington, D.C.: American Psychiatric Association; 2013. xliv, 947 p. p.

6. Taylor E. Antecedents of ADHD: a historical account of diagnostic concepts. Atten Defic Hyperact Disord. 2011;3(2):69-75.

$7 . \quad$ Thapar A, Cooper M. Attention deficit hyperactivity disorder. Lancet. 2016;387(10024):1240-50.

8. Murphy K, Barkley RA. Attention deficit hyperactivity disorder adults: comorbidities and adaptive impairments. Comprehensive Psychiatry. 1996;37(6):393401.

9. Biederman J, Faraone SV, Spencer T, Wilens T, Norman D, Lapey KA, et al. Patterns of psychiatric comorbidity, cognition, and psychosocial functioning in adults with attention deficit hyperactivity disorder. American Journal of Psychiatry. 1993;150(12):1792-8.

10. Barkley RA, Murphy KR, Fischer M. ADHD in adults : what the science says. New York: Guilford Press; 2008. xii, 500 p. p.

11. Larsson H, Anckarsater H, Rastam M, Chang Z, Lichtenstein P. Childhood attention-deficit hyperactivity disorder as an extreme of a continuous trait: a quantitative genetic study of 8,500 twin pairs. Journal of Child Psychology and Psychiatry and Allied Disciplines. 2012;53(1):73-80.

12. Franke B, Faraone SV, Asherson P, Buitelaar J, Bau CH, RamosQuiroga JA, et al. The genetics of attention deficit/hyperactivity disorder in adults, a review. Molecular Psychiatry. 2012;17(10):960-87.

13. Thapar A, Cooper M, Eyre O, Langley K. What have we learnt about the causes of ADHD? Journal of Child Psychology and Psychiatry and Allied Disciplines. 2013;54(1):3-16.

14. Thapar A, Rice F, Hay D, Boivin J, Langley K, van den Bree M, et al. Prenatal smoking might not cause attention-deficit/hyperactivity disorder: evidence from a novel design. Biological Psychiatry. 2009;66(8):722-7.

15. Skoglund C, Chen Q, D'Onofrio BM, Lichtenstein P, Larsson H. Familial confounding of the association between maternal smoking during pregnancy 
and ADHD in offspring. Journal of Child Psychology and Psychiatry and Allied Disciplines. 2014;55(1):61-8.

16

Wilens TE, Kwon A, Tanguay S, Chase R, Moore H, Faraone SV, et al. Characteristics of adults with attention deficit hyperactivity disorder plus substance use disorder: the role of psychiatric comorbidity. American Journal on Addictions. 2005;14(4):319-27.

17. Faraone SV, Biederman J, Mick E. The age-dependent decline of attention deficit hyperactivity disorder: a meta-analysis of follow-up studies. Psychological Medicine. 2006;36(2):159-65.

18. Barkley RA, Peters H. The earliest reference to ADHD in the medical literature? Melchior Adam Weikard's description in 1775 of "attention deficit" (Mangel der Aufmerksamkeit, Attentio Volubilis). Journal of Attention Disorder. 2012;16(8):623-30.

19. Hoffmann H. Merry Stories and Funny Pictures http://www.gutenberg.org/ebooks/12116: Project Gutenberg; 1848 [cited 2016 June 6]. This book was first published in German in 1844, and in English translation in 1848. Available from: http://www.gutenberg.org/ebooks/12116.

20. Lange KW, Reichl S, Lange KM, Tucha L, Tucha O. The history of attention deficit hyperactivity disorder. Atten Defic Hyperact Disord. 2010;2(4):241-55. 21. Still GF. Some abnormal psychical conditions in children: excerpts from three lectures. Journal of Attention Disorder. 2006;10(2):126-36.

22. Conners CK. Attention-deficit/hyperactivity disorder-historical development and overview. Journal of attention disorders. 2000;3(4):173-91.

23. Tredgold AF. Original Papers: THE NATURE OF MENTAL DEFICIENCY. Journal of Neurology and Psychopathology. 1922;2(8):311-24.

24. Teo T, Ball LC. Twin research, revisionism and metahistory. Hist Human Sci. 2009;22(5):1-23.

25. Heiman H. Postinfluenzal Encephalitis. Archives of Pediatrics and Adolescent Medicine. 1919;18(2):83.

26. Neumarker KJ. The Kramer-Pollnow syndrome: a contribution on the life and work of Franz Kramer and Hans Pollnow. Hist Psychiatry. 2005;16(Pt 4 (no 64)):435-51.

27. Strohl MP. Bradley's Benzedrine studies on children with behavioral disorders. Yale Journal of Biology and Medicine. 2011;84(1):27-33.

$28 . \quad$ Bradley C. The Behavior of Children Receiving Benzedrine. American Journal of Psychiatry. 1937;94(3):577-85.

$29 . \quad$ Clements SD, Peters JE. Minimal brain dysfunctions in the school-age child. Diagnosis and treatment. Archives of General Psychiatry. 1962;6(3):185-97.

30. American Psychiatric Association CoNaS. Diagnostic and statistical manual of mental disorders. 2d ed. Washington,: American Psychiatric Association; 1968. xv, 119 p. p.

31. Chess S. Diagnosis and treatment of the hyperactive child. New York State Journal of Medicine. 1960;60:2379-85.

32. Faraone SV, Biederman J, Friedman D. Validity of DSM-IV subtypes of attention-deficit/hyperactivity disorder: a family study perspective. Journal of the American Academy of Child and Adolescent Psychiatry. 2000;39(3):300-7. 
33.

Barkley RA. Attention-deficit hyperactivity disorder : a handbook for diagnosis and treatment. Fourth edition. ed. New York: The Guilford Press; 2015. xiii, 898 pages $\mathrm{p}$.

34. Lewis M, Hale GA. Attention and cognitive development. New York: Plenum Press; 1979. xv, 366 p. p.

35. American Psychiatric Association TFoNaS. Diagnostic and statistical manual of mental disorders. 3d ed. Washington, D.C.: American Psychiatric Association; 1980. 494 p. p.

36. Lee SI, Schachar RJ, Chen SX, Ornstein TJ, Charach A, Barr C, et al. Predictive validity of DSM-IV and ICD-10 criteria for ADHD and hyperkinetic disorder. Journal of Child Psychology and Psychiatry and Allied Disciplines. 2008;49(1):70-8.

37. Willcutt EG, Nigg JT, Pennington BF, Solanto MV, Rohde LA, Tannock R, et al. Validity of DSM-IV attention deficit/hyperactivity disorder symptom dimensions and subtypes. Journal of Abnormal Psychology. 2012;121(4):991-1010.

38. McLoughlin G, Ronald A, Kuntsi J, Asherson P, Plomin R. Genetic support for the dual nature of attention deficit hyperactivity disorder: substantial genetic overlap between the inattentive and hyperactive-impulsive components. Journal of Abnormal Child Psychology. 2007;35(6):999-1008.

39. Larsson H, Asherson P, Chang Z, Ljung T, Friedrichs B, Larsson JO, et al. Genetic and environmental influences on adult attention deficit hyperactivity disorder symptoms: a large Swedish population-based study of twins. Psychological Medicine. 2013;43(1):197-207.

40. American Psychiatric Association. Diagnostic and statistical manual of mental disorders : DSM-IV. 4th ed. Washington, DC: American Psychiatric Association; 1994. xxvii, 886 p. p.

41. Lahey BB, Applegate B, McBurnett K, Biederman J, Greenhill L, Hynd GW, et al. DSM-IV field trials for attention deficit hyperactivity disorder in children and adolescents. American Journal of Psychiatry. 1994;151(11):1673-85.

42. Crichton A. An inquiry into the nature and origin of mental derangement : comprehending a concise system of the physiology and pathology of the human mind. London: Printed for T. Cadell, junior, and W. Davies; 1798.

43. Gelder MG, Gath D, Mayou R. Oxford textbook of psychiatry. 2nd ed. London: ELBS; 1989. xiv, 1079 p. p.

44. Denckla MB. Attention deficit hyperactivity disorder-residual type. Journal of Child Neurology. 1991;6 Suppl:S44-50.

45. Quitkin F, Klein DF. Two behavioral syndromes in young adults related to possible minimal brain dysfunction. Journal of Psychiatric Research. 1969;7(2):13142.

46. American Psychiatric Association. Diagnostic and Statistical Manual of Mental Disorders, Forth Edition, DSM-IV-TR. Washington, D.C.: American Psychiatric Association; 2000. 943 p. p.

47. Larsson H, Dilshad R, Lichtenstein P, Barker ED. Developmental trajectories of DSM-IV symptoms of attention-deficit/hyperactivity disorder: genetic effects, family risk and associated psychopathology. Journal of Child Psychology and Psychiatry and Allied Disciplines. 2011;52(9):954-63. 
48.

Faraone SV, Biederman J, Doyle A, Murray K, Petty C, Adamson JJ, et al. Neuropsychological studies of late onset and subthreshold diagnoses of adult attention-deficit/hyperactivity disorder. Biological Psychiatry. 2006;60(10):1081-7.

49.

Faraone SV, Wilens TE, Petty C, Antshel K, Spencer T, Biederman J. Substance use among ADHD adults: implications of late onset and subthreshold diagnoses. American Journal on Addictions. 2007;16 Suppl 1:24-32; quiz 3-4.

50. Levy F, Hay DA, McStephen M, Wood C, Waldman I. Attention-deficit hyperactivity disorder: a category or a continuum? Genetic analysis of a large-scale twin study. Journal of the American Academy of Child and Adolescent Psychiatry. 1997;36(6):737-44.

51. Martin J, Hamshere ML, Stergiakouli E, O'Donovan MC, Thapar A. Genetic risk for attention-deficit/hyperactivity disorder contributes to neurodevelopmental traits in the general population. Biological Psychiatry. 2014;76(8):664-71.

52. Barkley RA, Fischer M, Smallish L, Fletcher K. The persistence of attention-deficit/hyperactivity disorder into young adulthood as a function of reporting source and definition of disorder. Journal of Abnormal Psychology. 2002;111(2):27989.

53. McKee TE. Comparison of a norm-based versus criterion-based approach to measuring ADHD symptomatology in college students. Journal of Attention Disorder. 2008;11(6):677-88.

54. Friedrichs B, Igl W, Larsson H, Larsson JO. Coexisting psychiatric problems and stressful life events in adults with symptoms of ADHD--a large Swedish population-based study of twins. J Atten Disord. 2012;16(1):13-22.

55. Willcutt EG. The prevalence of DSM-IV attention-deficit/hyperactivity disorder: a meta-analytic review. Neurotherapeutics. 2012;9(3):490-9.

56. Polanczyk G, de Lima MS, Horta BL, Biederman J, Rohde LA. The worldwide prevalence of ADHD: a systematic review and metaregression analysis. American Journal of Psychiatry. 2007;164(6):942-8.

57. Merikangas KR, He JP, Burstein M, Swanson SA, Avenevoli S, Cui L, et al. Lifetime prevalence of mental disorders in U.S. adolescents: results from the National Comorbidity Survey Replication--Adolescent Supplement (NCS-A). Journal of the American Academy of Child and Adolescent Psychiatry. 2010;49(10):980-9.

58. Moffitt TE, Houts R, Asherson P, Belsky DW, Corcoran DL, Hammerle M, et al. Is Adult ADHD a Childhood-Onset Neurodevelopmental Disorder? Evidence From a Four-Decade Longitudinal Cohort Study. American Journal of Psychiatry. 2015;172(10):967-77.

59. Polanczyk GV, Willcutt EG, Salum GA, Kieling C, Rohde LA. ADHD prevalence estimates across three decades: an updated systematic review and metaregression analysis. International Journal of Epidemiology. 2014;43(2):434-42.

60. Polanczyk GV, Moffitt TE. How evidence on the developmental nature of attention-deficit/hyperactivity disorder can increase the validity and utility of diagnostic criteria. Journal of the American Academy of Child and Adolescent Psychiatry. 2014;53(7):723-5.

61. Edvinsson D, Bingefors K, Lindstrom E, Lewander T. ADHD-related symptoms among adults in out-patient psychiatry and female prison inmates as 
compared with the general population. Upsala Journal of Medical Sciences. 2010;115(1):30-40.

62. Nylander L, Holmqvist M, Gustafson L, Gillberg C. ADHD in adult psychiatry. Minimum rates and clinical presentation in general psychiatry outpatients. Nord J Psychiatry. 2009;63(1):64-71.

63. Giacobini M, Medin E, Ahnemark E, Russo LJ, Carlqvist P. Prevalence, Patient Characteristics, and Pharmacological Treatment of Children, Adolescents, and Adults Diagnosed With ADHD in Sweden. Journal of Attention Disorder. 2014; $10.1177 / 1087054714554617$.

64. The National Board of Health and Welfare (Socialstyrelsen) SS. Statistikdatabas för läkemedel (Statistical data on medication) Stockholm, Sweden: Swedish National Board of Health and Welfare; 2016 [cited 2016 2016-05-26]. Statistical data on prescription of ADHD medication (methylphenidate, atomoxetin, amphetamine, dexamphetamine, lysdesamphetamine) ].

65. CDC. Increasing Prevalence of Parent-Reported AttentionDeficit/Hyperactivity Disorder Among Children - United States, 2003 and 2007. Centers for Disease Control and Prevention (CDC), Services UdoHaH; 2010 November 12, 2010. Report No.: Contract No.: 44.

66. Polanczyk G, Caspi A, Houts R, Kollins SH, Rohde LA, Moffitt TE. Implications of extending the ADHD age-of-onset criterion to age 12: results from a prospectively studied birth cohort. Journal of the American Academy of Child and Adolescent Psychiatry. 2010;49(3):210-6.

67. Vande Voort JL, He JP, Jameson ND, Merikangas KR. Impact of the DSM-5 attention-deficit/hyperactivity disorder age-of-onset criterion in the US adolescent population. Journal of the American Academy of Child and Adolescent Psychiatry. 2014;53(7):736-44.

68. van Emmerik-van Oortmerssen K, van de Glind G, Koeter MW, Allsop $\mathrm{S}$, Auriacombe $\mathrm{M}$, Barta $\mathrm{C}$, et al. Psychiatric comorbidity in treatment-seeking substance use disorder patients with and without attention deficit hyperactivity disorder: results of the IASP study. Addiction. 2014;109(2):262-72.

69. Bihlar Muld B, Jokinen J, Bolte S, Hirvikoski T. Attention deficit/hyperactivity disorders with co-existing substance use disorder is characterized by early antisocial behaviour and poor cognitive skills. BMC Psychiatry. 2013;13:336. 70 .

van Emmerik-van Oortmerssen K, van de Glind G, van den Brink W, Smit F, Crunelle CL, Swets M, et al. Prevalence of attention-deficit hyperactivity disorder in substance use disorder patients: a meta-analysis and meta-regression analysis. Drug and Alcohol Dependence. 2012;122(1-2):11-9.

71. Ohlmeier MD, Peters K, Te Wildt BT, Zedler M, Ziegenbein M, Wiese $\mathrm{B}$, et al. Comorbidity of alcohol and substance dependence with attentiondeficit/hyperactivity disorder (ADHD). Alcohol and Alcoholism. 2008;43(3):300-4.

72. van de Glind G, Konstenius M, Koeter MW, van Emmerik-van Oortmerssen K, Carpentier PJ, Kaye S, et al. Variability in the prevalence of adult ADHD in treatment seeking substance use disorder patients: results from an international multi-center study exploring DSM-IV and DSM-5 criteria. Drug and Alcohol Dependence. 2014;134:158-66. 
73. Zulauf CA, Sprich SE, Safren SA, Wilens TE. The complicated relationship between attention deficit/hyperactivity disorder and substance use disorders. Curr Psychiatry Rep. 2014;16(3):436.

74. Wilens TE, Biederman J, Faraone SV, Martelon M, Westerberg D, Spencer TJ. Presenting ADHD symptoms, subtypes, and comorbid disorders in clinically referred adults with ADHD. Journal of Clinical Psychiatry. 2009;70(11):155762.

75.

Ginsberg Y, Hirvikoski T, Lindefors N. Attention Deficit Hyperactivity

Disorder (ADHD) among longer-term prison inmates is a prevalent, persistent and disabling disorder. BMC Psychiatry. 2010;10:112.

76. Lee SS, Humphreys KL, Flory K, Liu R, Glass K. Prospective association of childhood attention-deficit/hyperactivity disorder (ADHD) and substance use and abuse/dependence: a meta-analytic review. Clinical Psychology Review. 2011;31(3):328-41.

77. Wilens TE, Martelon M, Joshi G, Bateman C, Fried R, Petty C, et al. Does ADHD predict substance-use disorders? A 10-year follow-up study of young adults with ADHD. Journal of the American Academy of Child and Adolescent Psychiatry. 2011;50(6):543-53.

78. Skoglund C, Brandt L, Almqvist C, D'Onofrio BM, Konstenius M, Franck J, et al. Factors Associated With Adherence to Methylphenidate Treatment in Adult Patients With Attention-Deficit/Hyperactivity Disorder and Substance Use Disorders. Journal of Clinical Psychopharmacology. 2016;10.1097/jcp.0000000000000501.

79. Edwards AC, Kendler KS. Twin study of the relationship between adolescent attention-deficit/hyperactivity disorder and adult alcohol dependence. J Stud Alcohol Drugs. 2012;73(2):185-94.

80. Elkins IJ, Malone S, Keyes M, Iacono WG, McGue M. The impact of attention-deficit/hyperactivity disorder on preadolescent adjustment may be greater for girls than for boys. Journal of Clinical Child and Adolescent Psychology. 2011;40(4):532-45.

81. Tamm L, Adinoff B, Nakonezny PA, Winhusen T, Riggs P. Attentiondeficit/hyperactivity disorder subtypes in adolescents with comorbid substance-use disorder. American Journal of Drug and Alcohol Abuse. 2012;38(1):93-100.

82. Tercyak KP, Lerman C, Audrain J. Association of attentiondeficit/hyperactivity disorder symptoms with levels of cigarette smoking in a community sample of adolescents. Journal of the American Academy of Child and Adolescent Psychiatry. 2002;41(7):799-805.

83. Gehricke JG, Hong N, Whalen CK, Steinhoff K, Wigal TL. Effects of transdermal nicotine on symptoms, moods, and cardiovascular activity in the everyday lives of smokers and nonsmokers with attention-deficit/hyperactivity disorder. Psychology of Addictive Behaviors. 2009;23(4):644-55.

84. Gehricke JG, Loughlin SE, Whalen CK, Potkin SG, Fallon JH, Jamner LD, et al. Smoking to self-medicate attentional and emotional dysfunctions. Nicotine Tob Res. 2007;9 Suppl 4:S523-36.

85. Ameringer KJ, Leventhal AM. Associations between attention deficit hyperactivity disorder symptom domains and DSM-IV lifetime substance dependence. American Journal on Addictions. 2013;22(1):23-32. 
86.

De Alwis D, Lynskey MT, Reiersen AM, Agrawal A. Attentiondeficit/hyperactivity disorder subtypes and substance use and use disorders in NESARC. Addictive Behaviors. 2014;39(8):1278-85.

87. Biederman J, Milberger S, Faraone SV, Kiely K, Guite J, Mick E, et al. Family-environment risk factors for attention-deficit hyperactivity disorder. A test of Rutter's indicators of adversity. Archives of General Psychiatry. 1995;52(6):464-70.

88. Reinblatt SP, Leoutsakos JM, Mahone EM, Forrester S, Wilcox HC, Riddle MA. Association between binge eating and attention-deficit/hyperactivity disorder in two pediatric community mental health clinics. International Journal of Eating Disorders. 2015;48(5):505-11.

89. Cortese S, Bernardina BD, Mouren MC. Attention-deficit/hyperactivity disorder (ADHD) and binge eating. Nutrition Reviews. 2007;65(9):404-11.

90. Bleck J, DeBate RD. Exploring the co-morbidity of attentiondeficit/hyperactivity disorder with eating disorders and disordered eating behaviors in a nationally representative community-based sample. Eat Behav. 2013;14(3):390-3.

91. Reinblatt SP, Mahone EM, Tanofsky-Kraff M, Lee-Winn AE, Yenokyan G, Leoutsakos JM, et al. Pediatric loss of control eating syndrome: Association with attention-deficit/hyperactivity disorder and impulsivity. International Journal of Eating Disorders. 2015;48(6):580-8.

92. Steadman KM, Knouse LE. Is the Relationship Between ADHD Symptoms and Binge Eating Mediated by Impulsivity? Journal of Attention Disorder. 2014; $10.1177 / 1087054714530779$.

93. Seymour KE, Reinblatt SP, Benson L, Carnell S. Overlapping neurobehavioral circuits in ADHD, obesity, and binge eating: evidence from neuroimaging research. CNS Spectr. 2015;20(4):401-11.

94. Coghill DR, Seth S, Matthews K. A comprehensive assessment of memory, delay aversion, timing, inhibition, decision making and variability in attention deficit hyperactivity disorder: advancing beyond the three-pathway models. Psychological Medicine. 2014;44(9):1989-2001.

95. Carmona S, Hoekzema E, Ramos-Quiroga JA, Richarte V, Canals C, Bosch R, et al. Response inhibition and reward anticipation in medication-naive adults with attention-deficit/hyperactivity disorder: a within-subject case-control neuroimaging study. Human Brain Mapping. 2012;33(10):2350-61.

96. Solanto MV, Abikoff H, Sonuga-Barke E, Schachar R, Logan GD, Wigal $\mathrm{T}$, et al. The ecological validity of delay aversion and response inhibition as measures of impulsivity in AD/HD: a supplement to the NIMH multimodal treatment study of AD/HD. Journal of Abnormal Child Psychology. 2001;29(3):215-28.

97. Sonuga-Barke EJ, Fairchild G. Neuroeconomics of attentiondeficit/hyperactivity disorder: differential influences of medial, dorsal, and ventral prefrontal brain networks on suboptimal decision making? Biological Psychiatry. 2012;72(2):126-33.

98. Cortese S, Kelly C, Chabernaud C, Proal E, Di Martino A, Milham MP, et al. Toward systems neuroscience of ADHD: a meta-analysis of 55 fMRI studies. American Journal of Psychiatry. 2012;169(10):1038-55.

99. Plichta MM, Scheres A. Ventral-striatal responsiveness during reward anticipation in ADHD and its relation to trait impulsivity in the healthy population: a 
meta-analytic review of the fMRI literature. Neuroscience and Biobehavioral Reviews. 2014;38:125-34.

100. Posner J, Park C, Wang Z. Connecting the dots: a review of resting connectivity MRI studies in attention-deficit/hyperactivity disorder. Neuropsychology Review. 2014;24(1):3-15.

101. Castellanos FX, Lee PP, Sharp W, Jeffries NO, Greenstein DK, Clasen LS, et al. Developmental trajectories of brain volume abnormalities in children and adolescents with attention-deficit/hyperactivity disorder. JAMA. 2002;288(14):1740-8. 102. Greven CU, Bralten J, Mennes M, O'Dwyer L, van Hulzen KJ, Rommelse N, et al. Developmentally stable whole-brain volume reductions and developmentally sensitive caudate and putamen volume alterations in those with attention-deficit/hyperactivity disorder and their unaffected siblings. JAMA Psychiatry. 2015;72(5):490-9.

103. Hoogman M, Rijpkema M, Janss L, Brunner H, Fernandez G, Buitelaar $\mathrm{J}$, et al. Current self-reported symptoms of attention deficit/hyperactivity disorder are associated with total brain volume in healthy adults. PloS One. 2012;7(2):e31273.

104. Shaw P, Malek M, Watson B, Sharp W, Evans A, Greenstein D. Development of cortical surface area and gyrification in attention-deficit/hyperactivity disorder. Biological Psychiatry. 2012;72(3):191-7.

105. Shaw P, Eckstrand K, Sharp W, Blumenthal J, Lerch JP, Greenstein D, et al. Attention-deficit/hyperactivity disorder is characterized by a delay in cortical maturation. Proceedings of the National Academy of Sciences of the United States of America. 2007;104(49):19649-54.

106. Shaw P, De Rossi P, Watson B, Wharton A, Greenstein D, Raznahan A, et al. Mapping the development of the basal ganglia in children with attentiondeficit/hyperactivity disorder. Journal of the American Academy of Child and Adolescent Psychiatry. 2014;53(7):780-9.e11.

107. Faraone SV, Perlis RH, Doyle AE, Smoller JW, Goralnick JJ, Holmgren MA, et al. Molecular genetics of attention-deficit/hyperactivity disorder. Biological Psychiatry. 2005;57(11):1313-23.

108. Retz W, Klein RG. Attention deficit hyperactivity disorder (ADHD) in adults. Basel ; New York: Karger; 2010. viii, 192 p. p.

109. Willerman L. Activity level and hyperactivity in twins. Child Development. 1973;44(2):288-93.

110. Goodman R, Stevenson J. A twin study of hyperactivity--II. The aetiological role of genes, family relationships and perinatal adversity. Journal of Child Psychology and Psychiatry and Allied Disciplines. 1989;30(5):691-709.

111. Boomsma DI, Saviouk V, Hottenga JJ, Distel MA, de Moor MH, Vink $\mathrm{JM}$, et al. Genetic epidemiology of attention deficit hyperactivity disorder (ADHD index) in adults. PloS One. 2010;5(5):e10621.

112. Larsson H, Chang Z, D'Onofrio BM, Lichtenstein P. The heritability of clinically diagnosed attention deficit hyperactivity disorder across the lifespan. Psychological Medicine. 2013;S0033291713002493 [pii]

10.1017/S0033291713002493:1-7.

113. Brikell I, Kuja-Halkola R, Larsson H. Heritability of attention-deficit hyperactivity disorder in adults. American Journal of Medical Genetics Part B: Neuropsychiatric Genetics. 2015;10.1002/ajmg.b.32335. 
114.

Rhee SH, Waldman ID, Hay DA, Levy F. Sex differences in genetic and environmental influences on DSM-III-R attention-deficit/hyperactivity disorder. Journal of Abnormal Psychology. 1999;108(1):24-41.

115. Rhee SH, Waldman ID. Etiology of sex differences in the prevalence of ADHD: an examination of inattention and hyperactivity-impulsivity. American Journal of Medical Genetics Part B: Neuropsychiatric Genetics. 2004;127b(1):60-4.

116. Taylor MJ, Lichtenstein P, Larsson H, Anckarsater H, Greven CU, Ronald A. Is There a Female Protective Effect Against Attention-Deficit/Hyperactivity Disorder? Evidence From Two Representative Twin Samples. Journal of the American Academy of Child and Adolescent Psychiatry. 2016;55(6):504-12.e2.

117. Kendler KS, Jacobson KC, Prescott CA, Neale MC. Specificity of genetic and environmental risk factors for use and abuse/dependence of cannabis, cocaine, hallucinogens, sedatives, stimulants, and opiates in male twins. American Journal of Psychiatry. 2003;160(4):687-95.

118. Dick DM, Viken RJ, Kaprio J, Pulkkinen L, Rose RJ. Understanding the covariation among childhood externalizing symptoms: genetic and environmental influences on conduct disorder, attention deficit hyperactivity disorder, and oppositional defiant disorder symptoms. Journal of Abnormal Child Psychology. 2005;33(2):219-29. 119. Young SE, Stallings MC, Corley RP, Krauter KS, Hewitt JK. Genetic and environmental influences on behavioral disinhibition. American Journal of Medical Genetics. 2000;96(5):684-95.

120. Lichtenstein P, Carlstrom E, Rastam M, Gillberg C, Anckarsater H. The genetics of autism spectrum disorders and related neuropsychiatric disorders in childhood. American Journal of Psychiatry. 2010;167(11):1357-63.

121. Willcutt EG, Pennington BF, DeFries JC. Twin study of the etiology of comorbidity between reading disability and attention-deficit/hyperactivity disorder. American Journal of Medical Genetics. 2000;96(3):293-301.

122. Doyle AE, Faraone SV. Familial links between attention deficit hyperactivity disorder, conduct disorder, and bipolar disorder. Curr Psychiatry Rep. 2002;4(2):146-52.

123. Pettersson E, Larsson H, Lichtenstein P. Common psychiatric disorders share the same genetic origin: a multivariate sibling study of the Swedish population. Molecular Psychiatry. 2016;21(5):717-21.

124. Chang Z, Lichtenstein P, Larsson H. The effects of childhood ADHD symptoms on early-onset substance use: a Swedish twin study. Journal of Abnormal Child Psychology. 2012;40(3):425-35.

125. Skoglund C, Chen Q, Franck J, Lichtenstein P, Larsson H. Attentiondeficit/hyperactivity disorder and risk for substance use disorders in relatives. Biological Psychiatry. 2015;77(10):880-6.

126. Derks EM, Vink JM, Willemsen G, van den Brink W, Boomsma DI. Genetic and environmental influences on the relationship between adult ADHD symptoms and self-reported problem drinking in 6024 Dutch twins. Psychological Medicine. 2014;44(12):2673-83.

127. Biederman J, Petty CR, Wilens TE, Fraire MG, Purcell CA, Mick E, et al. Familial risk analyses of attention deficit hyperactivity disorder and substance use disorders. American Journal of Psychiatry. 2008;165(1):107-15. 
128.

Bulik CM, Thornton LM, Root TL, Pisetsky EM, Lichtenstein P, Pedersen NL. Understanding the relation between anorexia nervosa and bulimia nervosa in a Swedish national twin sample. Biological Psychiatry. 2010;67(1):71-7.

129.

Mitchell KS, Neale MC, Bulik CM, Aggen SH, Kendler KS, Mazzeo

SE. Binge eating disorder: a symptom-level investigation of genetic and environmental influences on liability. Psychological Medicine. 2010;40(11):1899-906.

130. Trace SE, Baker JH, Penas-Lledo E, Bulik CM. The genetics of eating disorders. Annual Review of Clinical Psychology. 2013;9:589-620.

131. Root TL, Thornton LM, Lindroos AK, Stunkard AJ, Lichtenstein P, Pedersen NL, et al. Shared and unique genetic and environmental influences on binge eating and night eating: a Swedish twin study. Eat Behav. 2010;11(2):92-8.

132. Bulik CM, Sullivan PF, Kendler KS. Heritability of binge-eating and broadly defined bulimia nervosa. Biological Psychiatry. 1998;44(12):1210-8.

133. Reichborn-Kjennerud T, Bulik CM, Tambs K, Harris JR. Genetic and environmental influences on binge eating in the absence of compensatory behaviors: a population-based twin study. International Journal of Eating Disorders. 2004;36(3):30714.

134. Yang L, Neale BM, Liu L, Lee SH, Wray NR, Ji N, et al. Polygenic transmission and complex neuro developmental network for attention deficit hyperactivity disorder: genome-wide association study of both common and rare variants. American Journal of Medical Genetics Part B: Neuropsychiatric Genetics. 2013;162B(5):419-30.

135. Cross-Disorder Group of the Psychiatric Genomics C. Identification of risk loci with shared effects on five major psychiatric disorders: a genome-wide analysis. Lancet. 2013;381(9875):1371-9.

136. Mooney MA, McWeeney SK, Faraone SV, Hinney A, Hebebrand J, Nigg JT, et al. Pathway analysis in attention deficit hyperactivity disorder: An ensemble approach. American Journal of Medical Genetics Part B: Neuropsychiatric Genetics. 2016;10.1002/ajmg.b.32446.

137. Williams NM, Zaharieva I, Martin A, Langley K, Mantripragada K, Fossdal R, et al. Rare chromosomal deletions and duplications in attention-deficit hyperactivity disorder: a genome-wide analysis. Lancet. 2010;376(9750):1401-8.

138. Faraone SV, Mick E. Molecular genetics of attention deficit hyperactivity disorder. Psychiatric Clinics of North America. 2010;33(1):159-80.

139. Liu YS, Dai X, Wu W, Yuan FF, Gu X, Chen JG, et al. The Association of SNAP25 Gene Polymorphisms in Attention Deficit/Hyperactivity Disorder: a Systematic Review and Meta-Analysis. Molecular Neurobiology. 2016;10.1007/s12035-016-9810-9.

140. Gottesman, II, Gould TD. The endophenotype concept in psychiatry: etymology and strategic intentions. American Journal of Psychiatry. 2003;160(4):63645 .

141. Franke B, Neale BM, Faraone SV. Genome-wide association studies in ADHD. Human Genetics. 2009;126(1):13-50.

142. Doyle AE, Willcutt EG, Seidman LJ, Biederman J, Chouinard VA, Silva J, et al. Attention-deficit/hyperactivity disorder endophenotypes. Biological Psychiatry. 2005;57(11):1324-35. 
143.

Rommelse NN, Arias-Vasquez A, Altink ME, Buschgens CJ, Fliers E,

Asherson P, et al. Neuropsychological endophenotype approach to genome-wide linkage analysis identifies susceptibility loci for ADHD on 2q21.1 and 13q12.11. American Journal of Human Genetics. 2008;83(1):99-105.

144. Lahey BB, D'Onofrio BM. All in the Family: Comparing Siblings to Test Causal Hypotheses Regarding Environmental Influences on Behavior. Current Directions in Psychological Science. 2010;19(5):319-23.

145. Linnet KM, Wisborg K, Obel C, Secher NJ, Thomsen PH, Agerbo E, et al. Smoking during pregnancy and the risk for hyperkinetic disorder in offspring. Pediatrics. 2005;116(2):462-7.

146. Ouyang L, Fang X, Mercy J, Perou R, Grosse SD. Attentiondeficit/hyperactivity disorder symptoms and child maltreatment: a population-based study. Journal of Pediatrics. 2008;153(6):851-6.

147. Briscoe-Smith AM, Hinshaw SP. Linkages between child abuse and attention-deficit/hyperactivity disorder in girls: behavioral and social correlates. Child Abuse and Neglect. 2006;30(11):1239-55.

148. Stevens SE, Sonuga-Barke EJ, Kreppner JM, Beckett C, Castle J, Colvert $\mathrm{E}$, et al. Inattention/overactivity following early severe institutional deprivation: presentation and associations in early adolescence. Journal of Abnormal Child Psychology. 2008;36(3):385-98.

149. Sugaya L, Hasin DS, Olfson M, Lin KH, Grant BF, Blanco C. Child physical abuse and adult mental health: a national study. Journal of Traumatic Stress. 2012;25(4):384-92.

150. Rucklidge JJ, Brown DL, Crawford S, Kaplan BJ. Retrospective reports of childhood trauma in adults with ADHD. Journal of Attention Disorder. 2006;9(4):631-41.

151. Singer MJ, Humphreys KL, Lee SS. Coping Self-Efficacy Mediates the Association Between Child Abuse and ADHD in Adulthood. Journal of Attention Disorder. 2012;10.1177/1087054712465337.

152. Gould F, Clarke J, Heim C, Harvey PD, Majer M, Nemeroff CB. The effects of child abuse and neglect on cognitive functioning in adulthood. Journal of Psychiatric Research. 2012;46(4):500-6.

153. Elton A, Tripathi SP, Mletzko T, Young J, Cisler JM, James GA, et al. Childhood maltreatment is associated with a sex-dependent functional reorganization of a brain inhibitory control network. Human Brain Mapping. 2014;35(4):1654-67.

154. Rutter M. Gene-environment interdependence. Dev Sci. 2007;10(1):128.

155. Kraemer HC, Stice E, Kazdin A, Offord D, Kupfer D. How do risk factors work together? Mediators, moderators, and independent, overlapping, and proxy risk factors. American Journal of Psychiatry. 2001;158(6):848-56.

156. Rutter M, Moffitt TE, Caspi A. Gene-environment interplay and psychopathology: multiple varieties but real effects. Journal of Child Psychology and Psychiatry. 2006;47(3-4):226-61.

157. Rutter M. Proceeding From Observed Correlation to Causal Inference: The Use of Natural Experiments. Perspectives on Psychological Science. 2007;2(4):377-95. 
158.

Plomin R, DeFries JC, Knopik VS, Neiderhiser JM. Behavioral genetics. Sixth edition. ed. New York: Worth Publishers; 2013. xix, 503, 19, 19 pages p.

159. Bornovalova MA, Cummings JR, Hunt E, Blazei R, Malone S, Iacono WG. Understanding the relative contributions of direct environmental effects and passive genotype-environment correlations in the association between familial risk factors and child disruptive behavior disorders. Psychological Medicine. 2014;44(4):831-44.

160. Jaffee SR, Caspi A, Moffitt TE, Polo-Tomas M, Price TS, Taylor A. The limits of child effects: evidence for genetically mediated child effects on corporal punishment but not on physical maltreatment. Developmental Psychology. 2004;40(6):1047-58.

161. Harold GT, Leve LD, Barrett D, Elam K, Neiderhiser JM, Natsuaki $\mathrm{MN}$, et al. Biological and rearing mother influences on child ADHD symptoms: revisiting the developmental interface between nature and nurture. Journal of Child Psychology and Psychiatry and Allied Disciplines. 2013;54(10):1038-46.

162. Shadish WR, Cook TD, Campbell DT. Experimental and quasiexperimental designs for generalized causal inference. Boston: Houghton Mifflin; 2001. xxi, 623 p. p.

163. Galton F. The history of twins, as a criterion of the relative powers of nature and nurture (1,2). International Journal of Epidemiology. 2012;41(4):905-11.

164. Mayo O. Early research on human genetics using the twin method: who really invented the method? Twin Res Hum Genet. 2009;12(3):237-45.

165. Fisher RA. The Resemblance between Twins, a Statistical Examination of Lauterbach's Measurements. Genetics. 1925;10(6):569-79.

166. Thorndike EL. Measurement of Twins. Journal of Philosophy, Psychology \& Scientific Methods. 1905;II:547-53.

167. Boomsma D, Busjahn A, Peltonen L. Classical twin studies and beyond. Nat Rev Genet. 2002;3(11):872-82.

168. Institutet K. The Swedish Twin Registry http://ki.se/en/research/theswedish-twin-registry: Karolinska Institutet; 2016 [cited 2016 June 13]. Available from: http://ki.se/en/research/the-swedish-twin-registry.

169. Lichtenstein P, De Faire U, Floderus B, Svartengren M, Svedberg P, Pedersen NL. The Swedish Twin Registry: a unique resource for clinical, epidemiological and genetic studies. Journal of Internal Medicine. 2002;252(3):184205.

170. Neale MC, Cardon LR. Methodology for Genetic Studies of Twins and Families. . Dodrecht, Boston, London: Kluwer Academic Publishers; 1992.

171. Sandra Kooij JJ, Marije Boonstra A, Swinkels SH, Bekker EM, de Noord I, Buitelaar JK. Reliability, validity, and utility of instruments for self-report and informant report concerning symptoms of ADHD in adult patients. Journal of Attention Disorder. 2008;11(4):445-58.

172. Murphy P, Schachar R. Use of self-ratings in the assessment of symptoms of attention deficit hyperactivity disorder in adults. American Journal of Psychiatry. 2000;157(7):1156-9.

173. First MB, Spitzer, Robert L, Gibbon Miriam, and Williams, Janet B.W. Structured Clinical Interview for DSM-IV-TR Axis I Disorders, Research Version, Non- 
patient Edition. (SCID-I/NP) New York: Biometrics Research, New York State Psychiatric Institute, ; 2002 November 2002.

174. Furberg H, Lichtenstein P, Pedersen NL, Thornton L, Bulik CM, Lerman C, et al. The STAGE cohort: a prospective study of tobacco use among Swedish twins. Nicotine Tob Res. 2008;10(12):1727-35.

175. Lichtenstein P, Sullivan PF, Cnattingius S, Gatz M, Johansson S, Carlstrom E, et al. The Swedish Twin Registry in the third millennium: an update. Twin Res Hum Genet. 2006;9(6):875-82.

176. Peterson CM, Baker JH, Thornton LM, Trace SE, Mazzeo SE, Neale $\mathrm{MC}$, et al. Genetic and environmental components to self-induced vomiting. International Journal of Eating Disorders. 2015;10.1002/eat.22491.

177. Kessler RC, Adler LA, Gruber MJ, Sarawate CA, Spencer T, Van Brunt DL. Validity of the World Health Organization Adult ADHD Self-Report Scale (ASRS) Screener in a representative sample of health plan members. International Journal of Methods in Psychiatric Research. 2007;16(2):52-65.

178. Rodriguez A, Ginsberg Y, Fernholm A, Nyberg L. [ADHD difficult to diagnose in adults. ASRS v1.1 Self-Report Scales valuable help--now translated to Swedish]. Lakartidningen. 2007;104(18):1398-400.

179. Boker S, Neale M, Maes H, Wilde M, Spiegel M, Brick T, et al. OpenMx: An Open Source Extended Structural Equation Modeling Framework. Psychometrika. 2011;76(2):306-17.

180. Wolfe J KR. Gender issues in the assessment of posttraumatic stress disorder. In Assessing PsychologicalTrauma and PTSD. Keane eJWaTM, editor. New York: Guilford; 1997.

181. Capusan AJ, Bendtsen P, Marteinsdottir I, Larsson H. Comorbidity of Adult ADHD and Its Subtypes With Substance Use Disorder in a Large PopulationBased Epidemiological Study. Journal of Attention Disorder. 2016;10.1177/1087054715626511.

182. Gudjonsson GH, Sigurdsson JF, Sigfusdottir ID, Young S. An epidemiological study of ADHD symptoms among young persons and the relationship with cigarette smoking, alcohol consumption and illicit drug use. Journal of Child Psychology and Psychiatry and Allied Disciplines. 2012;53(3):304-12.

183. Sullivan MA, Rudnik-Levin F. Attention deficit/hyperactivity disorder and substance abuse. Diagnostic and therapeutic considerations. Annals of the New York Academy of Sciences. 2001;931:251-70.

184. Biederman J, Pettye CR, Hammerness P, Woodworth KY, Faraon SV. Examining the nature of the association between attention-deficit hyperactivity disorder and nicotine dependence: a familial risk analysis. Canadian Journal of Psychiatry Revue Canadienne de Psychiatrie. 2013;58(3):177-83.

185. Rodriguez D, Tercyak KP, Audrain-McGovern J. Effects of inattention and hyperactivity/impulsivity symptoms on development of nicotine dependence from mid adolescence to young adulthood. Journal of Pediatric Psychology. 2008;33(6):56375.

186. Biederman J, Wilens T, Mick E, Milberger S, Spencer TJ, Faraone SV. Psychoactive substance use disorders in adults with attention deficit hyperactivity disorder (ADHD): effects of ADHD and psychiatric comorbidity. American Journal of Psychiatry. 1995;152(11):1652-8. 
187.

Loflin M, Earleywine M, De Leo J, Hobkirk A. Subtypes of attention deficit-hyperactivity disorder (ADHD) and cannabis use. Substance Use and Misuse. 2014;49(4):427-34.

188. Knopik VS, Heath AC, Bucholz KK, Madden PA, Waldron M. Genetic and environmental influences on externalizing behavior and alcohol problems in adolescence: a female twin study. Pharmacology, Biochemistry and Behavior. 2009;93(3):313-21.

189. Polderman TJ, Benyamin B, de Leeuw CA, Sullivan PF, van Bochoven A, Visscher PM, et al. Meta-analysis of the heritability of human traits based on fifty years of twin studies. Nature Genetics. 2015;47(7):702-9.

190. Kendler KS, Bulik CM, Silberg J, Hettema JM, Myers J, Prescott CA. Childhood sexual abuse and adult psychiatric and substance use disorders in women: an epidemiological and cotwin control analysis. Archives of General Psychiatry. 2000;57(10):953-9.

191. Alemany S, Goldberg X, van Winkel R, Gasto C, Peralta V, Fananas L. Childhood adversity and psychosis: examining whether the association is due to genetic confounding using a monozygotic twin differences approach. European Psychiatry. 2013;28(4):207-12.

192. Lim L, Hart H, Mehta MA, Simmons A, Mirza K, Rubia K. Neural Correlates of Error Processing in Young People With a History of Severe Childhood Abuse: An fMRI Study. American Journal of Psychiatry. 2015;10.1176/appi.ajp.2015.14081042:appiajp201514081042.

193. Roth TL, Sweatt JD. Epigenetic marking of the BDNF gene by earlylife adverse experiences. Hormones and Behavior. 2011;59(3):315-20.

194. Romens SE, McDonald J, Svaren J, Pollak SD. Associations between early life stress and gene methylation in children. Child Development. 2015;86(1):3039.

195. Whitmore EA, Kramer JR, Knutson JF. The association between punitive childhood experiences and hyperactivity. Child Abuse and Neglect. 1993;17(3):357-66.

196. Neiderhiser JM, Reiss D, Pedersen NL, Lichtenstein P, Spotts EL, Hansson K, et al. Genetic and environmental influences on mothering of adolescents: a comparison of two samples. Developmental Psychology. 2004;40(3):335-51.

197. Jaffee SR, Caspi A, Moffitt TE, Dodge KA, Rutter M, Taylor A, et al. Nature X nurture: genetic vulnerabilities interact with physical maltreatment to promote conduct problems. Development and Psychopathology. 2005;17(1):67-84.

198. Lansford JE, Godwin J, Uribe Tirado LM, Zelli A, Al-Hassan SM, Bacchini D, et al. Individual, family, and culture level contributions to child physical abuse and neglect: A longitudinal study in nine countries. Development and Psychopathology. 2015;27(4 Pt 2):1417-28.

$199 . \quad$ Durrant JE. Evaluating the success of Sweden's corporal punishment ban. Child Abuse and Neglect. 1999;23(5):435-48.

200. Jay Schulz-Heik R, Rhee SH, Silvern L, Lessem JM, Haberstick BC, Hopfer $\mathrm{C}$, et al. Investigation of genetically mediated child effects on maltreatment. Behavior Genetics. 2009;39(3):265-76.

201. Huang MC, Schwandt ML, Ramchandani VA, George DT, Heilig M. Impact of multiple types of childhood trauma exposure on risk of psychiatric 
comorbidity among alcoholic inpatients. Alcoholism, Clinical and Experimental Research. 2012;36(6):1099-107.

202. McFarlane A, Clark CR, Bryant RA, Williams LM, Niaura R, Paul RH, et al. The impact of early life stress on psychophysiological, personality and behavioral measures in 740 non-clinical subjects. Journal of Integrative Neuroscience. 2005;4(1):27-40.

203. Simon V, Czobor P, Balint S, Meszaros A, Bitter I. Prevalence and correlates of adult attention-deficit hyperactivity disorder: meta-analysis. British Journal of Psychiatry. 2009;194(3):204-11.

204. SOU. Missbruket, Kunskapen, Vården (SOU 2011:6) : Missbruksutredningens forskningsbilaga Stockholm: Offentliga Förlaget; 2011.

205. CAN Cfa-on. Drogutvecklingen i Sverige 2011, CAN, Centralförbundet för alkohol- och narkotikaupplysning. Stockholm 2012 Contract No.: Rapport nr 130.

206. MacLean A, Sweeting H, Walker L, Patterson C, Raisanen U, Hunt K. "It's not healthy and it's decidedly not masculine": a media analysis of UK newspaper representations of eating disorders in males. BMJ Open. 2015;5(5):e007468.

207. Sonneville KR, Calzo JP, Horton NJ, Field AE, Crosby RD, Solmi F, et al. Childhood hyperactivity/inattention and eating disturbances predict binge eating in adolescence. Psychological Medicine. 2015;45(12):2511-20.

208. Biederman J, Ball SW, Monuteaux MC, Surman CB, Johnson JL, Zeitlin S. Are girls with ADHD at risk for eating disorders? Results from a controlled, five-year prospective study. Journal of Developmental and Behavioral Pediatrics. 2007;28(4):302-7.

209 . Hardt J, Rutter M. Validity of adult retrospective reports of adverse childhood experiences: review of the evidence. Journal of Child Psychology and Psychiatry and Allied Disciplines. 2004;45(2):260-73.

210. McGee RA, Wolfe DA, Yuen SA, Wilson SK, Carnochan J. The measurement of maltreatment: a comparison of approaches. Child Abuse and Neglect. $1995 ; 19(2): 233-49$.

211. Scott KM, McLaughlin KA, Smith DA, Ellis PM. Childhood maltreatment and DSM-IV adult mental disorders: comparison of prospective and retrospective findings. British Journal of Psychiatry. 2012;200(6):469-75.

212. Shaffer A, Huston L, Egeland B. Identification of child maltreatment using prospective and self-report methodologies: a comparison of maltreatment incidence and relation to later psychopathology. Child Abuse and Neglect. 2008;32(7):682-92.

213. MacDonald K, Thomas ML, Sciolla AF, Schneider B, Pappas K, Bleijenberg $G$, et al. Minimization of Childhood Maltreatment Is Common and Consequential: Results from a Large, Multinational Sample Using the Childhood Trauma Questionnaire. PloS One. 2016;11(1):e0146058.

214. Coughlin SS. Recall bias in epidemiologic studies. Journal of Clinical Epidemiology. 1990;43(1):87-91.

215. May-Chahal C, Cawson P. Measuring child maltreatment in the United Kingdom: a study of the prevalence of child abuse and neglect. Child Abuse and Neglect. 2005;29(9):969-84. 
216.

Annerback EM, Wingren G, Svedin CG, Gustafsson PA. Prevalence and characteristics of child physical abuse in Sweden - findings from a population-based youth survey. Acta Paediatrica. 2010;99(8):1229-36.

$217 . \quad$ Kloppen K, Haugland S, Svedin CG, Maehle M, Breivik K. Prevalence of Child Sexual Abuse in the Nordic Countries: A Literature Review. J Child Sex Abus. 2016;25(1):37-55.

218. Kendler KS, Neale MC, Kessler RC, Heath AC, Eaves LJ. Parental treatment and the equal environment assumption in twin studies of psychiatric illness. Psychological Medicine. 1994;24(3):579-90.

219. Nordsletten AE, Larsson H, Crowley JJ, Almqvist C, Lichtenstein P, Mataix-Cols D. Patterns of Nonrandom Mating Within and Across 11 Major Psychiatric Disorders. JAMA Psychiatry. 2016;73(4):354-61.

220. Kieling C, Hutz MH, Genro JP, Polanczyk GV, Anselmi L, Camey S, et al. Gene-environment interaction in externalizing problems among adolescents: evidence from the Pelotas 1993 Birth Cohort Study. Journal of Child Psychology and Psychiatry and Allied Disciplines. 2013;54(3):298-304.

221. Haberstick BC, Lessem JM, Hewitt JK, Smolen A, Hopfer CJ, Halpern $\mathrm{CT}$, et al. MAOA genotype, childhood maltreatment, and their interaction in the etiology of adult antisocial behaviors. Biological Psychiatry. 2014;75(1):25-30.

222. Capusan AJ, Bendtsen P, Marteinsdottir I, Kuja-Halkola R, Larsson H. Genetic and environmental contributions to the association between attention deficit hyperactivity disorder and alcohol dependence in adulthood: A large population-based twin study. American journal of medical genetics Part B, Neuropsychiatric genetics. 2015;10.1002/ajmg.b.32300.

223. Delaney SK, Hultner ML, Jacob HJ, Ledbetter DH, McCarthy JJ, Ball $\mathrm{M}$, et al. Toward clinical genomics in everyday medicine: perspectives and recommendations. Expert Review of Molecular Diagnostics. 2016;16(5):521-32.

224. Fulda KG, Lykens K. Ethical issues in predictive genetic testing: a public health perspective. Journal of Medical Ethics. 2006;32(3):143-7.

225. Salvatore JE, Gottesman, II, Dick DM. Endophenotypes for Alcohol Use Disorder: An Update on the Field. Curr Addict Rep. 2015;2(1):76-90.

226. Thornton LM, Mazzeo SE, Bulik CM. The heritability of eating disorders: methods and current findings. Current Topics in Behavioral Neurosciences. 2011;6:141-56.

227. Health NIoM. NIMH Research Domain Criteria (RDoc) http://www.nimh.nih.gov.e.bibl.liu.se/research-priorities/rdoc/index.shtml\#toc matrix: National Institute of Mental Health (NIMH) , part of National Institutes of Health (NIH) 2016 [cited 2016 2016-05-29]. 


\section{Articles}

The articles associated with this thesis have been removed for copyright reasons. For more details about these see:

http://urn.kb.se/resolve?urn=urn:nbn:se:liu:diva-130718 